\title{
Biomass Direct Liquefaction Options: TechnoEconomic and Life Cycle Assessment
}

PNNL

IJ Tews

Y Zhu

CV Drennan

DC Elliott

LJ Snowden-Swan
VTT

$\mathrm{K}$ Onarheim

Y Solantausta
Zeton

Dave Beckman

July 2014

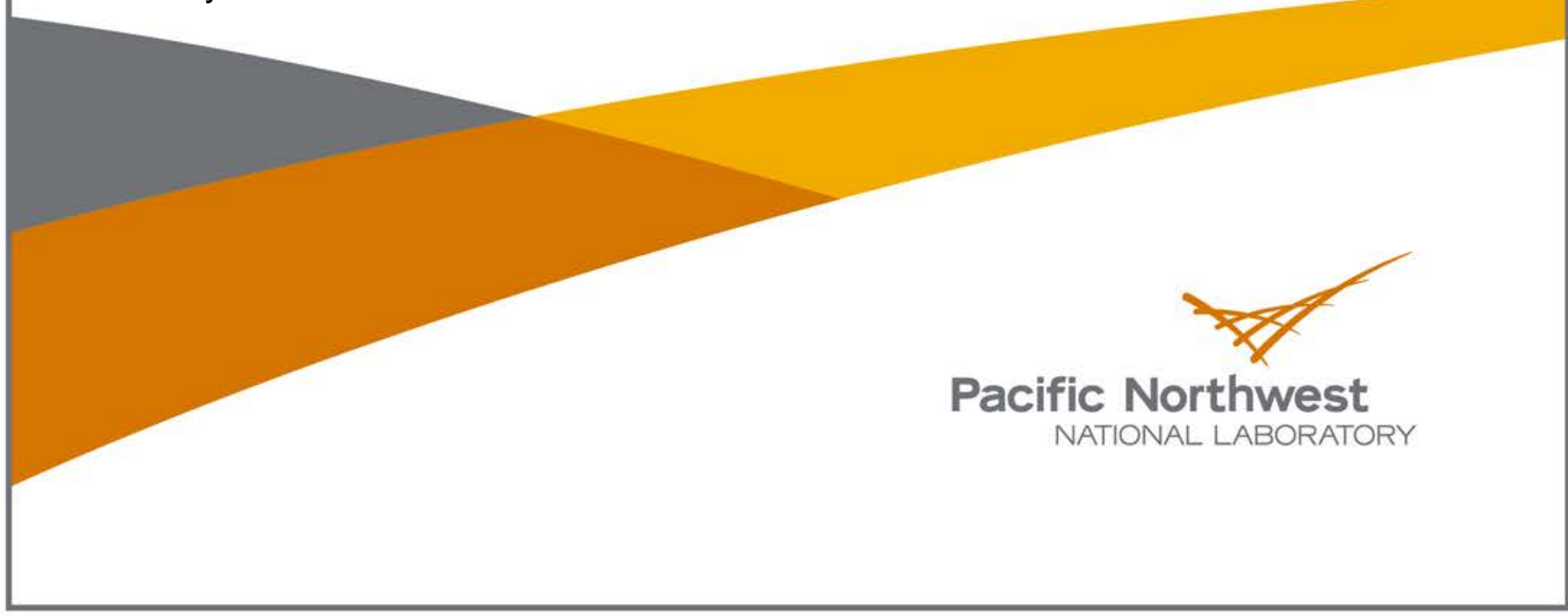




\title{
DISCLAIMER
}

This report was prepared as an account of work sponsored by an agency of the United States Government. Neither the United States Government nor any agency thereof, nor Battelle Memorial Institute, nor any of their employees, makes any warranty, express or implied, or assumes any legal liability or responsibility for the accuracy, completeness, or usefulness of any information, apparatus, product, or process disclosed, or represents that its use would not infringe privately owned rights. Reference herein to any specific commercial product, process, or service by trade name, trademark, manufacturer, or otherwise does not necessarily constitute or imply its endorsement, recommendation, or favoring by the United States Government or any agency thereof, or Battelle Memorial Institute. The views and opinions of authors expressed herein do not necessarily state or reflect those of the United States Government or any agency thereof.

\author{
PACIFIC NORTHWEST NATIONAL LABORATORY \\ operated by \\ BATTELLE \\ for the \\ UNITED STATES DEPARTMENT OF ENERGY \\ under Contract DE-AC05-76RL01830
}

Printed in the United States of America

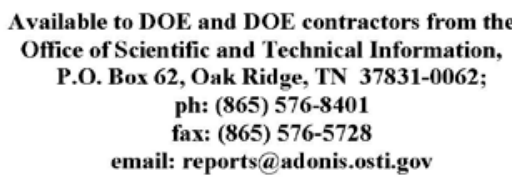

Available to the public from the National Technical Information Service, U.S. Department of Commerce, 5285 Port Royal Rd., Springfield, VA 22161 ph: (800) 553-6847 fax: $(703) 605-6900$

email: orders@ntis.fedworld.gov

online ordering: http://www.ntis.gov/ordering.htm

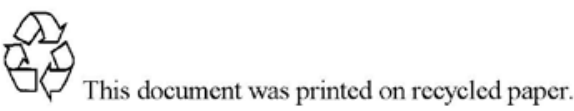

$(9 / 2003)$ 


\section{Biomass Direct Liquefaction Options: TechnoEconomic and Life Cycle Assessment}

PNNL

IJ Tews

Y Zhu

CV Drennan

DC Elliott

LJ Snowden-Swan

July 31, 2014
VTT

K Onarheim

Y Solantausta
Zeton

D Beckman

Prepared for

the U.S. Department of Energy

under Contract DE-AC05-76RL01830

Pacific Northwest National Laboratory

Richland, Washington 99352 



\section{Contents}

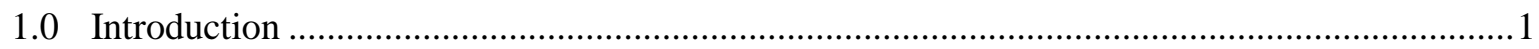

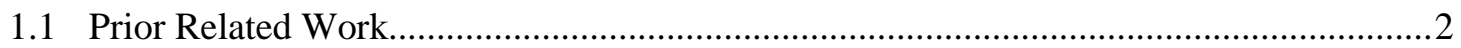

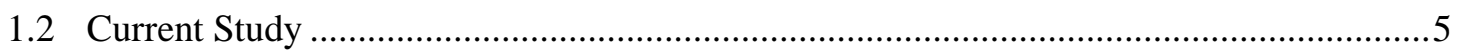

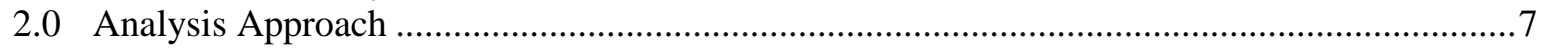

3.0 Process Design for Biomass Conversion to Liquids..............................................................11

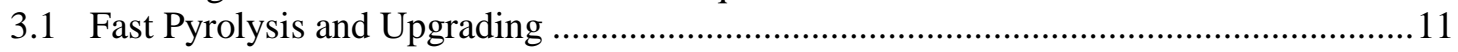

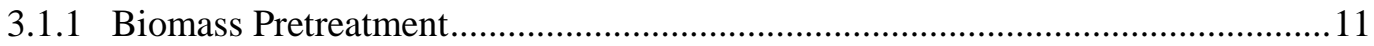

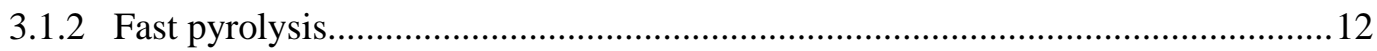

3.2 Hydrothermal Liquefaction and Hydrotreating ................................................................ 14

3.3 Liquid Product Upgrading by Hydroprocessing …........................................................18

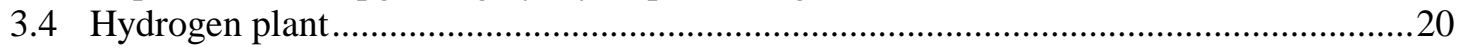

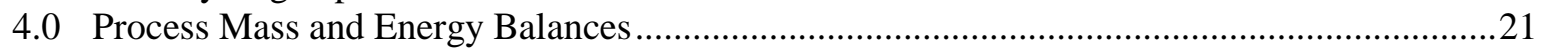

4.1 Mass Balance for Fast Pyrolysis and Upgrading........................................................22

4.2 Energy Balance for Fast Pyrolysis and Upgrading …....................................................23

4.3 Mass Balance for Hydrothermal Liquefaction and Hydrotreating ....................................24

4.4 Energy Balance for Hydrothermal Liquefaction and Hydrotreating ................................25

5.0 Comparative Analysis of Life Cycle GHGs ........................................................................26

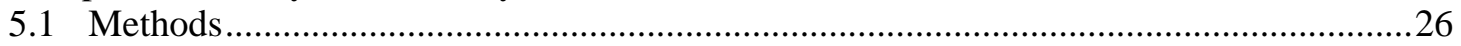

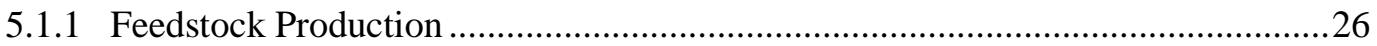

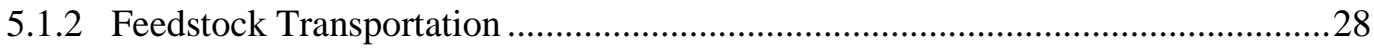

5.1.3 Feedstock Handling and Preprocessing at the Refinery …..................................28

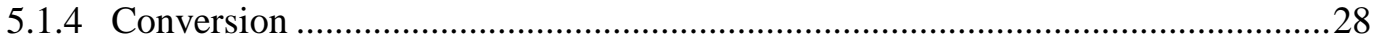

5.1.5 Fuel Distribution and Consumption ...................................................................30

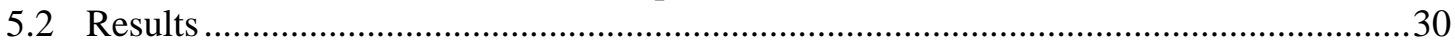

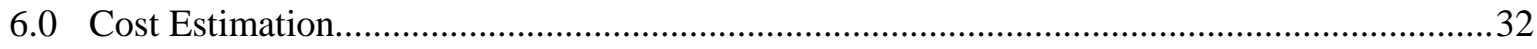

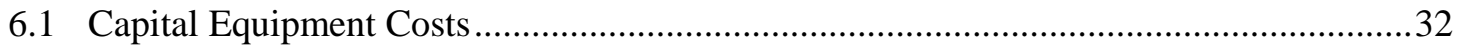

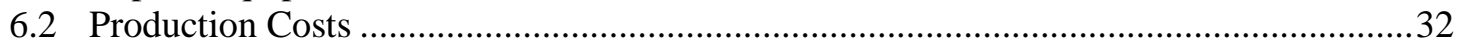

6.3 Fast Pyrolysis and Bio-oil Upgrading Process Costs .....................................................33

6.4 Hydrothermal Liquefaction and Biocrude Hydrotreating Costs .....................................34

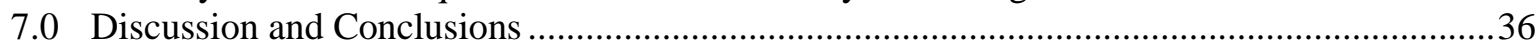

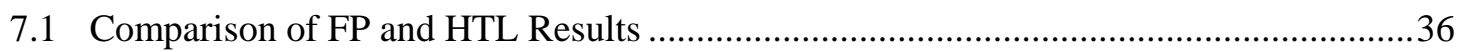

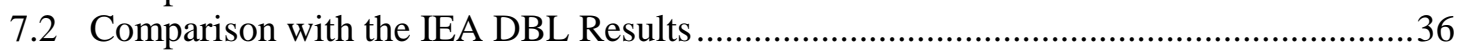

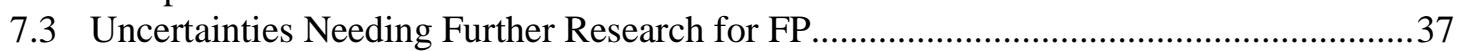

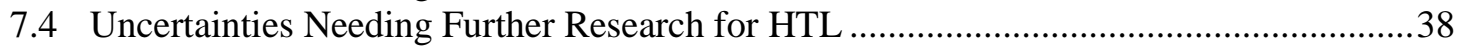

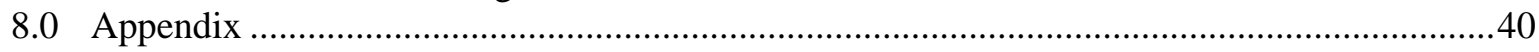

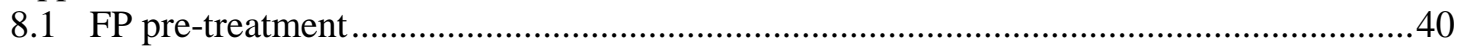

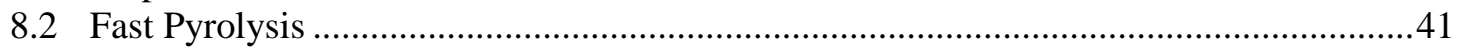

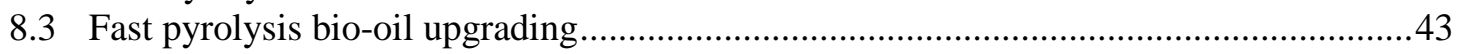

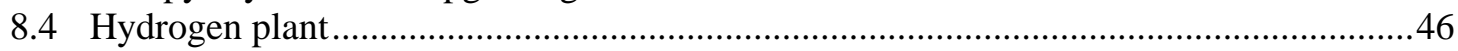

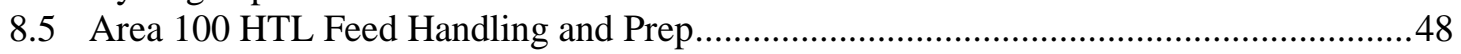

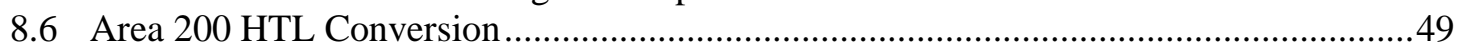

8.7 Area 300 Hydrothermal Liquefaction Biocrude Hydrotreating .....................................51

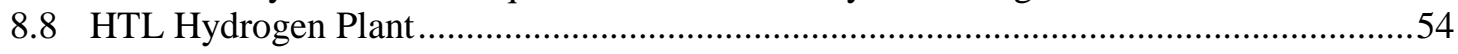




\section{Glossary of Terms}

Fast pyrolysis - thermal conversion in the absence of oxygen at short residence time, for woody biomass typical conditions are $<2$ seconds at $\sim 500{ }^{\circ} \mathrm{C}$

Hydrothermal - processing in hot pressurized water

Bio-oil - liquid product of fast pyrolysis

Biocrude - liquid oil product from hydrothermal liquefaction

Upgrading - multi-step hydroprocessing to convert bio-oil in liquid hydrocarbon products

Hydrotreating - single-step hydroprocessing to convert biocrude into liquid hydrocarbon products

Hydroprocessing - chemical reaction with hydrogen gas, typically a catalytic process operated at elevated pressure, usually to remove heteroatoms, remove unsaturation, and reduce molecular weight.

Heavy hydrocarbon -- hydrocarbon product distilling at temperatures higher than diesel

Nth plant - commercial plant operating an established process, not a pioneer plant 


\subsection{Introduction}

The purpose of this work was to assess the competitiveness of two biomass to transportation fuel processing routes, which were under development in Finland, the U.S. and elsewhere. Concepts included fast pyrolysis (FP), and hydrothermal liquefaction (HTL), both are followed by hydrodeoxygenation, and final product refining.

This work was carried out as a collaboration between VTT (Finland), and PNNL (USA). The public funding agents for the work were Tekes in Finland and the Bioenergy Technologies Office of the U.S. Department of Energy. The effort was proposed as an update of the earlier comparative technoeconomic assessment performed by the IEA Bioenergy Direct Biomass Liquefaction Task in the 1980s. ${ }^{1}$ New developments in HTL and the upgrading of the HTL biocrude product triggered the interest in reinvestigating this comparison of these biomass liquefaction processes. In addition, developments in FP bio-oil upgrading had provided additional definition of this process option, which could provide an interesting comparison.

Concepts employing syngas or biological processing to transportation fuels were excluded. It was not within the scope of this project to analyze a large number of alternatives in detail. The reader is referred, as an alternative, to a recent study ${ }^{2}$, where several alternative technologies were compared. A summary of that study is presented in Figure 1 below. The study suggested that fast pyrolysis to transportation fuels may be a viable alternative in the future, especially so if integration to a petroleum refinery was employed. The study also emphasized the fact that cost estimates of products for pioneer plants are significantly greater than for the nth plants.

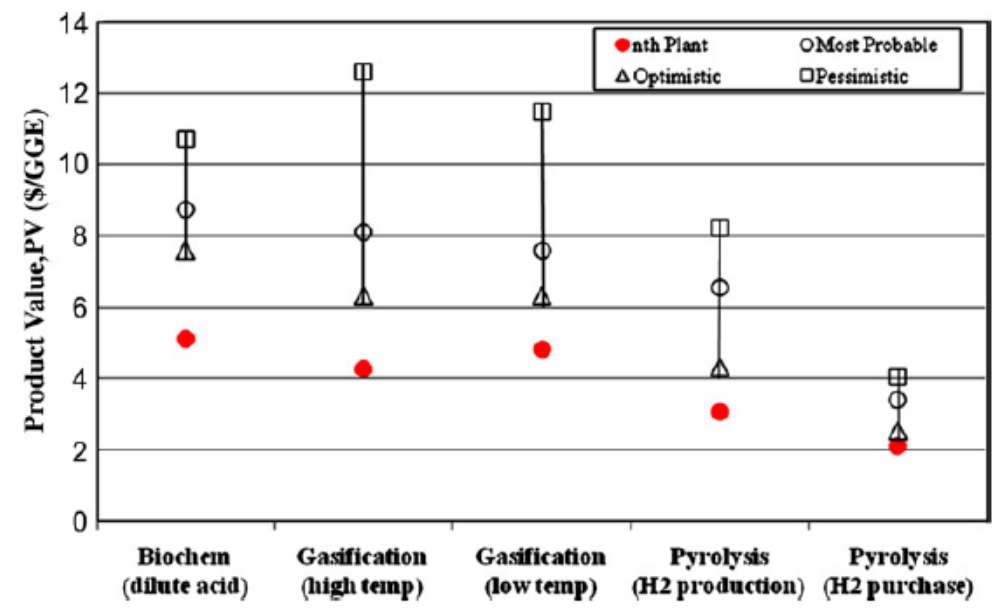

Figure 1. Estimates of product values for biofuel technologies by Anex et al. ${ }^{2}$

\footnotetext{
${ }^{1}$ Beckman, D., et al. Techno-Economic Assessment of Selected Biomass Liquefaction Processes. Final Report of IEA Cooperative Project Direct Biomass Liquefaction. VTT Research Reports 697 Technical Research Centre of Finland, Espoo 1990.

${ }^{2}$ Anex, R. et al. Techno-economic comparison of biomass-to-transportation fuels via pyrolysis, gasification, and biochemical pathways. Fuel 2010 89:29-35.
} 
The work reported by Anex et al. included analysis of published process data on the subject technologies, evaluation of reliability of data, generation of complete process concepts, building Aspen Plus $^{\circledR}$ performance balance models for these concepts, and estimating industrial scale performance balances as bases for sizing of equipment, and estimating investment and operational costs. Various sensitivity studies were carried out to define preferred concepts and their critical parameters. Missing data was reported, and further work on generating missing data of most promising concepts was suggested. Special emphasis was placed in evaluating the uncertainty related to comparison of processes under different stages of development. It poses special challenges in evaluating costs for these systems.

\subsection{Prior Related Work}

After the first oil price crisis, an effort was made to establish a synthetic fuel industry in the U.S. using coal and more unconventional fossil fuel sources. Later in the 1970's, biofuels were also introduced and developed. For example, the IEA Bioenergy established a series of projects where the development potential of new biomass liquefaction process concepts under development in participating countries (U.S., Canada, Sweden, Finland) was evaluated ${ }^{3}$. Duration of these studies is illustrated in Figure 2, which also explains why there was little industrial interest towards these systems. The early IEA assessments were carried out from 1982-92 during which oil prices plummeted to one third from the peak level.



Figure 2. Price of oil 1860-2011, light green line in 2011 dollars.

(red bar denotes duration of the IEA projects)

\footnotetext{
${ }^{3}$ A Study of a Biomass Liquefaction Test Facility, Final Report of IEA Cooperative Project Biomass Liquefaction Test Facility, Kjellström, B. ed. 1985 Statens Energiverk R:1, Stockholm.
} 
Evaluation of alternative transportation fuel production processes at that time was just beginning. Complete experimental mass balances were not available, and the studied process routes to transportation fuels were somewhat premature. A comparison of high-pressure biomass liquefaction (i.e. hydrothermal liquefaction) and fast pyrolysis to transportation fuels is summarized in Figure 3 below. Costs related to three stages of processing (primary conversion, oil upgrading, and final refining) are shown. Efficiencies for the "potential" concepts for fast pyrolysis and high pressure liquefaction processes to transportation fuels were 50 and $39 \%$ based on fuel LHV, respectively.

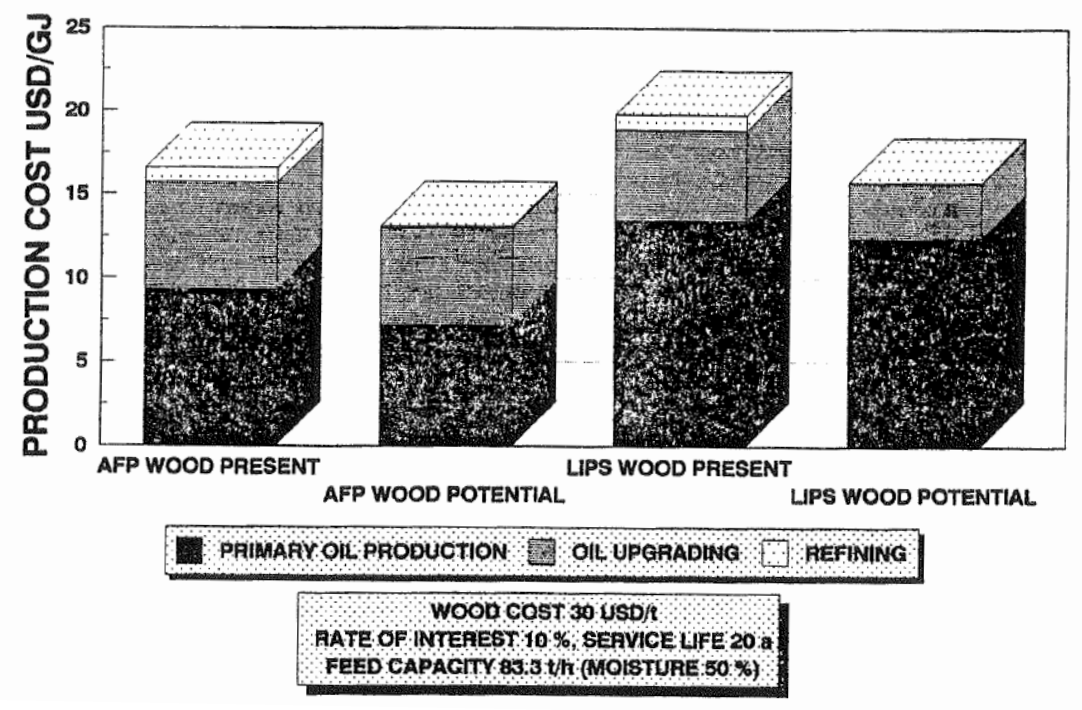

Figure 3. Production cost comparison of transportation fuels from biomass, costs for $1987^{4}$.

Fast pyrolysis was selected in these three consecutive IEA assessments ${ }^{4},{ }^{5}$ as the potentially most promising technology among the numerous biomass liquefaction routes for the production of fuel oils and transportation fuels, which were under development at the time of assessment.

First-of-a-kind synthetic fuel plants produced much higher cost fuels than initially estimated around 1975-80. Merrow et al. ${ }^{6,7}$ analyzed and pointed out a few fundamental mistakes, which plagued early industrial efforts. They established a cost evaluation method, which tried to capture the main negative drivers. Ultimately however, interest towards synfuels was reduced considerably with decreasing oil prices (note Fig 2), and there was relatively limited development during the 1990's. This is strong reminder that development efforts for alternative fuels are directly linked to the price of crude oil.

\footnotetext{
${ }^{4}$ McKeough, P. et al. Techno-ecomonic assessment of direct biomass liquefaction processes. Final Report of IEA Cooperative Project Biomass Liquefaction Test Facility. VTT Research Report 337, Technical Research Centre of Finland, Espoo. 1985.

${ }^{5}$ Solantausta, Y. et al. Assessment of liquefaction and pyrolysis systems. Biomass Bioenergy, 1992 2(1-6):279-297.

${ }^{6}$ Merrow, E., Chapel, S., Worthing, C., A review of cost estimation in new technologies: Implications for energy process plants. RAND-R-2481-DOE. RAND Corporation for the U.S. Department of Energy. Santa Monica, CA. July 1979.

${ }^{7}$ Merrow, E., Phillips, K., Myers, C., Understanding cost growth and performance shortfalls in pioneer process plants. R-2569-DOE, RAND Corporation for the U.S. Department of Energy. Santa Monica, CA.. September 1981.
} 
Once oil prices started to rise again in the early 2000s, sustainable renewable biofuels became the next synthetic fuels of interest. Reduction of the carbon footprint had become an issue, and biofuels offered a potential solution.

Holmgren et al. ${ }^{8}$ re-introduced fast pyrolysis and bio-oil hydrotreating to mainstream engineering discussion as a potential route to alternative renewable, liquid transportation fuels in 2008. Fast pyrolysis could serve transportation fuels markets using feedstock outside the food chain. As a result of this article, industry interest in biomass pyrolysis-derived fuels was awakened because the article was co-authored by both industrial and national laboratory stakeholders, UOP, PNNL and NREL. It was recognized that before industrial applications could be achieved, the new route to fuels would require considerable development efforts. However, it was reported that the route had industrial potential to be cost competitive with currently elevated petroleum product prices, along with $\mathrm{CO}_{2}$-reduction potential.

The U.S. DOE BETO published in 2009 a document, Production of Gasoline and Diesel from Biomass via Fast Pyrolysis, Hydrotreating, and Hydrocracking, a design case. ${ }^{9}$ Based on the analysis, 29 $\mathrm{wt} \%$ of renewable gasoline and diesel blendstock could be produced from wood feedstock at 7wt\% moisture. Additionally, fossil hydrogen was assumed for hydrotreating. PNNL and NREL prepared this report, which detailed cost and performance analysis on infrastructure-ready products from the production and upgrading of pyrolysis oil to hydrocarbon fuels. They also concluded that the route would be an economically attractive source of renewable fuels. They reported $55 \%$ of the feedstock carbon reported to products (gasoline and diesel pool). However, it was also reported that in their model $12 \%$ of feed carbon was derived from natural gas (NG), which was used to generate hydrogen for bio-oil hydrotreatment. For this reason, the report emphasised that integration of biomass upgrading with a petroleum refinery would improve the economic performance of the concept.

The report of Wright et al. ${ }^{10}$ by Iowa State University, Conoco, and NREL was the first study to employ the pioneer plant method for estimating investment cost contingencies in reporting biofuel cost estimates. An investment plant cost in excess of $\$ 900$ million was calculated for a demonstration plant using $2000 \mathrm{t} / \mathrm{d}$ biomass feed employing first-of-a-kind investment cost bases. The nth plant cost would be one third of that. When hydrogen for upgrading is generated from biomass, a biomass to liquid fuel efficiency for the hydrogen production scenario was estimated at 36\%. Feedstock to liquid fuel energy conversion efficiency for the hydrogen purchase scenario is estimated at $50 \%$ and includes the hydrogen energy input. The authors list several technical challenges, which still must be overcome to make the concept industrially viable. These include the challenges of alkaline content of biomass which can impact catalytic treatment and improvements in condenser technology at the scale employed to improve yield of liquid bio-oil and reduce material build-up in the system. Bio-oil upgrading faces several major challenges including: catalyst performance and lifetime, uncertainty over bio-oil separation technology performance, and the need for multiple process steps for hydrotreating.

\footnotetext{
${ }^{8}$ Holmgren, J. et al. Consider upgrading pyrolysis oils into renewable fuels. Hydrocarbon Processing 2008(Sep): 95-103

${ }^{9}$ Jones, S.B.et al. Production of gasoline and diesel from biomass via fast pyrolysis, hydrotreating and hydrocracking: a design case. PNNL-18284, Pacific Northwest National Laboratory, Richland, Washington February 2009.

${ }^{10}$ Wright, M. et al. Techno-economic analysis of biomass fast pyrolysis to transportation fuels. Fuel 2010 89:S2$\mathrm{S} 10$
} 
The processing scheme consisting of a forestry residue biomass fast pyrolysis followed by hydrodeoxygenation by co-feeding a mineral-oil refinery was proposed and evaluated in the EU project BIOCOUP. ${ }^{11}$ The results of these several studies and some related versions are collected in Figure 4 below. The transportation pool component (gasoline + light oil) efficiency for the concept, where vacuum gas oil and bio-oil, upgraded by HDO, were co-processed in a FCC, was estimated to be $43 \%$ when considering the LHV of the biomass fed to pyrolysis and fossil hydrogen used in bio-oil upgrading. In this case, HDO340 means incomplete bio-oil HDO carried out at $340{ }^{\circ} \mathrm{C}$. The pioneer plant method was employed in estimating capital costs. Demonstration plant production costs were estimated to be 2.3 times more expensive than the estimated costs for the nth plant for the HDO340 case.

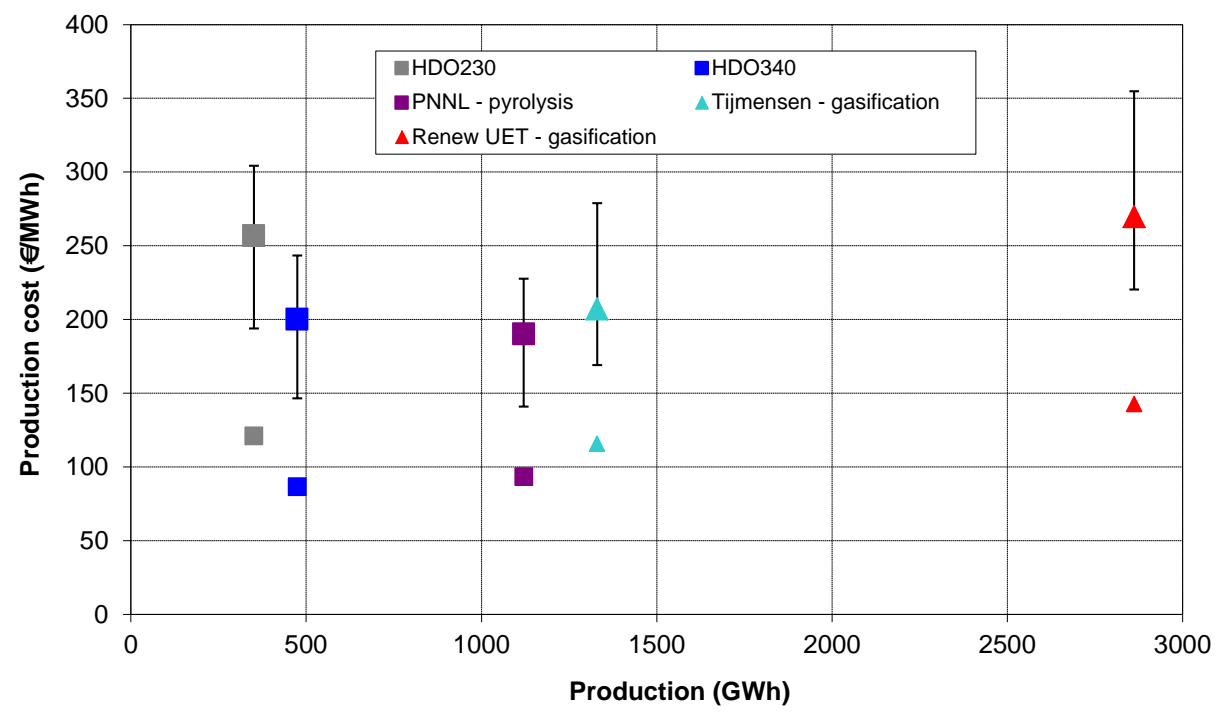

Figure 4. Gasoline production cost estimates from biofuels, HDO230 and HDO340 concepts from BIOCOUP co-refining, $\mathrm{PNNL}^{9}$, Renew ${ }^{12}$, Timensen ${ }^{13}$. Ranges refer to the range pioneer plant method intervals.

\subsection{Current Study}

Building upon all of the prior related work, this current study intends to perform a modern assessment of fast pyrolysis (FP) and hydrothermal liquefaction (HTL) both followed by hydrodeoxygenation to produce a liquid hydrocarbon product, defined in terms of a gasoline, diesel and heavy oil compatible fractions. Forest residue wood biomass was the feedstock used in the model. The concepts were selected due to the similar development challenges with these concepts and similar stage of development.

\footnotetext{
${ }^{11}$ http://www.biocoup.com/index.php?id=18

12 RENEW - Renewable fuels for advanced powertrains, 2008, http://www.renew-fuel.com/home.php.

13 Tijmensen, M.J.A., et al. Exploration of the possibilities for production of Fischer Tropsch liquids and power via biomass gasification, Biomass Bioenergy 2002 23:129-152.
} 
This current evaluation was an extension of the assessment carried out within the IEA Bioenergy agreement during the 1980's. A fresh assessment was needed, using recent research data and process improvements to inform a techno-economic evaluation that could guide the efforts of stakeholders interested in developing these systems and identify high value topics for national research investments in bringing the technology to fruition. This has resulted in a higher confidence assessment due to the recent abundance of experimental research data and industrial activities available than during prior evaluations.

Fast pyrolysis of biomass to replace fuel oils was recently scaled-up to industrial operation by Valmet, Ensyn and BTG. Examples of industrial projects for heat or power production are those of Fortum Power and Heat ${ }^{14}$ in Finland, BTG BTL ${ }^{15}$ in the Netherlands, Green Fuel Nordic Oy ${ }^{16}$ in Finland, and Ensyn's expansion in Canada and an announced project with Premium One in Malyasia. ${ }^{17}$ There has also been the first industrial pilot plant for the production of transportation fuels through fast pyrolysis and hydrotreatment by $\mathrm{UOP}^{18}$ under construction in Hawaii, supported in-part by the U.S. DOE and was expected to be fully operational in 2015. Therefore, industrial applications producing higher value fuels may be expected prior 2020.

The impetus for this study was to determine if recent advancements in both fast pyrolysis bio-oil upgrading and in hydrothermal liquefaction may have impacted the relative cost competitiveness of these two routes. For example, it has been found that the hydrotreating of fast pyrolysis bio-oil modeled in the earlier report ${ }^{1}$ will need additional processing for stabilization of the bio-oil, so a reduced space velocity is required. Also, the reducing gas requirement in the earlier report for HTL (and therefore a need for significant diversion of biomass feedstock to the gasification process) was not needed. In addition, the once through HTL process without biocrude recycle for slurry formation has now been demonstrated. These important developments are modeled in this study.

\footnotetext{
${ }^{14}$ http://www.fortum.com/en/mediaroom/Pages/fortum-invests-eur-20-million-to-build-the-worlds-first-industrialscale-integrated-bio-oil-plant.aspx

15 http://www.empyroproject.eu/

$16 \mathrm{http://www.greenfuelnordic.fi/en/page/23?newsitem=10}$

${ }^{17}$ http://www.ensyn.com/projects/renfrew-ontario/ http://www.ensyn.com/projects/indi-projectitaly/ http://www.ensyn.com/projects/lahad-datumalaysia/ http://www.industriaeinnovazione.it/en/ER-sito-Indi.pdf page 37

${ }^{18}$ http://www.uop.com/honeywells-uop-awarded-department-energy-grant-conversion-waste-biomass-green$\underline{\text { transportation-fuels/ }}$
} 


\subsection{Analysis Approach}

A techno-economic assessment is a standard tool for evaluating alternatives. The accuracy of this tool is highly dependent on the quality and reliability of the data at hand, thus the techno-economic viability of undemonstrated process concepts can be difficult to evaluate.

Conceptual models of the conversion processes fast pyrolysis and hydrothermal liquefaction of biomass with upgrading of bio-oil have been developed using process simulation software Aspen Plus ${ }^{\circledR}$. The models are based on literature data and experimental results from partners involved in the project. Inherent differences in the process equipment and products were captured in this assessment. Fast pyrolysis bio-oil is a more thermally unstable feedstock for catalytic hydroprocessing than petroleumderived feedstocks and therefore requires a more nuanced approach in upgrading. Hydrothermal liquefaction produces a more stable biocrude for upgrading, at the expense of high-pressure processing equipment and lower product yield, but can be more easily hydrotreated to the hydrocarbon liquid fuel products desired in this study with lower processing cost impact.

Aspen Plus ${ }^{\circledR}$ simulates steady-state chemical process reactions and calculates mass and energy balances based on experimentally derived operating conditions. Furthermore, physical properties of the chemical compounds chosen to represent the reactants and products were provided by the Aspen Plus ${ }^{\circledR}$ thermodynamic database. Heat and material balances generated by the models were further validated and then used to complete a technoeconomic assessment (TEA).

In order to model the biomass liquefaction technologies, model compound mixtures needed to be defined to represent the products of both the liquefaction step but also the hydroprocessing product. The organic products are a complex mixture of hundreds of compounds. The number and type of compounds used in the Aspen model to represent the organic liquid products and the associated aqueous phase must reasonably match key properties of such as $\mathrm{C}, \mathrm{H}, \mathrm{O}, \mathrm{N}, \mathrm{S}$, density, heating value, GC/MS data, distillation range, and aqueous solubility. A significant effort and time was spent on development and refining of these lists. Based on earlier models at PNNL and VTT, an updated list of model compounds was developed for fast pyrolysis bio-oil. Using that list as a starting point a second list was developed for hydrothermal liquefaction. Whereas the hydroprocessed products from the two liquefaction technologies are nearly the same, the model compound list developed to represent the hydrocarbon liquid fuel product was the same for each liquefaction model.

A model compound list for fast pyrolysis bio-oil was developed as shown in Table 1. These are for the most part commonly found components in bio-oil. However, each component also represents a group of similar components in real bio-oil. A user defined component, pyrolignin was created to allow for a better representation of bio-oil in ASPEN since there is no lignin oligomer component in the Aspen data base.

HTL organic products are a complex mixture of hundreds of compounds. The compounds chosen for the Aspen model are shown in Table 2. Note, that this list does not imply that these compounds occur in the given percentages in actual HTL biocrude, rather each compound represents a group of compounds that taken together exhibit the bulk properties. Carbon dioxide and ammonia in the aqueous phase actually form their ionic species in various amounts and types, including $\mathrm{NH}_{4}{ }^{+}, \mathrm{NH}_{2} \mathrm{COO}^{-}, \mathrm{HCO}_{3}{ }^{-}, \mathrm{CO}_{3}{ }^{\circ}$. For 
simplification purpose, these ion formations are not simulated in this model, but their pure original compounds are considered.

Table 1. Compounds Used to Model Fast Pyrolysis Bio-oil

\begin{tabular}{|l|c|c|c|c|c|c|c|}
\hline \multicolumn{1}{|c|}{ HTL OIL } & Wt\% & C & H & O & N & S & CAS \\
\hline Acetic Acid & $2.7 \%$ & 2 & 4 & 2 & & & $64-19-7$ \\
\hline Ethylene glycol & $0.1 \%$ & 2 & 6 & 2 & & & $107-21-1$ \\
\hline Acetol & $2.9 \%$ & 3 & 6 & 2 & & & $116-09-6$ \\
\hline Glycolaldehyde & $8.7 \%$ & 2 & 4 & 2 & & & $141-46-8$ \\
\hline Guaiacol & $11.4 \%$ & 7 & 8 & 2 & & & $90-05-1$ \\
\hline Furfural & $2.7 \%$ & 5 & 4 & 2 & & & $98-01-1$ \\
\hline Levoglucosan & $27.5 \%$ & 6 & 10 & 5 & & & $498-07-7$ \\
\hline Water & $28.7 \%$ & 0 & 2 & 1 & & & $7732-18-5$ \\
\hline Oleic Acid & $8.5 \%$ & 18 & 34 & 2 & & & $112-80-1$ \\
\hline ethylthioethanol & $0.1 \%$ & 4 & 10 & 1 & & 1 & $110-77-0$ \\
\hline 2-Pyrrolidone & $2.0 \%$ & 4 & 7 & 1 & 1 & & $616-45-5$ \\
\hline Pyrolignin & $4.7 \%$ & 24 & 32 & 4 & & & User Defined \\
\hline Total & $\mathbf{1 0 0 \%}$ & & & & & & \\
\hline
\end{tabular}

Table 2. Compounds Used to Model HTL Gas and Liquid Products

\begin{tabular}{|c|c|c|c|c|c|c|c|}
\hline HTL OIL & Wt\% & C & $\mathbf{H}$ & 0 & $\mathbf{N}$ & $\mathbf{S}$ & CAS \\
\hline 2-Pyrrolidone & $0.12 \%$ & 4 & 7 & 1 & 1 & & $616-45-5$ \\
\hline ethylthioethanol & $0.01 \%$ & 4 & 10 & 1 & & 1 & $110-77-0$ \\
\hline 2-Butanone & $1.62 \%$ & 4 & 8 & 1 & & & $78-93-3$ \\
\hline 1,2-Benzenediol & $0.00 \%$ & 6 & 6 & 2 & & & $120-80-9$ \\
\hline 4-propyl-1,3-Benzenediol & $7.75 \%$ & 9 & 12 & 2 & & & $18979-60-7$ \\
\hline dihydro-5-methyl-2(3H)-Furanone & $0.03 \%$ & 5 & 8 & 2 & & & $108-29-2$ \\
\hline 2,6-dimethoxy-Phenol & $2.70 \%$ & 8 & 10 & 3 & & & 91-10-1 \\
\hline 4,5-dimethyl-1,3-Benzenediol & $8.11 \%$ & 8 & 10 & 2 & & & $527-55-9$ \\
\hline 2-methoxy-4-propyl-Phenol & $24.38 \%$ & 10 & 14 & 2 & & & $2785-87-7$ \\
\hline Cyclopentanone & $5.41 \%$ & 5 & 8 & 1 & & & $120-92-3$ \\
\hline 2-methyl-Cyclopentanone & $3.25 \%$ & 6 & 10 & 1 & & & $1120-72-5$ \\
\hline 2-methyl-2-Cyclopenten-1-one & $0.41 \%$ & 6 & 8 & 1 & & & $1120-73-6$ \\
\hline Phenol & $1.64 \%$ & 6 & 6 & 1 & & & $108-95-2$ \\
\hline 2,3-dimethyl-2-Cyclopenten-1-one & $2.57 \%$ & 7 & 10 & 1 & & & $1121-05-7$ \\
\hline 4-methyl-Phenol & $2.27 \%$ & 7 & 8 & 1 & & & $106-44-5$ \\
\hline Diphenylmethane & $7.30 \%$ & 13 & 12 & & & & $101-81-5$ \\
\hline Benzyl ether & $9.74 \%$ & 14 & 14 & 1 & & & $103-50-4$ \\
\hline 9-methylanthracene & $14.62 \%$ & 15 & 12 & & & & 779-02-2 \\
\hline Pyrolignin & $1.08 \%$ & 24 & 32 & 4 & & & User Defined \\
\hline Formic Acid & $1.46 \%$ & 1 & 2 & 2 & & & $64-18-6$ \\
\hline Water & $5.53 \%$ & & 2 & 1 & & & $7732-18-5$ \\
\hline Total & $100 \%$ & & & & & & \\
\hline
\end{tabular}

The hydroprocessed products from the biomass liquefaction systems contain numerous compounds and a limited number is used for modeling purposes. Table $\mathbf{3}$ shows the mixture of compounds used to 
represent the hydrotreated oil in the models. Note, that this list does not imply that these compounds occur in the given percentages in actual hydrotreated oil, rather each compound represents a group of compounds that taken together exhibit the bulk properties.

Table 3. Compounds Used to Model Hydroprocessed Products

\begin{tabular}{|l|c|c|c|c|c|c|c|}
\hline \multicolumn{1}{|c|}{ Compound } & C & H & O & N & S & Wt\% & CAS \\
\hline Hexane & 6 & 14 & & & & $3.7 \%$ & $110-54-3$ \\
\hline Dodecane & 12 & 26 & & & & $4.4 \%$ & $112-40-3$ \\
\hline 4-methylnonane & 10 & 22 & & & & $4.1 \%$ & $17301-94-9$ \\
\hline ethylcyclopentane & 7 & 14 & & & & $2.9 \%$ & $1640-89-7$ \\
\hline 1-methyl-1-ethylcyclopentane & 8 & 16 & & & & $3.7 \%$ & $16747-50-5$ \\
\hline Cyclohexane & 6 & 12 & & & & $3.2 \%$ & $110-82-7$ \\
\hline propylcylcohexane, & 9 & 18 & & & & $3.2 \%$ & $1678-92-8$ \\
\hline 1,3-dimethyladamantane & 12 & 20 & & & & $4.7 \%$ & $702-79-4$ \\
\hline 1-ethenyl-4-ethyl-Benzene & 10 & 12 & & & & $7.0 \%$ & $3454-07-7$ \\
\hline 4-methylphenanthrene & 15 & 12 & & & & $24.4 \%$ & $832-64-4$ \\
\hline Indeno[1,2,3-cd]pyrene & 22 & 12 & & & & $6.8 \%$ & User Defined \\
\hline 1,2-Diphenylethane & 14 & 14 & & & & $8.3 \%$ & $103-29-7$ \\
\hline Indane & 9 & 10 & & & & $3.4 \%$ & $496-11-7$ \\
\hline 1-n-hexyl-1,2,3,4-tetrahydronaphthalene & 16 & 24 & & & & $17.1 \%$ & $66325-11-9$ \\
\hline 1-phenyl-Naphthalene & 16 & 12 & & & & $2.9 \%$ & $605-02-7$ \\
\hline 5-Methyl-2-(1-methylethyl)phenol & 10 & 14 & 1 & & & $3.7 \%$ & $89-83-8$ \\
\hline 2-4-6-Trimethyl-pyridine & 8 & 10 & & 1 & & $4.4 \%$ & $108-75-8$ \\
\hline Dibenzothiophene & 12 & 5 & & & 1 & $4.1 \%$ & $132-65-0$ \\
\hline Total & & & & & & $\mathbf{1 0 0 \%}$ & \\
\hline
\end{tabular}

Numerous technical assumptions were made in order to accomplish this modeling task due to the early stage of development of these biomass conversion technologies. Feedstock analyses used in the models are based on extensive research conducted on biomass material at VTT. Chipped forest residue was assumed as raw material for the bio-oil production processes. Table $\mathbf{4}$ shows the specification of the feedstock as a summary. Moisture content of the received biomass feedstock is assumed to be at $50 \%$.

Table 4. Summary of Feedstock Properties Based on Dry Matter.

\begin{tabular}{|cc|cc|}
\hline \multicolumn{2}{|c|}{ Proximate } & Analysis, \% & \multicolumn{2}{c|}{ Ultimate } & Analysis, \% \\
\hline Ash & 1.5 & Ash & 1.5 \\
FC & 18.5 & C & 50.9 \\
VM & 80.0 & H & 6.0 \\
& & N & 0.3 \\
& & S & 0.03 \\
& & O & 41.3 \\
\hline
\end{tabular}

Because fast pyrolysis (FP) and hydrothermal liquefaction (HTL) conversion processes require different types of feedstock preparation, the method of preparation and feeding to the reactor will be discussed in subsequent chapters. The same feedstock was used consistently in all model development and analysis. Pre-treatment (grinding and drying) is done at the plant. Size reduction and particle drying 
for fast pyrolysis is well understood. In the case of hydrothermal liquefaction there is less information and an assumed low concentration of biomass in water was assumed as a conservative basis. The use of recycle water for heat transfer to the feedstock is an untested method which was assumed for this analysis.

The plant capacity is set at processing a total of 2000 metric tons per day (474 MW) of bone-dry biomass (x MW), in order that the studies will be on a basis similar to that which was used by the Bioenergy Technologies Office of U.S. Department of Energy. ${ }^{9}$ In the model, the 2000 metric tons per day are processed through four $500 \mathrm{mtpd}$ reactor units for FP, instead of one large unit. The reactor size was based on literature reports on reactor size for fast pyrolysis. HTL processing is in an earlier stage of development and therefore the assumed reactor train size (2000 metric ton per day) may be more open to question. The plant is assumed to be an established (" $\mathrm{n}$ th") plant design rather than a first of its kind (pioneer) plant.

The upgrading of the liquefaction products is also at an early stage of development. The 3 stage hydrotreating model used here for fast pyrolysis bio-oil has been demonstrated for extended periods in the laboratory, but has not been scaled up. The exothermic nature was not adequately modeled here so that the full impact is not incorporated. A single stage of hydrotreating for the HTL biocrude has also been tested in the laboratory but there is no long term validation of the method available from which to extrapolate catalyst lifetime.

The production of hydrogen from the product gases has not been tested for these specific cases. In addition, the assumed use of the hydrotreater byproduct water and the condenser blow down for makeup water in the steam reformer are also untested.

Finally, the long-term catalyst lifetimes assumed here have not been demonstrated for either the biooil hydroprocessing or for the steam reforming. 


\subsection{Process Design for Biomass Conversion to Liquids}

Two energy conversion routes were considered:

1. Fast pyrolysis of biomass and upgrading of the bio-oil product,

2. Hydrothermal liquefaction of biomass and hydrotreating of the biocrude product.

In both cases the desired end product was the same: a mixture of liquid hydrocarbon that boil in the ranges of gasoline, diesel and heavy fuel oils. Based on experimental data, Aspen Plus ${ }^{\circledR}$ models were generated for each of the biomass liquefaction choices, fast pyrolysis with bio-oil upgrading and hydrothermal liquefaction with biocrude hydrotreating.

\subsection{Fast Pyrolysis and Upgrading}

The fast pyrolysis and upgrading process includes raw material preprocessing, pyrolysis and upgrading with separation into gasoline, diesel, and heavy hydrocarbon boiling range fractions -- all on a single site. Heat input to the fast pyrolysis process is generated in the char-fired boiler. Figure 5 shows the block diagram for the process. Modelling the pyrolysis reactor with yields has been based on a compilation of experimental results ${ }^{19}$ and the model for the upgrading was based on experimental results, as well. $^{20}$

\subsubsection{Biomass Pretreatment}

The first step in biomass pretreatment for the fast pyrolysis process is drying the feedstock from 50 wt \% moisture as received to about $8-10 \mathrm{wt} \%$ moisture. This is done in a conventional belt dryer that can use a variety of energy sources, for instance, steam, hot water and electricity. Heat for the modeled dryer is generated in the char-fired boiler as steam and hot water. After drying, the biomass is ground to particle size $<5 \mathrm{~mm}$.

Raw material moisture strongly affects the product bio-oil moisture. The higher the bio-oil moisture, the lower is its heating value. As a consequence, raw material for the fast pyrolysis process must be dried to approximately 8-10 wt\% moisture in order to keep the bio-oil moisture below $30 \mathrm{wt} \%$, at which point phase separation occurs. The use of dried biomass also facilitates the fast heat-up in the pyrolysis process required for high bio-oil yield. The forest residue is also ground to a particle size of below $5 \mathrm{~mm}$. The small size is necessary in order to ensure complete reaction of the particle during the short residence time in the reactor.

\footnotetext{
${ }^{19}$ Oasmaa, A. et al. Fast pyrolysis bio-oils from wood and agricultural residues. Energy Fuels, 2009 24:1380-1388. doi: 10.1021/ef901107f

${ }^{20}$ Elliott, D.C. et al. Catalytic hydroprocessing of fast pyrolysis bio-oil from pine sawdust. Energy Fuels, 2012 26:3891-3896. doi: 10.1021/ef3004587
} 


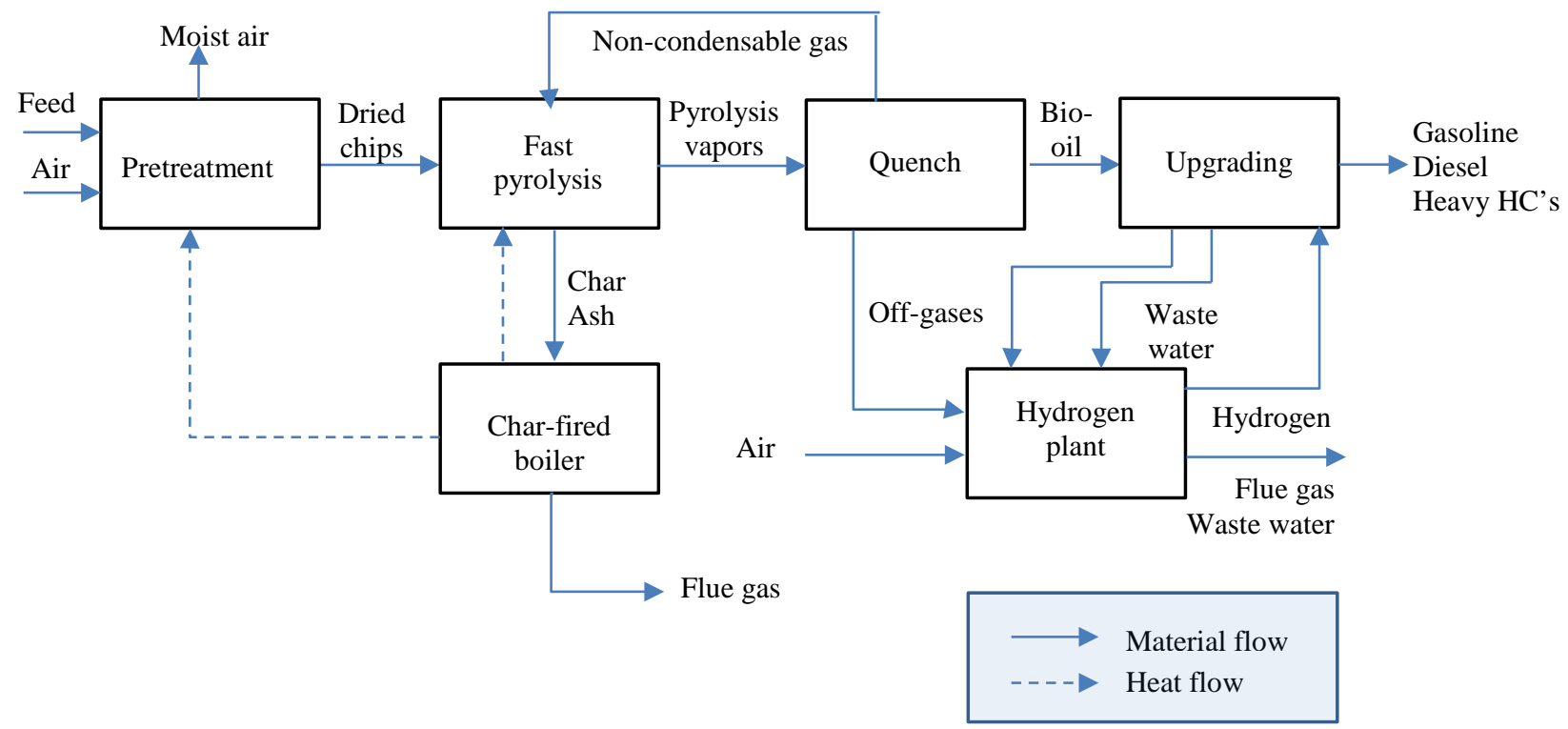

Figure 5. Fast pyrolysis and bio-oil upgrading process flow diagram

\subsubsection{Fast pyrolysis}

Ground, dried biomass enters a circulating fluidized bed reactor and is rapidly heated to $520^{\circ} \mathrm{C}$ under atmospheric pressure in an oxygen-free environment. The reactor is heated with hot sand from the char boiler. After a biomass particle residence time of 1-2 seconds the resulting pyrolysis vapors, noncondensable gases, char and sand exit the reactor. Char and sand are separated directly after the reactor in cyclones and sent to the char boiler where char is combusted and sand is re-heated. Pyrolysis vapors and non-condensable gases are sent to a quench tower. Vapors are quickly condensed to about $35^{\circ} \mathrm{C}$ in order to limit the rate of secondary and polymerization reactions in the bio-oil product. Condensed bio-oil is used as quenching medium in the quench tower. Non-condensable gases exit the quench tower in gas phase. Part of these gases are recycled to the reactor as fluidizing medium. The rest of the gases are used as fuel in the hydrogen reformer. Figure 6 shows the fast pyrolysis process that was modeled.

The products from fast pyrolysis are detailed in Tables 5-7.

Table 5. Fast Pyrolysis Yield, wt\% Based on Dry Biomass Feedstock

$\begin{array}{lcc}\text { Products } & \text { mass } & \text { carbon basis } \\ \text { Bio-oil } & 51.2 & 54.9 \\ \text { Char } & 24.4 & 35.7 \\ \text { Reaction Water } & 12.3 & 0 \\ \text { Gas } & 12.1 & 9.4\end{array}$




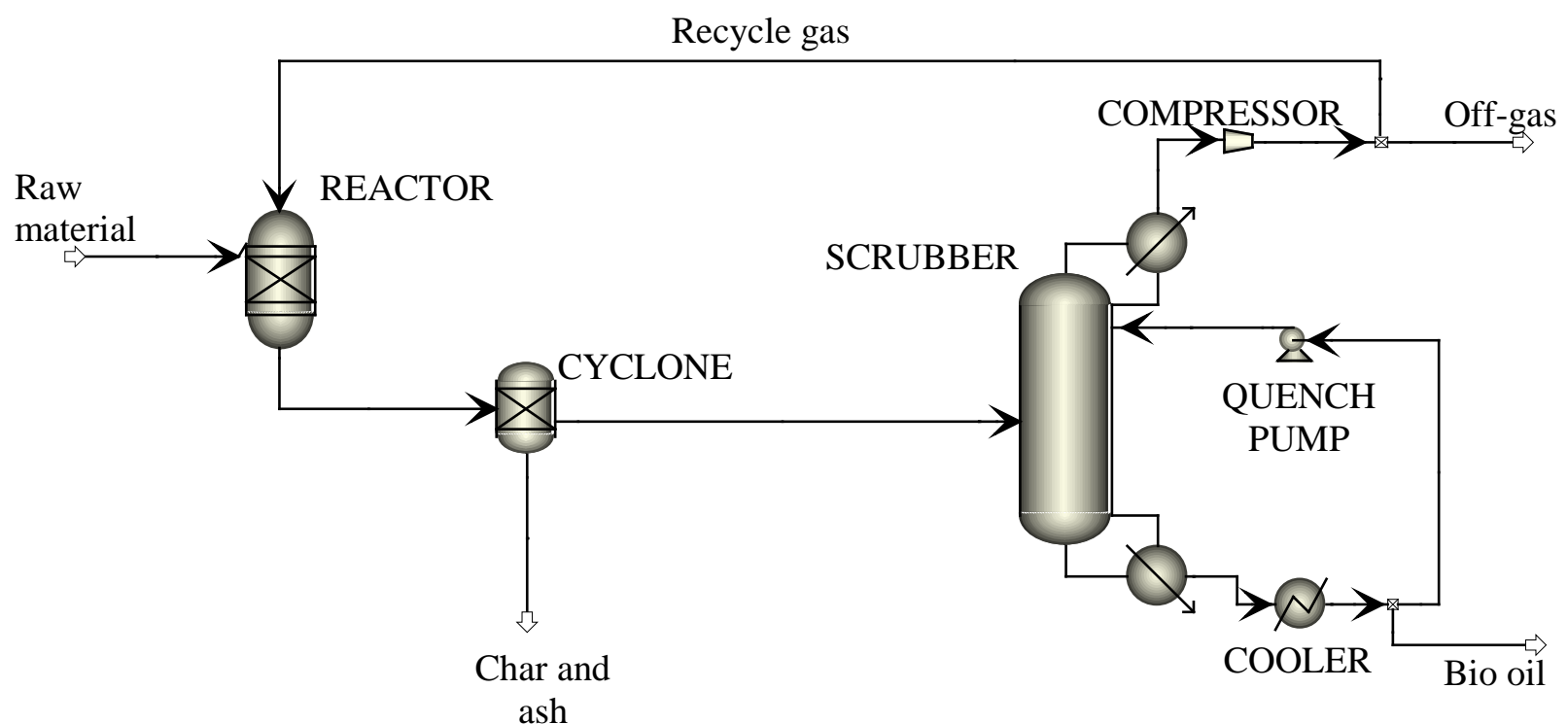

Figure 6 Unit Operations in the Fast Pyrolysis Plant

Table 6. Bio-oil Composition

$\begin{array}{ll}\text { Bio-oil Components } & \underline{\mathrm{wt} \%} \\ \text { Organic phase } & 71.3 \\ \text { Water } & 28.7\end{array}$

Table 7. Gas Phase Composition

$\begin{array}{lr}\text { Gas Component } & \text { mole \% } \\ \mathrm{CO}_{2} & 32.5 \\ \mathrm{CO} & 43.0 \\ \mathrm{CH}_{4} & 12.0 \\ \mathrm{H}_{2} \mathrm{O} & 6.4 \\ \text { Ethylene } & 4.7 \\ \text { Ethane } & 1.4\end{array}$

Bio-oil produced in the fast pyrolysis process is unstable and cannot be directly blended with conventional fossil fuels. The bio-oil is put through a hydrotreatment process where hydrogen is used to upgrade the unstable oil by de-oxygenation. The upgraded bio-oil is then distilled into hydrocarbon fractions that boil in the gasoline, diesel, and heavy ranges. 


\subsection{Hydrothermal Liquefaction and Hydrotreating}

Hydrothermal liquefaction (HTL) and subsequent hydrotreating (see Figure 7) is defined by five major processing areas: feedstock pretreatment, HTL, hydrotreating, hydrogen production and wastewater treatment (and other utilities).

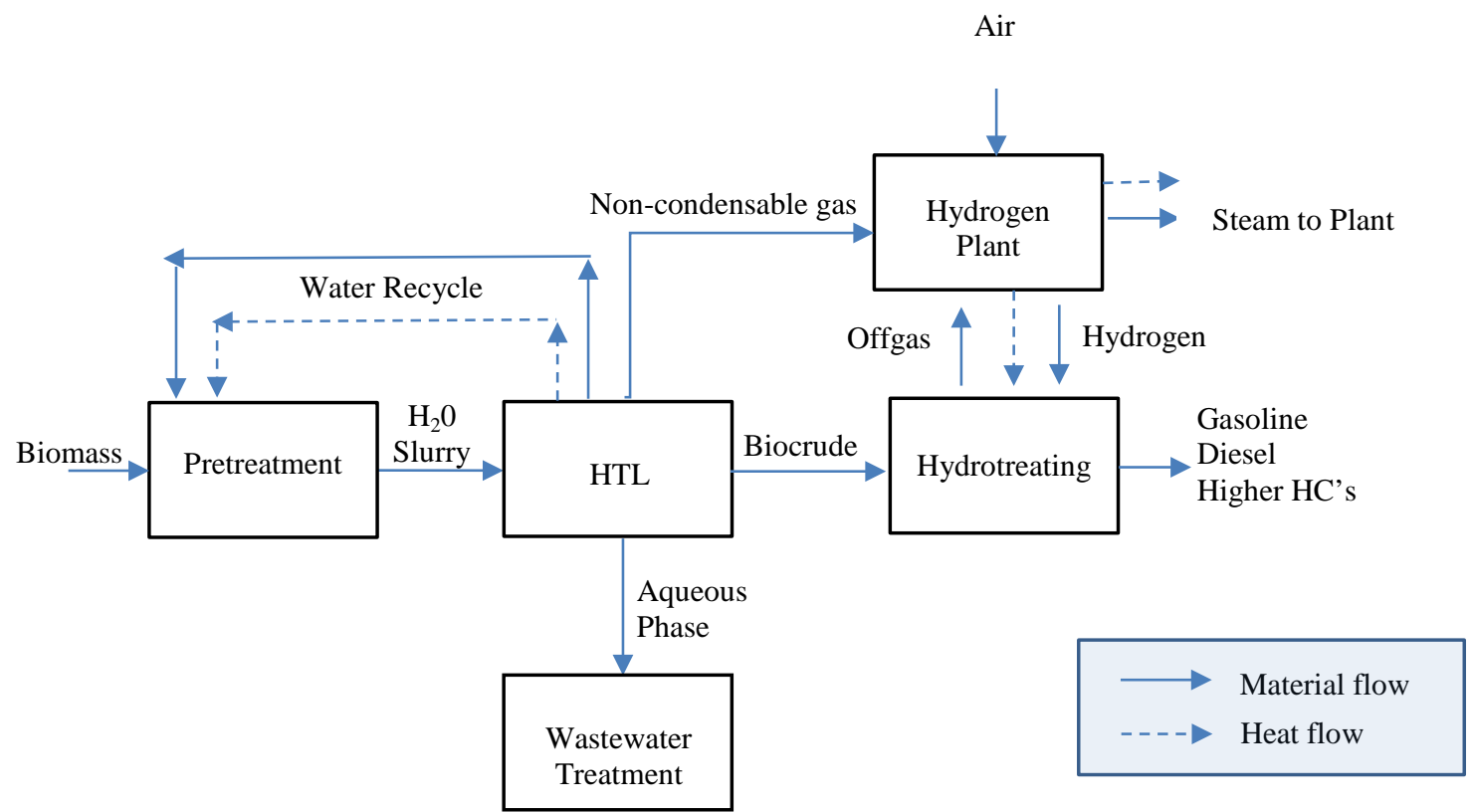

Figure 7. Hydrothermal liquefaction and hydrotreating process flow diagram

In the feedstock pretreatment, forest residue biomass is ground to fine particles without drying and softened by direct injection of hot water, to produce a slurry comprising water with $8 \mathrm{wt} \%$ solids loading. It is believed that the particle size for HTL does not need to be reduced to as great degree as in fast pyrolysis, so the difference in grinding costs for the dry chips versus the wet chips has not been accounted for in this study. The slurry is further preheated and pressurized to HTL reaction pressures. Feedstock solids loading specification for the HTL process is based on experimental data from laboratory testing. The base case model, shown in Figure 8 assumes 8 wt\% solids loading in the slurry pumped to about 0.6 MPa and sent to the HTL process area.

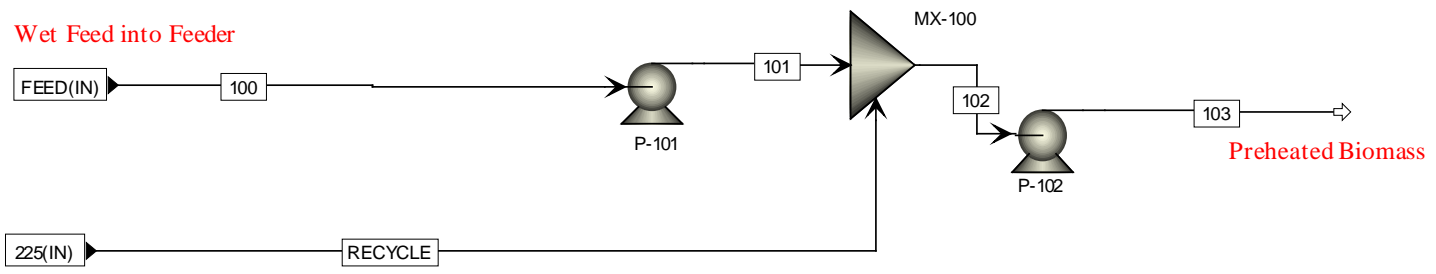

Figure 8. Biomass pretreatment process 
The HTL process model is based on experimental tests conducted at PNNL for the National Advanced Biofuels Consortium (NABC). ${ }^{21}$ In the process model, the biomass-water slurry from the biomass pretreatment process is assumed to be pumped and preheated by the hot liquid effluent from the HTL reactor. Ongoing work with pump manufacturers indicates that large scale biomass/water slurry pumping is considered feasible; however, this still needs to be verified in field tests.

As seen in Figure 9, the preheated slurry is sent to the HTL reactor operating at 20.3 MPa and $355^{\circ} \mathrm{C}$. For this large-scale system and the economy of scale-up, the HTL reactor scheme is assumed to be plug flow rather than the CSTR more commonly seen in laboratory experiments. The reactor has a shell and tube design with slurry in the tube and a heat transfer fluid system on the shell side. A heater fired by process gases is used to provide heat to the heat transfer fluid and maintain isothermal conditions in the HTL reactor.

The biomass slurry undergoes a conversion reaction to biocrude, aqueous, and gas phase products. The hot effluent from the HTL reactor is sent to a settler/filter to separate fine particles from the hot liquid. The filtered solids are mainly composed of precipitated minerals with some unreacted biomass or char. Further processing of the separated solids is not considered in this model and the materials are assumed to be disposed as solid wastes. The liquid effluent from the settler/filter exchanges heat with the incoming biomass-water slurry and is then depressurized. After cooling to $117^{\circ} \mathrm{C}$ and depressurization to 0.1 MPa the products go through a 3-phase separator, SP-210, and exit in the gas phase, aqueous phase and biocrude product streams S208, S209, and S213 respectively. Yields for each product stream are reported in Table 8 on both a mass basis and on a carbon basis. All product distribution data from the Aspen mass balance was checked against experimental results produced by PNNL.

Table 8. Hydrothermal Liquefaction Yield, wt\% Based on Dry Biomass Feedstock

$\underline{\text { Products }}$

Organic portion of Biocrude

Organics in Aqueous Phase

Solids

Reaction Water

Gas

$\begin{array}{rr}\underline{\text { mass }} & \text { carbon basis } \\ 34.6 & 52.4 \\ 35.4 & 36.3 \\ 5.7 & 0.5 \\ 6.8 & -0- \\ 17.5 & 10.8\end{array}$

Table 8 indicates a large fraction of biomass converted to organics present in the biocrude phase as well as in the aqueous phase. This amount of organic in the aqueous phase is greatly diluted by the large fraction of water used in the hydrothermal system. The data in Table $\mathbf{8}$ represent a single pass yield from the dry biomass solids and do not include the large amount of process water recycled within HTL, in order to reduce the solids loading of the slurry stream to $8 \mathrm{wt} \%$.

\footnotetext{
${ }^{21}$ Schmidt, A.J. et al. Mid-stage 2 report on the hydrothermal liquefaction strategy for the NABC leadership team. PNNL-21768, Pacific Northwest National Laboratory, Richland, Washington, September 2012. Zhu, Y. et al. Techno-economic analysis of liquid fuel production from woody biomass via hydrothermal liquefaction (HTL) and upgrading. Applied Energy, in press. 2014.
} 


\section{HTL Reactor}

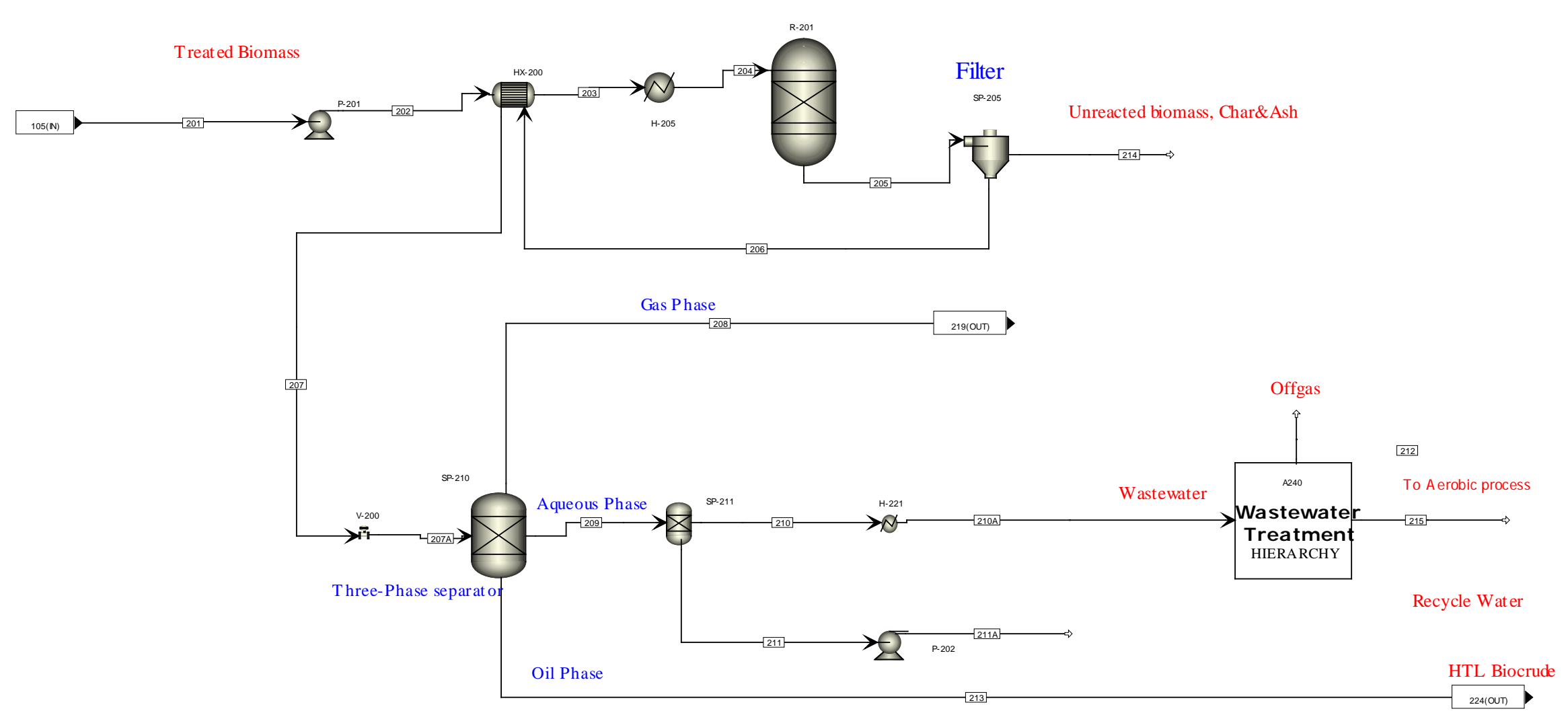

Figure 9. Hydrothermal Liquefaction and Subsequent Product Separation Process 
The recovered biocrude phase consists mainly of oxygenated hydrocarbons and a certain percentage of moisture, as is represented in Table 9. The model assumes that all the ash is separated with the solids, which is an over-simplification of the process, as some ash components will be soluble in the aqueous. The biocrude stream is processed further through hydrodeoxygenation for the production of the finished liquid hydrocarbon product.

Table 9. Liquid Product Composition

\begin{tabular}{lr} 
Biocrude Components & $\mathrm{wt} \%$ \\
\hline Organics & 95.5 \\
Water & 5.5 \\
Ash & 0 \\
& \\
Aqueous Phase Components & $\underline{\mathrm{wt} \%}$ \\
Process water + reaction water & 96.9 \\
Dissolved organics & 3.1 \\
Ash & 0
\end{tabular}

The recovered aqueous phase consists mostly of the water used to form the feed slurry, but also contains dissolved aqueous phase organics -- alcohols, acids, and other oxygenates. The majority of this stream is recycled for slurry formation in the feed pretreatment section. The balance (about 5\%) is sent to wastewater treatment, which includes anaerobic digestion (AD). In the $\mathrm{AD}$ reactor the organics found in the aqueous stream are converted to $\mathrm{CH}_{4}$ and $\mathrm{CO}_{2}$ which is sent to the hydrogen plant where it is used as reformer feedstock as well as fuel gas for fired heaters. The surplus is sent to the boiler to generate process steam.

The gas product (shown in Table 10) includes carbon dioxide $\left(\mathrm{CO}_{2}\right)$, methane $\left(\mathrm{CH}_{4}\right)$, and a little hydrogen $\left(\mathrm{H}_{2}\right)$ and other light hydrocarbon gases (ethane, propane, butane). These products are assumed to be sent to the hydrogen plant for hydrogen production.

Table 10. Gas Phase Composition

$\begin{array}{lr}\text { Gas Component } & \text { volume \% } \\ \mathrm{CO}_{2} & 90.2 \\ \mathrm{CO} & 0 \\ \mathrm{CH}_{4} & 3.0 \\ \mathrm{H}_{2} & 0.9 \\ \text { Ethane } & 2.5 \\ \text { Propane } & 1.9 \\ \text { Butane } & 1.5\end{array}$


In the biocrude hydrotreating section, the biocrude is reacted with hydrogen gas over a catalyst until oxygen content below $1 \%$ is achieved. The resulting hydrocarbon oil has a wide boiling range from lighter than gasoline to heavier than diesel. Similar to the fast pyrolysis case, the hydrocarbon products boil in the gasoline, diesel, and heavy hydrocarbon ranges.

\subsection{Liquid Product Upgrading by Hydroprocessing}

The upgrading process models for the fast pyrolysis process and the hydrothermal liquefaction process are similar. Also the hydrogen plant is designed on the same basis in both models.

Liquids produced from biomass by direct liquefaction (e.g. fast pyrolysis or hydrothermal liquefaction) can be upgraded through a catalyzed reaction process where the oxygenated product is exposed to hydrogen under elevated pressure and high temperature ${ }^{22}$. This process reduces the oxygen content via hydrodeoxygenation and decarboxylation reactions such that the resulting concentration is below $1 \%$ while also bringing much of the product into the appropriate molecular weight range for useful liquid fuels. The end result improves the overall value and usability of the finished product. Hydroprocessing is conducted in a continuous-flow, fixed-bed reactor packed with catalyst. The reactor effluent is then distilled into to gasoline, diesels and heavy fuel fractions as depicted in Figure 10. Distillations represented in this model are hypothetical and based on previous work and literature findings ${ }^{9}$.

In this part of the process, the bio-oil is pumped to $13.6 \mathrm{MPa}$ and combined with compressed hydrogen from the hydrogen plant. The mixture is preheated by heat exchange with the hydrotreating reactor effluent and sent to the hydrotreating system. The experimental liquid hourly space velocity used in the HTL case is 0.15 volume of oil per volume of catalyst bed per hour. The bio-oil is almost completely converted at $400{ }^{\circ} \mathrm{C}$ to light hydrocarbons, some $\mathrm{C}_{1}-\mathrm{C}_{3}$, mainly $\mathrm{C}_{4}$ to $\mathrm{C}_{17}$, and a small fraction of heavier components. Although many similarities exist in the upgrading of fast pyrolysis bio-oil and hydrotreating of HTL biocrude, there are some key differences as well. The nature of the bio-oil feed to the HDO reactor and the number of stages needed for each process to achieve similar products differ in the FP and HTL cases. HTL biocrude contains a significantly lower concentration of oxygen before upgrading and is more thermally stable therefore it can be adequately processed in one stage of HDO utilizing a conventional sulfided NiMo catalyst. However, FP bio-oil is more oxygenated and thermally reactive, therefore several stages have to be employed for stabilization and upgrading to achieve a finished product ${ }^{9}$. These were specified as $\mathrm{Ru} / \mathrm{C}$ in the stabilization, sulfided $\mathrm{Ru} / \mathrm{C}$ in the first stage hydrotreater, and sulfided NiMo in the second hydrotreater. Space velocities for the three steps are 0.5, 0.22 and 0.22 , respectively. The operating conditions and production yields for the hydrotreating reaction simulation were based on the experimental tests for both the $\mathrm{FP}^{23}$ and HTL models. ${ }^{24}$ Costs and energy demands are therefore different for the two cases and the differences lead to different outcomes in the techno-economic assessment.

\footnotetext{
22 Elliott, D.C. Historical Developments in Hydroprocessing Bio-oil. Energy Fuels 2007 21:1792-1815.

23 Jones, S.B.; Snowden-Swan, L.L. Production of Gasoline and Diesel from Biomass via Fast Pyrolysis, Hydrotreating and Hydrocracking: 2012 State of Technology and Projections to 2017. PNNL-22684, Pacific Northwest National Laboratory, Richland, Washington, February 2013.

${ }^{24}$ Zhu, Y. et al. Techno-economic analysis of liquid fuel production from woody biomass via hydrothermal liquefaction (HTL) and upgrading. Applied Energy, accepted for publication 2014.
} 


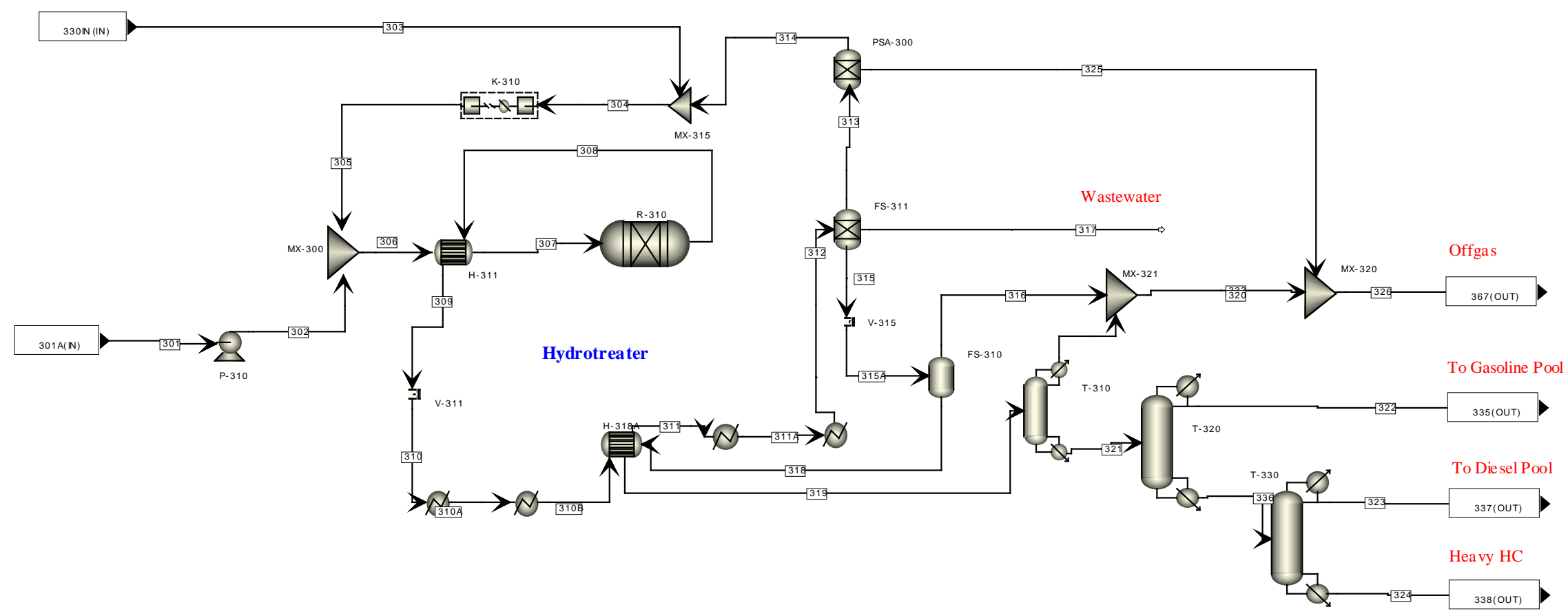

Figure 10. Hydrodeoxygenation and Distillation to Fuels Process 
The effluent from the hydrotreating reactors is cooled by pre-heating the reactor inlet stream. The effluent is further cooled by other process streams, then air, and finally trim cooled with cooling water. The cooled effluent is separated into product oil, wastewater, and off-gas streams. The off-gas from the hydrotreaters is sent to a Pressure Swing Adsorption (PSA) system and $80 \%$ of hydrogen in the feed is assumed be recovered. This assumption is based on current cost information for a PSA unit which can operate at this recovery efficiency. The recovered hydrogen is mixed with makeup hydrogen and compressed to feed back to the reactors. The low pressure PSA tail gas stream, which is not rich in hydrogen and but contains reformable light hydrocarbons, is sent to the hydrogen plant for hydrogen production.

The hydrotreated oil is then further processed by removing butane and lighter components in a lights removal column. This column also serves to adjust the initial boiling point of the gasoline fraction. The overhead gas containing light organics is used as hydrogen plant feedstock. The hydrotreated oil is further separated into gasoline and diesel range fuels, and a heavy fraction which boils above $400^{\circ} \mathrm{C}$. In this case, the gasoline, diesel, and heavy boiling range fraction are assumed to be the final fuel blend-stock product.

\subsection{Hydrogen plant}

Hydrogen for the bio-oil upgrading process is produced by steam reforming in an onsite hydrogen plant. The hydrogen plant mainly relies on off-gas from the biomass conversion processes and upgrading processes, or from the anaerobic digestion wastewater treatment for the hydrothermal liquefaction case.

The gas mixture is pre-heated with heat from the reformer furnace while wastewater from the biomass conversion processes and the upgrading processes is heated with the reformer furnace flue gases to saturated steam. Steam is mixed into the pre-heated gas mixture and sent to the reformer which operates at $3.1 \mathrm{MPa}$ and $850{ }^{\circ} \mathrm{C}$. The reformed gas is cooled down and then undergoes a water-gas shift reaction in a separate shift reactor in order to further increase hydrogen production. The reformed gas goes through a knock-out for water removal and hydrogen is separated in a PSA unit before it is sent to the bio-oil upgrading reactor. The condensed water from the knock-out is mixed with hydrotreater wastewater and used for steam production in a recycle loop. Such reuse of the hydrotreater water as reformer feed needs to be validated. The remaining gas after hydrogen is separated in a pressure-swing adsorption (PSA) process is sent to the reformer furnace for combustion. 


\subsection{Process Mass and Energy Balances}

Using Aspen Plus ${ }^{\circledR}$ models, overall mass and energy balances could be generated for the processes of interest based on versions developed by the participants in earlier research efforts. For each process option a new model was developed for use in the analysis. Each model was based on relevant information including technical information from literature as well as experimental values. In order to develop comparable models for fast pyrolysis with upgrading and hydrothermal liquefaction with hydrotreating, several key challenges were addressed. The initial models had different sets of compounds chosen to represent primary and upgraded products. Furthermore, the ultimate analysis of the forest residue biomass feedstock was not the same in each model. Fast pyrolysis bio-oil, when compared to HTL biocrude, is markedly different in oxygen content as well as water content. Therefore, it was necessary that the model compound sets used to represent the two primary products were somewhat different. In order to facilitate some comparison between the two primary liquid products several key compounds were chosen to appear in the composition of both. Due to these changes new mass balances surrounding the FP and HTL reactors were developed as appropriate inputs based on the mole flow of C, $\mathrm{H}, \mathrm{O}, \mathrm{N}$ and $\mathrm{S}$, specified by the new model compounds in the products.

Similarly in the upgrading section of each model, mass balances were developed to calculate mole flow of $\mathrm{C}, \mathrm{H}, \mathrm{O}, \mathrm{N}$ and $\mathrm{S}$ coming in as primary liquid and leaving as upgraded oil, gas, and solids. Detailed mass balances were calculated in an Excel-based calculator defining the RYield reactor block output. Molecular flow rates for C, H, O, N and S were calculated based on laboratory data and balanced against chosen model compounds, which would represent the finished fuel products. Composition of the final product was nearly the same for both models. Excel Solver (Linear Program Function) was used to determine possible answers for 16 equations with 16 unknowns. ${ }^{25}$ Solver is an Excel based analysis tool used for optimization of data. Solver helps to find an optimal value in one cell (referred to as the target cell) based on restrictions and the desired outcome such as an overall mass balance of reactants and products. The function works by changing a group of cells related to the target cell to find the desired optimal value. In this particular case Solver is used to determine the best mass rate of $10+$ products such that all atoms (C, H, O, N and S) are balanced with respect to the reactants. Specifically in this model this technique was used in developing a balance around the Hydrotreating reactor in the upgrading area of both processes. Because the makeup of both the unprocessed bio-oil or biocrude and the finished product includes many constituents this was an optimal way to develop a mass balance around the reactor which is a necessary output for Aspen Plus.

However before a realistic composition of finished fuel was produced, a first "best-guess" estimate of the flow rates for each constituent had to be made. If the Solver function is used without the initial guess it can come up with unrealistic solutions which can satisfy the constraints of a complete material balance but are not useful for implementation in the model (i.e. negative flow rate). That is why when a plausible solution was found the final fuel product values produced by the Solver method was correlated with known finished fuel simulated distillation (Simdist) information. The constricting data to solve these equations included the elemental mass balance (mass of elements coming in had to equal the mass of elements exiting the reactor), the production of water, which is measured experimentally, as well as

\footnotetext{
${ }^{25}$ The implementation of the Solver analytical method used was developed by Aye Meyer at PNNL
} 
setting the oxygen content of the final product oil to below 1\%. Furthermore, a starting point for the plausible distillation curve of the finished products was developed and compared to Gas Chromatography Simulated Distillation data developed on upgraded products at PNNL. The method used, ASTM D2887, was developed for diesel fuel testing, and, therefore, is still being refined for other products, but was used here as a starting point for addressing the validity of the model product composition. Solver function solutions were achieved and the resulting compound yields were used in the process models.

\subsection{Mass Balance for Fast Pyrolysis and Upgrading}

The mass balance for fast pyrolysis and bio-oil upgrading is depicted in Figure 11.

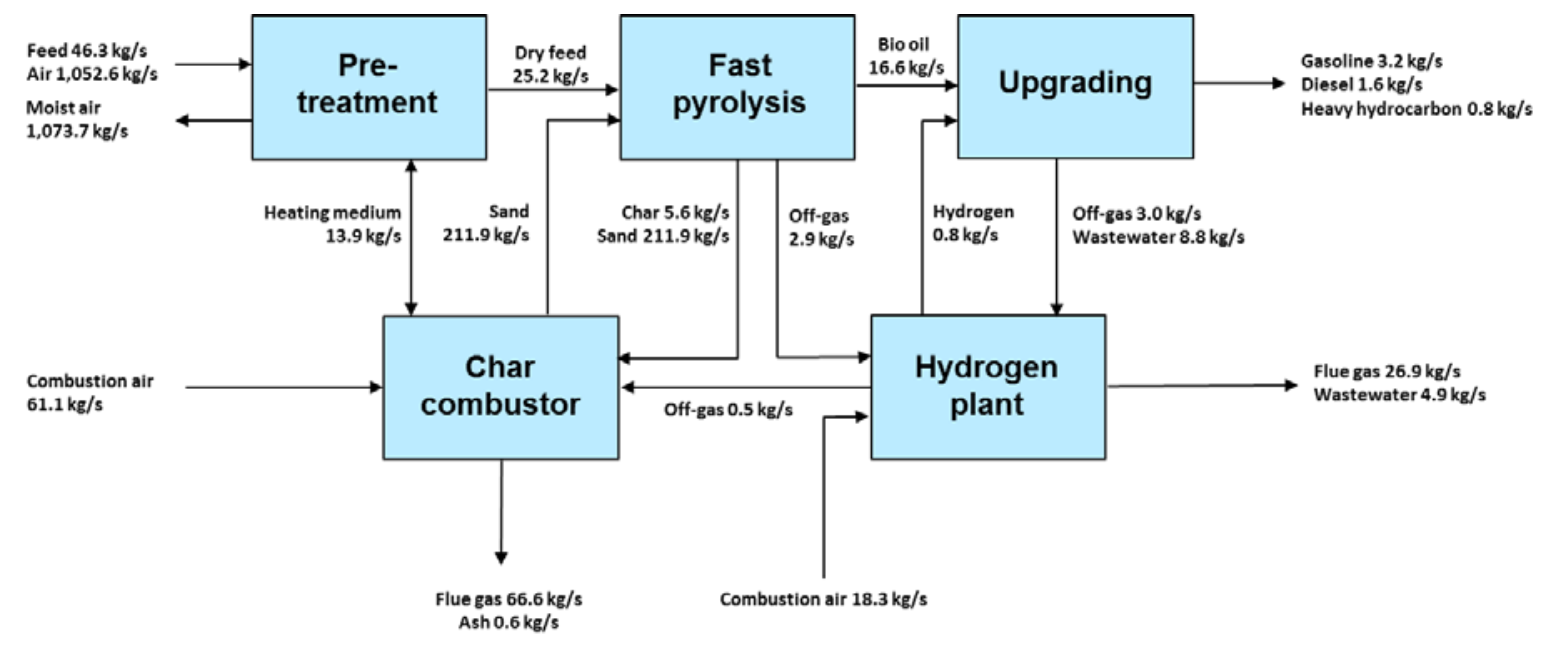

Figure 11. Mass Balance for the Fast Pyrolysis

The tabular form of the mass balance data for fast pyrolysis and bio-oil upgrading is given in Table 11. The overall mass balance for fast pyrolysis and upgrading shows a $24 \%$ yield (5.6/23.15 kg/s) of hydrocarbon liquids on a dry biomass basis.

Table 11. Mass Balance for the Fast Pyrolysis Pathway

\begin{tabular}{llr} 
Mass balance fast pyrolysis, $\mathbf{k g} / \mathbf{s}$ & \multicolumn{1}{c}{ IN } & OUT \\
\hline Wet forest residue & 46.3 & \\
Combustion air & 79.4 & \\
Flue gas & & 93.5 \\
Moisture & & 21.1 \\
Gasoline & 3.2 \\
Diesel & 1.6 \\
Heavy hydrocarbon & & 0.8 \\
Wastewater & & 4.9 \\
Ash & & 0.6 \\
\hline TOTAL & 125.7 & 125.7 \\
\hline
\end{tabular}




\subsection{Energy Balance for Fast Pyrolysis and Upgrading}

The energy balance for fast pyrolysis and bio-oil upgrading is depicted in Figure 12.

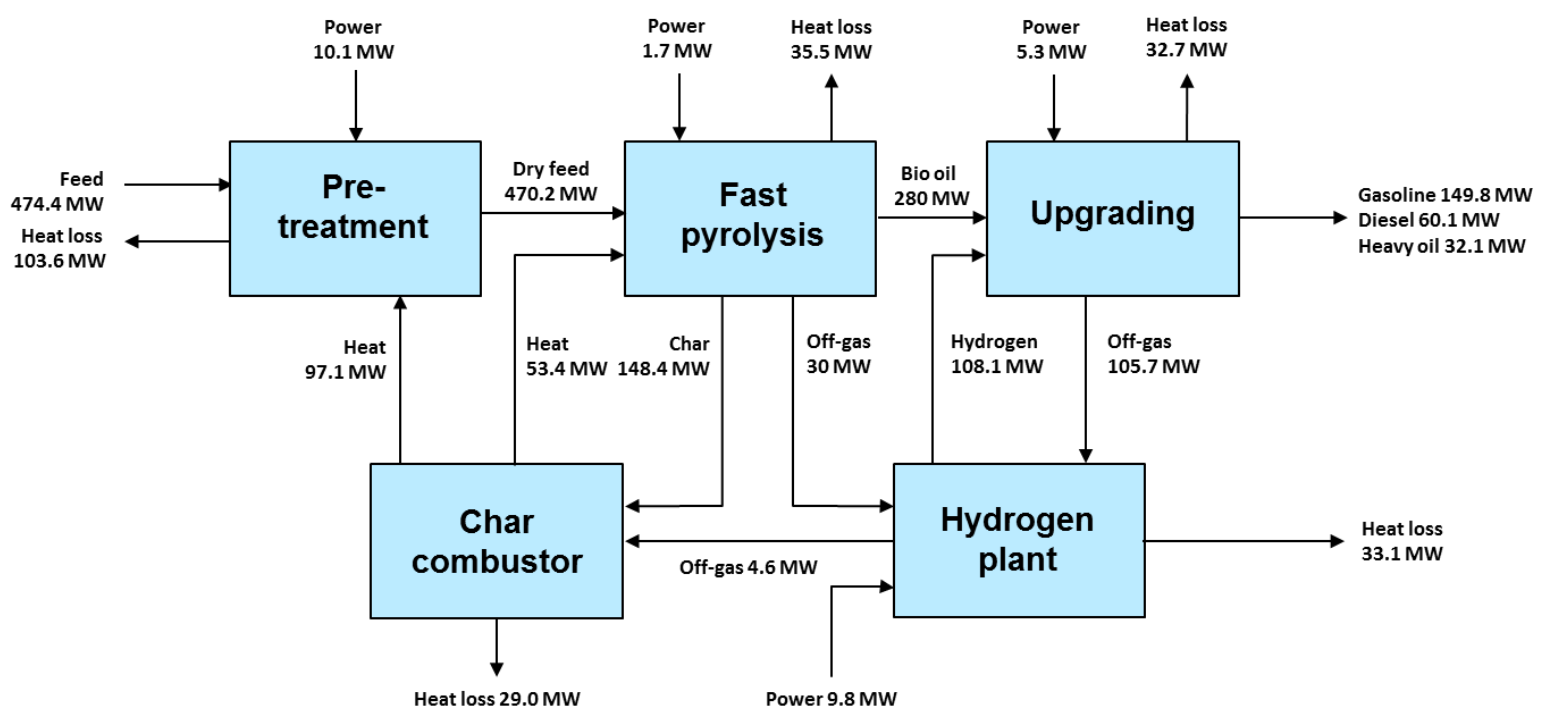

Figure 12. Energy balance (HHV basis) for Fast Pyrolysis

The overall energy balance for the fast pyrolysis process is off by 3.9\%. This is largely related to the hydroprocessing product specification and the choice of model components for this part of the model. The energy balance for other individual blocks range within a window of $0.04-0.5 \%$.

The lower heating values for calculating the overall process efficiency for fast pyrolysis and upgrading are given in Table 12. The overall energy efficiency of fast pyrolysis and upgrading shows a $54.4 \%$ yield of hydrocarbon liquids based on feed and power inputs. The Power inputs are calculated by Aspen-Plus and are reported here without adjustment between electrical and thermal energy.

Table 12. Input and output for Fast Pyrolysis based on LHV

\begin{tabular}{lrr} 
Energy balance fast pyrolysis, LHV, MW & IN & \multicolumn{1}{c}{ OUT } \\
\hline Feedstock & 387.5 & \\
& & \\
Power & 27.0 & \\
Gasoline & & 139.4 \\
Diesel & 55.5 \\
Heavy hydrocarbon & 30.5 \\
Heat loss & \\
\hline TOTAL & & 189.1 \\
\hline & 414.5 & 414.5 \\
\hline
\end{tabular}




\subsection{Mass Balance for Hydrothermal Liquefaction and Hydrotreating}

The mass balance for hydrothermal liquefaction and biocrude hydrotreating is depicted in Figure 13.

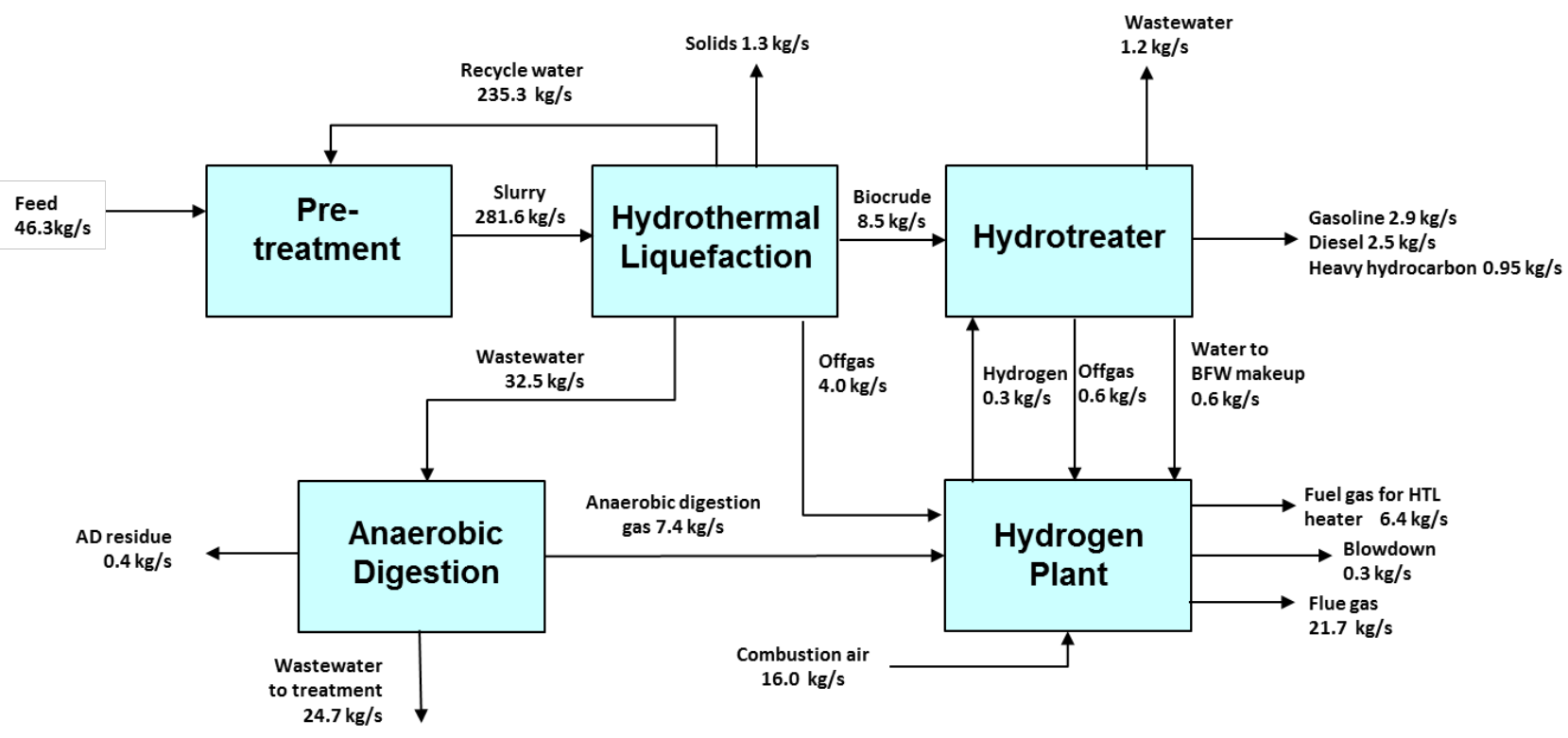

Figure 13. Mass Balance for HTL and Upgrading Process

The tabular form of the mass balance data for hydrothermal liquefaction and hydrotreating is given in Table 13. The overall mass balance of hydrothermal liquefaction and hydrotreating shows a $27 \%$ yield $(6.35 / 23.15 \mathrm{~kg} / \mathrm{s})$ of hydrocarbon liquids on a dry biomass basis.

Table 13. Mass Balance for the Hydrothermal Liquefaction Pathway

\begin{tabular}{lrr}
\hline Mass balance hydrothermal liquefaction, kg/s & IN & OUT \\
\hline Wet Forest residue & 46.3 & \\
Combustion air & 16.0 & \\
Flue gas & 21.7 \\
Fuel gas & 6.4 \\
Gasoline & 2.9 \\
Diesel & 2.5 \\
Heavy oil & 0.95 \\
Wastewater & 25.9 \\
Solids & 1.3 \\
AD Residue & 0.4 \\
Blowdown & \\
\hline TOTAL & 0.3 \\
\hline
\end{tabular}




\subsection{Energy Balance for Hydrothermal Liquefaction and Hydrotreating}

The energy balance for hydrothermal liquefaction and biocrude hydrotreating is depicted in Figure 14.

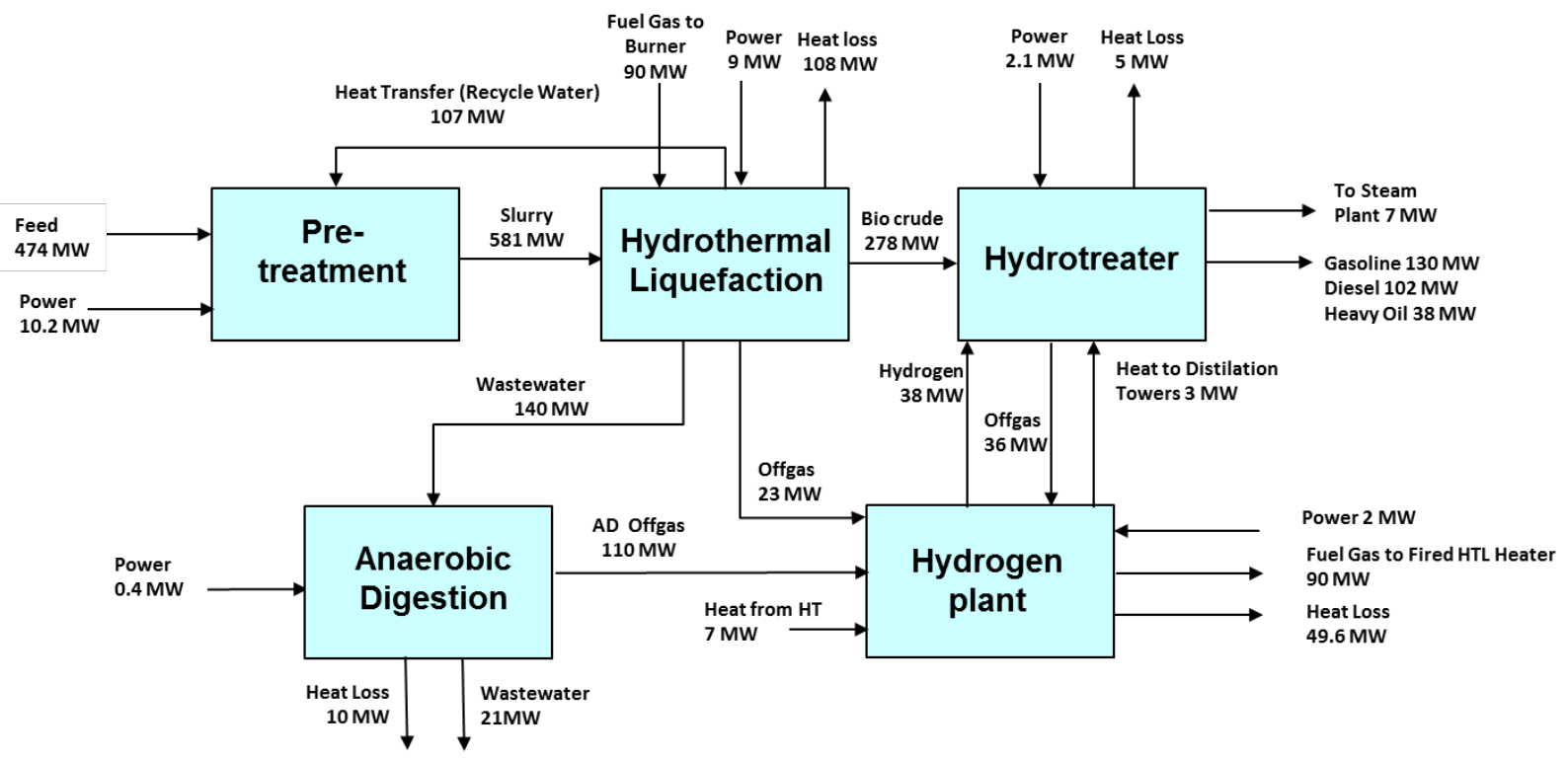

Figure 14. Energy balance (HHV basis) for HTL

The overall energy balance for the HTL process is off by $4.2 \%$. This is largely related to the hydrothermal liquefaction product specification and the choice of model components for this part of the model. The energy balance for other individual blocks range within a window of $0.2-3.5 \%$.

The tabular form of the energy flow data for hydrothermal liquefaction and hydrotreating is given in Table 14. The overall energy efficiency of hydrothermal liquefaction and hydrotreating shows a 62.3\% yield of hydrocarbon liquids based on feed and power inputs. The Power inputs are calculated by AspenPlus and are reported here without adjustment between electrical and thermal energy. There is an excess steam product, which is unlikely to be useful for byproduct power production, and so is relegated to heat loss.

Table 14. Energy balance for Hydrothermal Liquefaction based on LHV

\begin{tabular}{lrr}
\hline HTL Energy Flows, LHV, MW & IN & OUT \\
\hline Feedstock & 387.5 & \\
Power & 23.7 & \\
Gasoline & & 121.7 \\
Diesel & & 97.6 \\
Heavy Oil & & 36.8 \\
Heat Loss & & 155.1 \\
\hline Total & 411.2 & 411.2 \\
\hline
\end{tabular}




\subsection{Comparative Analysis of Life Cycle GHGs}

Life cycle greenhouse gas emissions (GHGs) are estimated for fuels from the fast pyrolysis and upgrading pathway and the HTL and hydrotreating pathway. Shown in Figure 15, the scope of the fuel cycle includes feedstock production through final fuel consumption in an automobile. The functional unit for the analysis is grams of $\mathrm{CO}_{2}$-equivalent per $\mathrm{MJ}$ fuel consumed ( $\mathrm{g} \mathrm{CO}_{2}$-e/MJ).

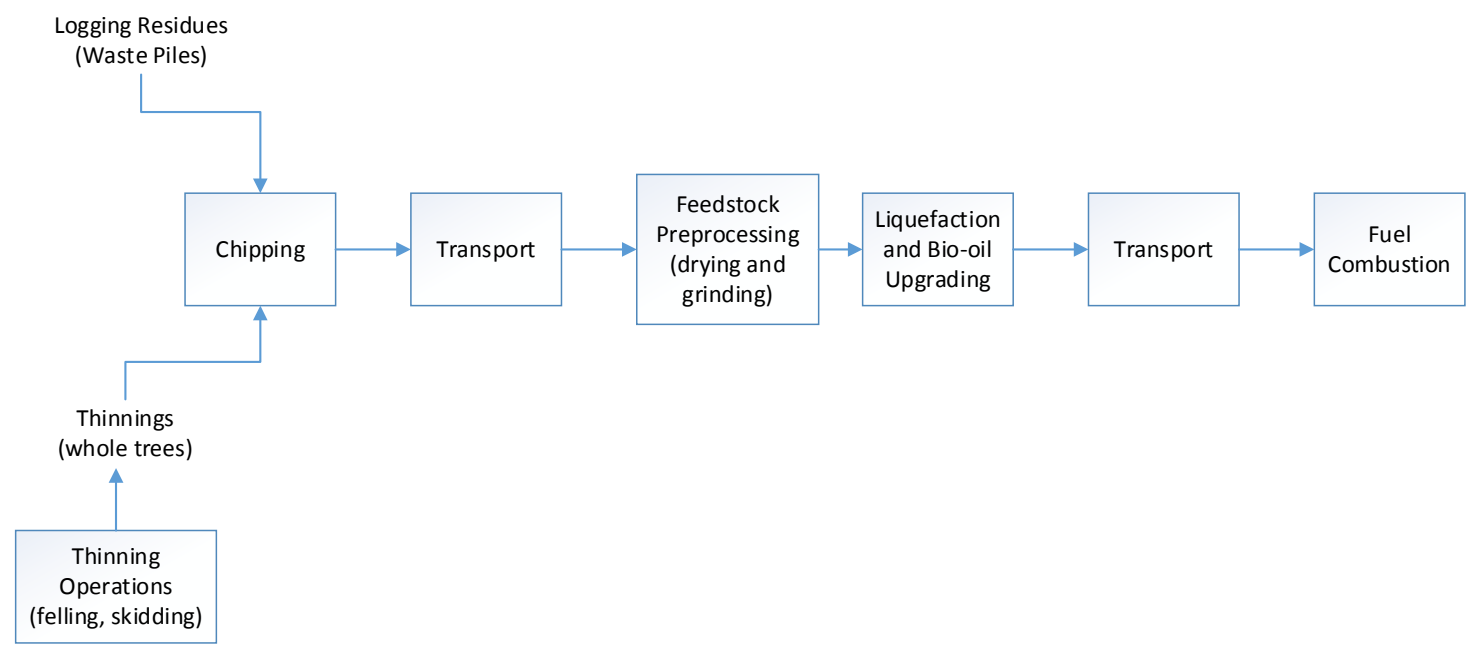

Figure 15. Life cycle of fuels produced from liquefaction of woody feedstocks and bio-oil upgrading.

\subsection{Methods}

The SimaPro software ${ }^{26}$ is used to model and estimate cumulative GHGs and energy use for the fuel cycle. A 50/50 mixture of two woody feedstocks, logging residues and forest thinnings, is analyzed. The nature of these feedstocks and differences between the two are discussed more in the feedstock production section. It is assumed that the carbon released to the atmosphere during the conversion and fuel combustion stages is equal to that taken up from the atmosphere during growth of the trees, and therefore biogenic carbon is not tracked in the analysis (with the exception of any biogenic methane emitted during these stages, which is accounted for in the analysis). This is in agreement with the most recent version of the IPCC GWP 100 impact assessment method included in SimaPro 8. Temporal changes in forest carbon stocks associated with forest residue removal are assumed to be negligible, as discussed in more detail in the feedstock production section.

\subsubsection{Feedstock Production}

As shown in Figure 15, a mixture of logging residues and forest thinnings (50/50) is considered as feedstock for the liquefaction technologies. A variety of approaches have been taken with regard to allocation of burdens and consideration of potential changes in forest carbon stocks associated with removing residues for bioenergy production. Woody residues resulting from forest treatments in the U.S.

${ }^{26}$ SimaPro Life Cycle Assessment Software, v. 8.0. Amersfoort, the Netherlands: Product Ecology Consultants, 2013. 
have historically been burned onsite. ${ }^{27}$ As such, this material is most often treated as a waste product, receiving only the burdens of collection and necessary preprocessing (e.g., chipping) to prepare the feedstock for transport from the landing to the refinery. ${ }^{28}$ Others consider the residue to be a co-product of the forest stand that is purposely grown for both timber and bioenergy, and as such allocate a portion of the burdens of growing and harvesting timber to the residues. ${ }^{29}$ Recent studies on the potential GHG implications of increased residue removal argue that in the short term, GHG emissions are higher with immediate conversion/combustion of forest residues as compared to if the residues were left to decay more slowly over time. ${ }^{30}$ However, others argue there is no significant change in forest carbon stock over the long term with a sustainable level of residue removal. For this analysis, the following assumptions are made for the forest feedstocks:

- Forest residue is a waste product of logging operations and consists of the unmerchantable parts of harvested trees, e.g., tops, small branches, and leaves, that are piled up and either left to decompose or burned on the forest floor as part of forest management. As such, this feedstock does not carry any environmental burdens associated with the harvested timber.

- Forest thinnings consist of whole trees that are removed as part of forest management operations to enhance growth and manage fire risk. As such, this feedstock carries the full burdens of thinning operations.

- Extra fertilizer is not required as a result of residue removal.

- Soil carbon losses due to removal of residue and thinnings are not considered in the analyses.

Both residues and thinnings are assigned the burdens of chipping at the landing prior to transportation. The diesel usage for each stage of feedstock collection comes from Johnson et al..$^{27}$ and is shown in Table 15. The chipper used for logging residues is a horizontal grinder, which requires a hydraulic loader. Forest thinnings are processed with a whole tree chipper, which skids whole trees directly onto the chipper bed and therefore does not require a separate loader. Note that more fuel is consumed for chipping residues with a horizontal grinder than for chipping thinnings with a whole tree

27 Johnson, L, B Lipke, and E Oneil. 2012. "Modeling Biomass Collection and Woods Processing Life-Cycle Analysis,” Forest Prod. J. 62(4): 258-272.

Jones, G., D. Loeffler, D. Calkin, and W. Chung. 2010. "Forest treatment residues for thermal energy compared with disposal by onsite burning: Emissions and energy return,” Biomass and Bioenergy 34: 737-746.

${ }^{28}$ Daystar, J, C Reeb, R Venditti, R Gonzalez, and ME Puettman. 2012. "Life-Cycle Assessment of Bioethanol from Pine Residues via Indirect Biomass Gasification to Mixed Alcohols,” Forest Prod. J. 62(4):314-325. Forest Products Society. Lipke, B, ME Puettman. 2013. "Life-Cycle Carbon from Waste Wood Used in District Heating and Other Alternatives," Forest Prod. J. 63(1/2): 12-23. Forest Products Society. Hsu, D.D. 2012. "Life cycle assessment of gasoline and diesel produced via fast pyrolysis and hydroprocessing," Biomass and Bioenergy 45:4147.

${ }^{29}$ Dias, A.C. 2014. “Life cycle assessment of fuel chip production from eucalypt forest residues,” Int J Life Cycle Assess, 19:705-717. Sorsa, R. and S. Soimakallio. 2012. "Does bio-oil derived from logging residues in Finland meet the European Union greenhouse gas performance criteria?” Energy Policy, http://dx.doi.org/10.1016/j.enpol.2012.10.056.

30 Repo, A, H Böttcher, G Kindermann, and J Liski. 2014. “Sustainability of forest bioenergy in Europe: land-userelated carbon dioxide emissions of forest harvest residues,” GCB Bioenergy, doi: 10.1111/gcbb.12179. John Wiley \& Sons Ltd. Domke, G.M., D.R. Becker, A.W. D’Amato, A.R. Ek, and C.W. Woodall. 2012. “Carbon emissions associated with the procurement and utilization of forest harvest residues for energy, northern Minnesota, USA,” Biomass and Bioenergy 36: 141-150. 
chipper. Emissions associated with equipment production and maintenance aren’t included in the analysis.

Table 15. Feedstock harvesting and collection assumptions.

\begin{tabular}{|l|l|l|}
\hline Feedstock Collection Process & \multicolumn{2}{|c|}{ Diesel Consumption, L/dry tonne } \\
\hline & Logging Residue $^{1}$ & Forest Thinnings $^{1}$ \\
\hline Feller & 0 & 0.81 \\
\hline Skidder & 0 & 2.64 \\
\hline Loader & 0.82 & N/A \\
\hline Chipper & 3.01 & 1.3 \\
\hline Total & 3.83 & 4.75 \\
\hline
\end{tabular}

${ }^{1}$ Johnson et al. 2012. (ref \#27)

\subsubsection{Feedstock Transportation}

After chipping, wood chips are transported from the forest landing 75 miles to the biorefinery. ${ }^{27} \mathrm{~A}$ transport process from the EcoInvent database, ${ }^{31}$ "operation, lorry 16-32t, EURO5”, is used to model the emissions of feedstock transport. The process assumes $0.21 \mathrm{~kg}$ fuel $/ \mathrm{km}$ for the lorry operation. Fuel consumption associated with the return trip back to the forest is not included in the analysis.

\subsubsection{Feedstock Handling and Preprocessing at the Refinery}

At the biorefinery, wood chips are unloaded and then cleaned with an electromagnet. ${ }^{32}$ Equipment is also necessary for control and collection of dust produced during handling and processing. For the pyrolysis pathway, the chips are dried using waste heat from the char combustor and then ground to a powder of $2 \mathrm{~mm}$ or less to meet the reactor feed specification. For the HTL pathway, the chips are not dried, but are instead ground at 50\% moisture content. Grinding energy is taken from Rensfelt et $\mathrm{al}^{33}$ for $8 \%$ moisture content wood flour production. As data on grinding of green wood could not be obtained from the literature, it is assumed that the grinding energy needed for both pathways is equal. HTL does not require as small of particle size as fast pyrolysis, and thus, the increased energy required for moist wood may be somewhat offset by lower energy required for larger particle size. Energy consumption values and associated references for the feedstock grinding and handling steps are given in Table 16.

\subsubsection{Conversion}

Mass and energy balance information from the process models, along with life cycle inventory data from the EcoInvent ${ }^{31}$ and U.S. Life Cycle Inventory ${ }^{34}$ databases is used to populate the model. Key

\footnotetext{
${ }^{31}$ EcoInvent 2011. EcoInvent Database Version 2.2, Hamburg, Germany: Swiss Center for Life Cycle Inventories.

${ }^{32}$ Searcy and Hess. 2010. "Uniform-Format Feedstock Supply System: A Commodity-Scale Design to Produce an Infrastructure-Compatible Biocrude from Lignocellulosic Biomass,” INL/EXT-10-2037 Revision 0.

${ }^{33}$ Rensfelt, Lindman, Bjerle, Kelen: Raport inom NE-området Syntetiska drivmedel, Project PDU. Slutrapport. 8004-15 KTH.

${ }^{34}$ U.S. Life Cycle Inventory Database. 2012. National Renewable Energy Technology Laboratory. https://www.lcacommons.gov/nrel/search.
} 
assumptions are given in Table 17. Catalyst consumption is scaled based on flows from Jones et al. ${ }^{35}$ In the absence of life cycle inventory data for actual hydroprocessing catalysts (for example, specific CoMo

Table 16. Feedstock handling and preprocessing assumptions.

\begin{tabular}{|l|l|l|}
\hline Processing Step & Energy Consumption & Reference \\
\hline Grinding energy & $71.2 \mathrm{kwh} / \mathrm{dm}$ tonne & $\# 33$ \\
\hline Handling, dust collection, chip cleaning & $5 \mathrm{kwh} / \mathrm{dm}$ tonne & $\# 32$ \\
\hline Front-end loader & $0.42 \mathrm{~L}$ diesel/dm tonne & $\# 32$ \\
\hline \multicolumn{2}{|l|}{} \\
\hline Electricity Grid Mix & $50 \%$ & \\
Coal & $20 \%$ & \multirow{2}{*}{$\# 31$} \\
Nuclear & $17 \%$ & \\
NG & $10 \%$ & \\
Renewable & $3 \%$ & \\
Oil/Industrial gas & & \\
\hline
\end{tabular}

Table 17. Conversion stage assumptions for 2000 dry tonne/day biorefinery.

\begin{tabular}{|c|c|c|}
\hline & Fast Pyrolysis and Upgrading & HTL and Hydrotreating \\
\hline Fuel Products LHV, MJ/kg & & \\
\hline Gasoline & 43.6 & 42.1 \\
\hline Diesel & 35.1 & 39.2 \\
\hline Heavy oil & 39.7 & 38.8 \\
\hline Fuel Products Flow, kg/hr & & \\
\hline Gasoline & 11498 & 10408 \\
\hline Diesel & 5697 & 8957 \\
\hline Heavy oil & 2767 & 3414 \\
\hline Allocation to Fuels (by energy content), \% & & \\
\hline Gasoline & 62 & 48 \\
\hline Diesel & 25 & 38 \\
\hline Heavy oil & 14 & 14 \\
\hline $\begin{array}{l}\text { Net electricity for plant, MW } \\
\text { (excluding grinding energy, see Table 16) }\end{array}$ & 21.07 & 17.76 \\
\hline Electricity grid mix, $\%^{31}$ & \multicolumn{2}{|c|}{ (see Table 2) } \\
\hline Catalyst Type & \multirow{2}{*}{\multicolumn{2}{|c|}{ Zeolite (proxy in absence of data for actual catalysts) }} \\
\hline Catalyst Lifetime, years ${ }^{35}$ & & \\
\hline Hydrotreating & \multicolumn{2}{|c|}{1} \\
\hline Hydrocracking & \multicolumn{2}{|c|}{1} \\
\hline Steam Reforming & \multicolumn{2}{|c|}{3.5} \\
\hline $\begin{array}{l}\text { Catalyst sulfiding agent } \\
\text { Dimethyl sulfide use, } \mathrm{kg} / \mathrm{hr}^{35}\end{array}$ & \multicolumn{2}{|c|}{$\begin{array}{l}\text { Dimethyl sulfoxide (proxy for dimethyl sulfide) } \\
23\end{array}$} \\
\hline Wastewater, kg/hr & 17640 & 94320 \\
\hline
\end{tabular}

\footnotetext{
35 Jones, S., P. Meyer, L. Snowden-Swan, A. Padmaperuma, E. Tan, A. Dutta, J. Jacobson, and K. Cafferty. 2013. "Process Design and Economics for the Conversion of Lignocellulosic Biomass to Hydrocarbon Fuels: Fast Pyrolysis and Hydrotreating Bio-oil Pathway,” PNNL-23053NREL/TP-5100-61178.
} 
and Ru based formulations), a zeolite product from the EcoInvent database ("zeolite, powder, at plant/RER with US electricity U”) is used as a proxy. The actual hydrotreating catalysts may have a very different GHG impact than that approximated with zeolite, depending on the specific metals used (e.g., precious metals) and their loadings, as well as the level of regeneration and/or reclamation that occurs as part of spent material management. Sulfiding agent consumption is scaled based on flows from Jones et al. ${ }^{35}$ It is assumed that the sulfiding agent is dimethyl sulfide and in the absence of life cycle inventory for this compound, dimethyl sulfoxide from the EcoInvent database ("dimethyl sulfoxide, at plant/RER with US electricity U”) is used as a proxy. As dimethyl sulfoxide is produced commercially via oxidation of dimethyl sulfide, this is a conservative estimate of life cycle inventory for dimethyl sulfide.

\subsubsection{Fuel Distribution and Consumption}

Emissions associated with fuel distribution to the end user (fuel transportation and operation of storage tanks and fueling stations) are modeled using an EcoInvent database process ("petrol, unleaded, at refinery/kg/RER/U”). Emissions of biogenic methane and $\mathrm{N}_{2} \mathrm{O}$ from combustion of gasoline and diesel fuel in a vehicle are adapted from GREET. ${ }^{36}$

\subsection{Results}

Shown in Figure 16 are the estimated life cycle GHGs for fuels from the fast pyrolysis and HTL conversion pathways. Emissions for HTL are lower than for pyrolysis due to lower electricity consumption, as shown in Figure 17. The difference in plant electricity consumption stems primarily from the fact that HTL oil is less oxygenated than pyrolysis oil, and therefore requires less hydrogen (and

power to compress the hydrogen) for upgrading per unit of fuel energy produced. In addition, fuel yield is about 14\% higher for HTL than for pyrolysis, resulting in lower energy consumption per unit fuel for conversion as well as for feedstock production, transport and preprocessing stages. Emissions reductions for both technology routes are over $60 \%$ relative to the 2005 baseline for petroleum based gasoline and diesel. $^{37}$ The results suggest these fuels meet the Energy Independence and Security Act of 2007 Renewable Fuel Standard (RFS2) ${ }^{38}$ cellulosic biofuel definition, however, final qualification is made by the EPA based on their independent analysis and determination.

\footnotetext{
${ }^{36}$ GREET Model, The Greenhouse Gases, Regulated Emissions, and Energy Use in Transportation Model, 2013. Argonne National Laboratory, Chicago, IL.

${ }^{37}$ U.S. EPA, Docket \# EPA-HQ-OAR-2005-0161-3173. 2010. "Fuel-Specific Lifecycle Greenhouse Gas Emissions Results,” Accessed at http://www.regulations.gov/\#!documentDetail;D=EPA-HQ-OAR-2005-0161-3173.

${ }^{38}$ Code of Federal Regulations, 42 USC 7545. 2007. Energy Independence and Security Act. Public Law 100-140.
} 


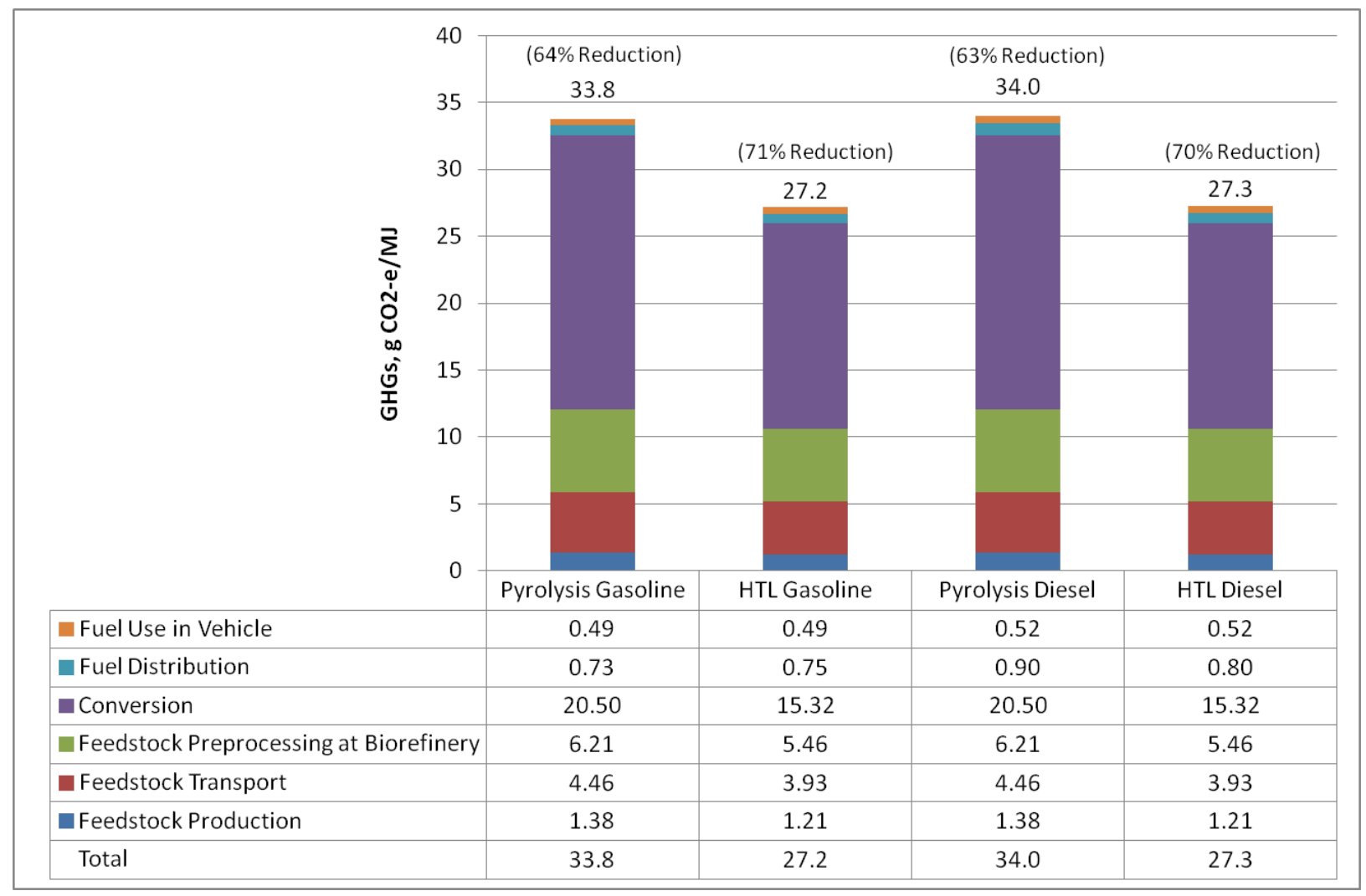

Figure 16. Life cycle GHG emissions for fuels from liquefaction and upgrading for forest residue/forest thinnings mixture (50/50). Percent reduction is relative to the 2005 petroleum baseline GHGs calculated for the RFS2, $93.08 \mathrm{~g} \mathrm{CO}_{2}$-e/MJ and $91.94 \mathrm{~g} \mathrm{CO}_{2}-\mathrm{e} / \mathrm{MJ}$ for gasoline and diesel, respectively ${ }^{37}$

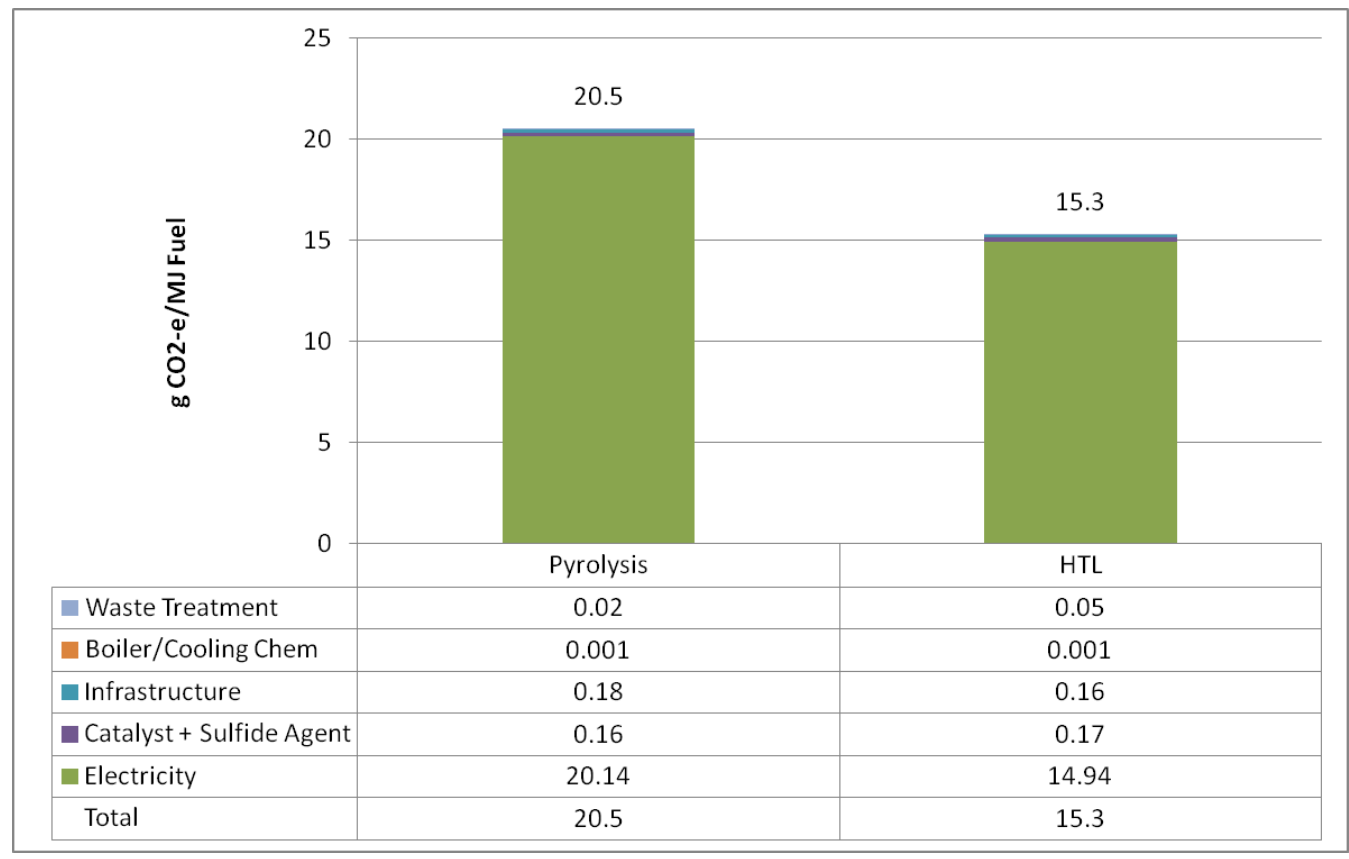

Figure 17. Conversion stage partial life cycle GHG emissions for fuels produced from liquefaction and bio-oil upgrading. 


\subsection{Cost Estimation}

\subsection{Capital Equipment Costs}

The capital cost estimate is determined by aggregating individual equipment costs and applying factors. The equipment costs used in the economic analysis were developed from existing sources by extrapolation to appropriate scale of stream flow. Individual equipment costs were not developed within this study. The equipment cost estimates for fast pyrolysis were derived from Jones et al. ${ }^{23}$, which used a $400 \mathrm{t} / \mathrm{d}$ reactor size, by adjusting the equipment based on the feed rate in this study (4 X $500 \mathrm{t} / \mathrm{d}$ ) using a 0.7 power factor. The uninstalled costs are the summation of equipment estimates. The installed costs (Fixed Capital Investment, FCI) are calculated from the equipment costs with a range of relevant factors applied for the different types of equipment by Jones et al. ${ }^{23}$ Installation factors used in the cost analysis of the equipment were obtained by several methods. Primary sources include Harris Group ${ }^{39}$, SRI PEP 2007 Yearbook $^{40}$ as well as Aspen Capital Cost Estimator. ${ }^{41}$ Values were either obtained directly or calculated based on equipment costs provided by the source.

\subsection{Production Costs}

Annual production cost is evaluated by adding operation and capital costs. Operation cost includes fixed and variable terms. Capital costs are estimated based on annuity.

Capital to be depreciated and used as part of production cost estimate is derived from the above fixed installed capital investment ( FCI) costs by adding estimates for start-up costs (10 \% of FCI), and interest during construction. A two year construction time is assumed.

Fixed operating costs include:

- $\quad$ operating labor (which is a function of plant size, 5 shifts assumed, 6 persons per shift)

- maintenance labor (1\% of FCI assumed)

- $\quad$ overheads (2 \% of FCI assumed)

- maintenance materials (3 \% of FCI assumed)

- $\quad$ taxes, insurance (2\% of FCI assumed)

- $\quad$ other fixed costs ( $1 \%$ of FCI assumed)

Variable operating costs include:

- feedstock cost

- natural gas

- electricity consumption

- catalyst costs

- $\quad$ waste handling

\footnotetext{
${ }^{39}$ Dutta, A., Talmadge, M., Hensley, J., Worley, M., Dudgeon, D., Barton, D., Groenendijk, P., Ferrari, D., Stears, B., Searcy, E., Wright, C., Hess, J.R. 2011. Process design and economics for conversion of lignocellulosic biomass to ethanol: thermochemical pathway by indirect gasification and mixed alcohol synthesis. Golden, CO: National Renewable Energy Laboratory. http://www.nrel.gov/docs/fy11osti/51400.pdf

${ }^{40}$ SRI 2007. "Hydrogen production from natural gas ” PEP Yearbook, Vol 1E, SRI International, Menlo Park, California.

${ }^{41}$ http://www.aspentech.com/products/aspen-icarus-process-evaluator.aspx
} 
Parameters used in the assessment are summarized in Table 18 below.

Table 18. Parameters used in economic assessment

\begin{tabular}{|c|c|c|}
\hline Feedstock forest residue cost & 30 & $\$ / t$ (50\% moisture) \\
\hline & 12.9 & \$/MWh \\
\hline Electricity & 6.9 & \$/kWh \\
\hline Wastewater & 0.73 & $\$ / \mathrm{t}$ \\
\hline Labor rate & 0.05 & $\mathrm{M} \$ / \mathrm{a}$ \\
\hline Interest rate & 10 & $\%$ \\
\hline Service life & 20 & $\mathrm{a}$ \\
\hline Annuity & 0.1175 & \\
\hline Interest during construction & 11 & $\%$ \\
\hline Annual operating time & 7000 & $\mathrm{~h} / \mathrm{a}$ \\
\hline $\mathrm{Ru} / \mathrm{C}$ catalyst & 132 & $\$ / \mathrm{kg}$ \\
\hline NiMo catalyst & 75 & $\$ / \mathrm{kg}$ \\
\hline
\end{tabular}

\subsection{Fast Pyrolysis and Bio-oil Upgrading Process Costs}

The capital costs are grouped into the subsections of the process and presented in Table 19 below.

Table 19. Fast Pyrolysis and Bio-oil Upgrading Capital Costs (millions of \$)

\begin{tabular}{llllc}
\hline Process Section & PID & Installed & Uninstalled & \\
\hline \hline Feedstock Handling and Prep & A100 & $\$ 21.4$ & $\$ 8.7$ & $6 \%$ \\
Fast Pyrolysis & A100 & $\$ 210.0$ & $\$ 61.9$ & $59 \%$ \\
Hydrotreating & A310 & $\$ 76.3$ & $\$ 35.6$ & $21 \%$ \\
Hydrogen Plant & A400 & $\$ 41.1$ & $\$ 21.4$ & $11 \%$ \\
Utilities & A700 & $\mathbf{\$} 9.2$ & $\$ 3.2$ & $3 \%$ \\
\hline Total & & $\mathbf{\$ 3 5 8 . 0}$ & $\mathbf{\$ 1 3 0 . 8}$ & $\mathbf{1 0 0 \%}$ \\
\hline
\end{tabular}

A summary of the production cost estimate for the fast pyrolysis case is shown in Table 20. The costs are given for both the primary fast pyrolysis step only, as well as the additional fixed and variable costs for upgrading the bio-oil to hydrocarbon liquids. Catalyst replacement costs are indicated in the table also. The three catalysts used in the upgrading as well as a cost for the reforming catalyst for hydrogen production are included. The catalyst lifetimes are all assumed at one year. The total costs of the finished product, for both primary bio-oil production, as well as upgraded hydrocarbon liquid production, are calculated in the bottom row. 
Table 20. Fast Pyrolysis production cost estimate

\begin{tabular}{|c|c|c|c|c|c|c|}
\hline & \multicolumn{3}{|c|}{ Fast Pyrolysis } & \multicolumn{3}{|c|}{ Upgrading } \\
\hline & $\mathrm{M} \$ / \mathrm{a}$ & $\$ / \mathrm{t}$ & $\$ / G J$ & $\mathrm{M} \$ / \mathrm{a}$ & $\$ / \mathrm{t}$ & $\$ / G J$ \\
\hline \multicolumn{7}{|l|}{ FIXED OPERATING COST } \\
\hline Operating labor & 1.1 & 3 & 0.2 & 0.3 & 2 & 0.1 \\
\hline Maintenance labor & 2.3 & 6 & 0.4 & 1.3 & 9 & 0.2 \\
\hline Overheads & 4.6 & 11 & 0.8 & 2.5 & 18 & 0.4 \\
\hline Maintenance materials & 6.9 & 17 & 1.1 & 3.8 & 27 & 0.6 \\
\hline Taxes, insurance & 4.6 & 11 & 0.8 & 2.5 & 18 & 0.4 \\
\hline Others & 2.3 & 6 & 0.4 & 1.3 & 9 & 0.2 \\
\hline Total & 21.9 & 52 & 3.6 & 11.7 & 84 & 2.0 \\
\hline \multicolumn{7}{|l|}{ CATALYST COST } \\
\hline Hydrogen plant catalyst & & & & 0.2 & 2 & 0.0 \\
\hline Stabilizer catalyst & & & & 4.6 & 33 & 0.8 \\
\hline $1^{\text {st }}$ HDO catalyst & & & & 10.4 & 75 & 1.8 \\
\hline $2^{\text {nd }}$ HDO catalyst & & & & 4.3 & 31 & 0.7 \\
\hline Total & & & & 19.5 & 138 & 3.3 \\
\hline \multicolumn{7}{|l|}{ VARIABLE OPERATING COST } \\
\hline Feedstock & 35.0 & 84 & 5.8 & 96.7 & 694 & 16.5 \\
\hline Electricity & 5.8 & 14 & 0.9 & 7.3 & 53 & 1.3 \\
\hline Waste water treatment & 0.0 & 0 & 0.0 & 0.1 & 1 & 0.0 \\
\hline Natural gas & 0.0 & 0 & 0.0 & 0 & 0 & 0.0 \\
\hline Total & 40.8 & 98 & 6.7 & 104.2 & 747 & 17.8 \\
\hline CAPITAL CHARGES & 34.0 & 81 & 5.6 & 18.6 & 134 & 3.2 \\
\hline PRODUCTION COST & 96.7 & 231 & 16.0 & 153.9 & 1103 & 26.3 \\
\hline
\end{tabular}

\subsection{Hydrothermal Liquefaction and Biocrude Hydrotreating Costs}

The capital costs for hydrothermal liquefaction are grouped into the subsections of the process and presented in Table 21 below.

Table 21. Hydrothermal Liquefaction and Biocrude Hydrotreating Capital Costs (millions of \$)

\begin{tabular}{llllc}
\hline Process Section & PID & Installed & Uninstalled & \\
\hline \hline Feed Handling and Preparation & A100 & $\$ 22.5$ & $\$ 9.8$ & $9 \%$ \\
HTL Oil Production & A200 & $\$ 150.8$ & $\$ 75.0$ & $62 \%$ \\
Wastewater Treatment & A240 & $\$ 22.0$ & $\$ 8.9$ & $9 \%$ \\
HTL Oil Upgrading & A310 & $\$ 21.6$ & $\$ 20.9$ & $9 \%$ \\
Hydrogen Plant & A400 & $\$ 19.5$ & $\$ 10.1$ & $8 \%$ \\
Utilities & A700 & $\mathbf{\$} 7.9$ & $\$ 1.0$ & $3 \%$ \\
\hline Total & & $\mathbf{\$ 2 4 4 . 3}$ & $\mathbf{\$ 1 2 5 . 7}$ & $\mathbf{1 0 0 \%}$ \\
\hline
\end{tabular}


A summary of the production cost estimate for the hydrothermal liquefaction case is shown in Table 22. The costs are given for both the primary liquefaction step only, as well as the additional fixed and variable costs for hydrotreating the biocrude to hydrocarbon liquids. Catalyst replacement costs are indicated in the table also. The hydrotreating catalyst used in the upgrading as well as a cost for the reforming catalyst for hydrogen production are included. The catalyst lifetimes are both assumed at one year. The total costs of the finished product, for both primary bio-oil production, as well as upgraded hydrocarbon liquid production, are calculated in the bottom row.

Table 22. Hydrothermal Liquefaction production cost estimate

\begin{tabular}{|c|c|c|c|c|c|c|}
\hline & \multicolumn{3}{|c|}{ Hydrothermal Liquefaction } & \multicolumn{3}{|c|}{ Upgrading } \\
\hline & $\mathrm{M} \$ / \mathrm{a}$ & $\$ / \mathrm{t}$ & \$/GJ & M \$/a & $\$ / \mathrm{t}$ & $\$ / G J$ \\
\hline \multicolumn{7}{|l|}{ FIXED OPERATING COST } \\
\hline Operating labor & 1.1 & 5 & 0.2 & 0.3 & 2 & 0.0 \\
\hline Maintenance labor & 2.0 & 9 & 0.3 & 0.5 & 3 & 0.1 \\
\hline Overheads & 3.9 & 18 & 0.6 & 1.0 & 6 & 0.1 \\
\hline Maintenance materials & 5.9 & 27 & 0.9 & 1.5 & 9 & 0.2 \\
\hline HTL catalyst & 3.4 & 16 & 0.5 & & & \\
\hline Taxes, insurance & 3.9 & 18 & 0.6 & 1.0 & 6 & 0.1 \\
\hline Others & 2.0 & 9 & 0.3 & 0.5 & 3 & 0.1 \\
\hline Total & 22.1 & 103 & 3.3 & 4.7 & 30 & 0.7 \\
\hline \multicolumn{7}{|l|}{ CATALYST COST } \\
\hline $\mathrm{H}_{2}$ plant catalyst & & & & 0.1 & 1 & 0.0 \\
\hline HDO catalyst & & & & 3.9 & 24 & 0.6 \\
\hline Total & & & & 4.0 & 25 & 0.6 \\
\hline \multicolumn{7}{|l|}{ VARIABLE OPERATING COST } \\
\hline Feedstock & 35.0 & 163 & 5.3 & 96.1 & 600 & 14.2 \\
\hline Solids Disposal & 0.6 & 3 & 0.1 & & & \\
\hline Electricity & 9.2 & 43 & 1.4 & 1.9 & 12 & 0.3 \\
\hline Waste water treatment & 0.5 & 2 & 0.1 & 0.0 & 0 & 0.0 \\
\hline Total & 45.2 & 211 & 6.8 & 98.0 & 612 & 14.5 \\
\hline CAPITAL CHARGES & 28.7 & 134 & 4.3 & 7.2 & 45 & 1.1 \\
\hline PRODUCTION COST & 96.1 & 449 & 14.5 & 114.0 & 712 & 16.9 \\
\hline
\end{tabular}




\subsection{Discussion and Conclusions}

\subsection{Comparison of FP and HTL Results}

The differences in the processes led to significant differences in the results related to the process yields, efficiencies, and costs as presented in Table 23. The energy efficiency to bio-oil/biocrude intermediate in the primary liquefaction step is essentially the same for both processes even though the FP route gives nearly twice the mass yield. The capital investment for the fast pyrolysis process is only slightly more than the hydrothermal liquefaction process. The much lower energy content of the FP biooil compared to the HTL biocrude causes the FP bio-oil to be more expensive on an energy basis while much cheaper on a mass basis. The HTL pathway delivers higher mass and energy efficiencies compared to FP when considering the total process to hydrocarbon liquid fuels. As a result, the HTL hydrotreated product is cheaper on both a mass basis and an energy basis. The FP upgraded product is a slightly more energy dense product (more completely hydrogenated). The more complex upgrading process, and required higher capital costs, cause it to be more expensive on both a mass and energy basis.

Table 23. Comparison of the Results for Fast Pyrolysis versus Hydrothermal Liquefaction

\begin{tabular}{|l|r|r|r|r|}
\hline & FP & FP + Upgrading & HTL & HTL + HT \\
\hline Energy efficiency to liquid fuel, LHV & 60.2 & 54.4 & 64.5 & 62.3 \\
\hline Fixed Capital Investment, \$M & 231 & 358 & 195 & 244 \\
\hline Liquid fuel mass yield, \% feed, dry basis & 51.1 & 24.2 & 35.1 & 27.4 \\
\hline Liquid fuel product cost, \$/GJ & 16.0 & 26.3 & 14.5 & 16.9 \\
\hline Liquid fuel product cost, \$/metric ton & 231 & 1103 & 449 & 712 \\
\hline Liquid fuel product cost, \$/gallon gasoline equivalent & NA & 3.09 & NA & 2.00 \\
\hline
\end{tabular}

\subsection{Comparison with the IEA DBL Results}

The initial intention of this study was to update the earlier technoeconomic comparative assessment undertaken in the 1980s by the IEA Bioenergy Direct Biomass Liquefaction team ${ }^{4}$ based on the process developments over the past quarter century and in light of the changes in strategy for hydrothermal liquefaction and fast pyrolysis bio-oil upgrading. Since that study, hydrothermal liquefaction has been simplified by the removal of the reducing gas atmosphere and the focus on once through processing of biomass in an aqueous slurry. Similarly, the difficulties in upgrading of fast pyrolysis bio-oil have been further investigated and have led to additional low-temperature catalytic processing to stabilize the bio-oil prior to higher temperature catalytic hydrotreating and hydrocracking.

In Table 24 a comparison is made of the process results from the IEA study ${ }^{1}$ and the current study. For comparison we have used the IEA fast pyrolysis (AFP) potential case, which was based on a case that was only conceptual at that time of a circulating fluid-bed pyrolysis system, and the liquefaction (LIPS) present case, which used the lower concentration slurries more aligned with the water slurry feedstock modeled in the current study. It is clear that the simplification of HTL, by eliminating the reducing gas 
production and processing environment has improved its relative standing compared to fast pyrolysis. While the overall efficiency and yields were lower and the costs were higher for HTL in the earlier study, these new results suggest that the process can be even more efficient and less costly than fast pyrolysis. The comparison of the capital costs has shifted such that those of the high-pressure HTL process are about the same as for FP for the liquefaction step while the hydrotreating capital cost for HTL is less than the upgrading of fast pyrolysis bio-oil. Compared to the earlier study wherein the capital cost for the HTL process was 1.9 times the FP process, in the current study the capital for FP is 1.5 times that for HTL. The overall mass yield of product calculated for HTL is slightly higher than FP, compared to being slightly lower in the earlier study. Although the product costs are higher than in the earlier study, when compared to the current costs of equivalent products, the FP upgraded product has dropped slightly in relative cost, while the relative cost of the HTL hydrotreated product has dropped dramatically from 2.0 to 0.8. Part of this drop in relative cost in both cases can be attributed to the use of lower cost forest residue biomass as a feedstock. The current study is based on $\$ 30$ per wet ton while the earlier work used $\$ 30$ per dry ton (considered high for the U.S. at that time).

Table 24. Comparison of the Results of the IEA DBL Study with the Current Effort

\begin{tabular}{|l|c|c|c|c|}
\hline & \multicolumn{2}{|c|}{ IEA DBL Process Models } & \multicolumn{2}{c|}{ Current Study } \\
\hline & AFP Potential & LIPS Present & FP \& Upgrade & HTL \& HT \\
\hline Total energy efficiency to product, LHV & 52 & 41 & 50 & 57 \\
\hline Fixed Capital Investment, \$M & AFP & AFP x 1.9 & 358 & 244 \\
\hline Product mass yield, \% dry feed & 25 & 23 & 24 & 27 \\
\hline Ratio of Product cost to value & 1.2 & 2.0 & $1.2^{*}$ & $0.8^{*}$ \\
\hline
\end{tabular}

Product in all cases is a mixed gasoline/diesel/heavy hydrocarbon product

Total energy efficiency assuming 40\% conversion efficiency for MWth $\rightarrow$ MWe

* The equivalent values of the upgraded products for the present study were calculated on a weight averaged basis using the following values for products: gasoline $=\$ 986 /$ ton, diesel $=\$ 916 /$ ton, heavy hydrocarbon product $=\$ 698 /$ ton. The weight averaged total product value for upgraded FP is $\$ 925 /$ ton and for hydrotreated HTL the total product value is $\$ 915 /$ ton.

\subsection{Uncertainties Needing Further Research for FP}

The FP model assumes that there is no ash left in the bio-oil and that it is all removed from the system in the char. In fact, the separation is not perfect and there is certainly some mineral content left in the biooil. Mineral deposition in the catalytic hydrotreater could be an issue in long-term operation. The effects of long-term operation could be significant without sufficient flushing of mineral content from the catalyst bed by the water.

The FP model includes a multi-stage hydroprocessing reactor system which has only been developed to laboratory bench-scale. The use of a precious metal catalyst in the first stage of the hydroprocessing is considered problematic. Longer-term operations of up to $1440 \mathrm{~h}$ have demonstrated that the multi-stage concept can be made to work, if proper first stage stabilization is accomplished. 
Use of the aqueous byproducts from hydrotreating and steam reforming for makeup water in the steam generator for hydrogen production needs to be demonstrated. The quality of the aqueous products was assumed to be sufficient and the fouling by the trace hydrocarbon organics was considered unimportant.

Direct steam reforming of the byproduct gases from the pyrolysis unit as well as the hydrotreater systems was also assumed. Although limited studies have confirmed that the pyrolysis gases can be directly reformed, the direct reforming of the hydrocarbon-containing gas product from the bio-oil upgrader has not been tested at any scale.

Further research on the composition of primary bio-oil is needed in order to better represent families of compounds using Aspen Plus ${ }^{\circledR}$ database model compounds. Although a significant effort was made within this study to accurately depict all primary and upgraded products, the largest effort was on identifying appropriately representative upgraded product compounds. However, the use of Aspen-Plus software in the fractionation of the product components was not uniformly representative of the gasoline and diesel product groups as shown by the difference in the model compositions for these product groups, which then reflected on the energy efficiency calculations. Bio-oil compounds are more challenging as analysis of such oxygenated oils is difficult using standard methods such as GCMS. NMR data helped to inform some of the model compound choices, but further investigation would help enhance the accuracy of representing major product groups.

The overall energy balance for the fast pyrolysis process is off by $3.9 \%$. This is largely related to the hydroprocessing product specification and the choice of model components for this part of the model. The energy balance for other individual blocks range within a window of $0.04-0.5 \%$. Further model development may allow these parameters to be tightened up.

\subsection{Uncertainties Needing Further Research for HTL}

The HTL model is based on $8 \%$ solids in the water slurry. This is a conservative assumption which requires larger volume in the high-pressure reactor and drives up water recycle and associated heat losses. Pumping to high-pressure for hydrothermal processing of slurries at $8 \%$ biomass solids in water is relatively straightforward. Laboratory processing of wood in water slurries at up to $13 \mathrm{wt} \%$ have been demonstrated with sufficient wet milling of the biomass. The scale-up and cost of such a pretreatment is an important area of further research.

Further, the Case D from the Harris report was used for the reactor concept and that configuration requires the demonstration of a high-temperature liquid-phase separator, which would allow the recycle of the hot water to the slurry formation and facilitate heat integration.

The HTL model assumes that there is no ash left in the biocrude or the aqueous byproduct and that it is all removed from the system in the solids separator. In fact, the separation is not perfect and there is certainly some mineral content left in both the aqueous and biocrude products. The effects of long-term operation could be significant without sufficient flushing of mineral content from the water via the 
wastewater stream to Anaerobic Digestion. Further, mineral deposition in the catalytic hydrotreater could be an issue in long-term operation.

While in the model the aqueous byproduct is sent to anaerobic digestion for recovery of the dissolved organic as methane gas for hydrogen production, the biological treatment of such water has not been demonstrated. The alternative of catalytic hydrothermal gasification may be a better option, but its higher risk and developmental uncertainty call for more testing.

The use of the aqueous byproducts from hydrotreating and steam reforming for makeup water in the steam generator for hydrogen production needs to be demonstrated also. The quality of the aqueous products was assumed to be sufficient and the potential for fouling by the trace hydrocarbon organics was considered unimportant.

Direct steam reforming of the hydrotreater product gases and the anaerobic digestion gas was assumed. The direct reforming of the hydrocarbon-containing gas product from the biocrude hydrotreater has not been tested at any scale. Reforming of AD gas also needs to be validated and any gas processing requirements determined.

Further research on the composition of primary biocrude is needed in order to better represent families of compounds using Aspen Plus ${ }^{\circledR}$ database model compounds. Although a significant effort was made within this study to accurately depict all primary and upgraded products, the largest effort was on identifying correct upgraded product compounds. However, the use of Aspen-Plus software in the fractionation of the product components was not uniformly representative of the gasoline and diesel product groups as shown by the difference in the model compositions for these product groups, which then reflected on the energy efficiency calculations. Biocrude compounds are more challenging as analysis of such oxygenated oils is difficult using standard methods such as GCMS. NMR data helped to inform some of the model compound choices, but further investigation would help enhance the accuracy of representing major product groups. 


\subsection{Appendix}

The following sections provide the process diagrams and the data tables from the Aspen Plus ${ }^{\circledR}$ modeling of fast pyrolysis and bio-oil upgrading and hydrothermal liquefaction and biocrude hydrotreating. Note: Quantities in stream tables are for one train of $500 \mathrm{tDM} /$ day

\subsection{FP pre-treatment}

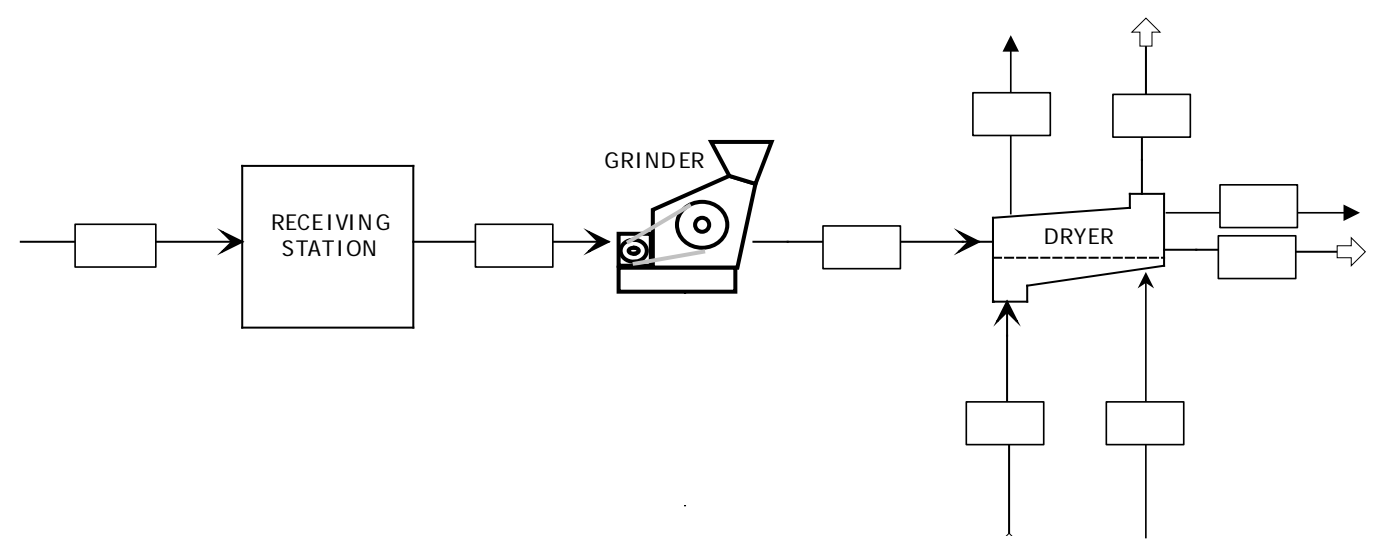

\begin{tabular}{|c|c|c|c|c|c|c|c|c|c|}
\hline Stream no. & 100 & 101 & 102 & 103 & 104 & 105 & 106 & 107 & 108 \\
\hline Temperature C & 25 & 25 & 25 & 25 & 0 & 25 & 25 & 127,4 & 120,3 \\
\hline Pressure bar & 1 & 1 & 1 & 1 & 1,01325 & 1 & 1 & 2 & 2 \\
\hline Vapor Frac & 0 & 0 & 0 & 0 & 1 & 1 & 0 & 1 & 0,8990334 \\
\hline Total Flow cu & $5,82 \mathrm{E}-03$ & $5,82 \mathrm{E}-03$ & $5,82 \mathrm{E}-03$ & $5,06 \mathrm{E}-04$ & 198,6225 & 207,2067 & $5,32 \mathrm{E}-03$ & 12,81183 & 11,31485 \\
\hline Enthalpy $\mathrm{J} / \mathrm{k}$ I & $-2,86 E+08$ & $-2,86 E+08$ & $-2,86 E+08$ & $-2,86 E+08$ & $-3,94 E+05$ & $-3,50 E+04$ & $-2,86 E+08$ & -238350000 & $-2,43 E+08$ \\
\hline Total Flow kg, & 20835 & 20835 & 20835 & 1811,739 & 947326,00 & 947326,00 & 19023,26 & 49900 & 49900 \\
\hline $\mathrm{H} 2 \mathrm{O}$ & 20835 & 20835 & 20835 & 1811,739 & 0 & 0 & 19023,26 & 49900 & 49900 \\
\hline $\mathrm{N} 2$ & 0 & 0 & 0 & 0 & 748387,00 & 748387,00 & 0 & 0 & 0 \\
\hline $\mathrm{O} 2$ & 0 & 0 & 0 & 0 & 198938,00 & 198938,00 & 0 & 0 & 0 \\
\hline Total Flow kg, & 41670 & 41670 & 41670 & 22646,74 & 947326,00 & 947326,00 & 19023,26 & 49900 & 49900 \\
\hline Substream: NC & & & & & & & & & \\
\hline WOOD & 20835 & 20835 & 20835 & 20835 & 0 & 0 & 0 & 0 & 0 \\
\hline
\end{tabular}




\subsection{Fast Pyrolysis}

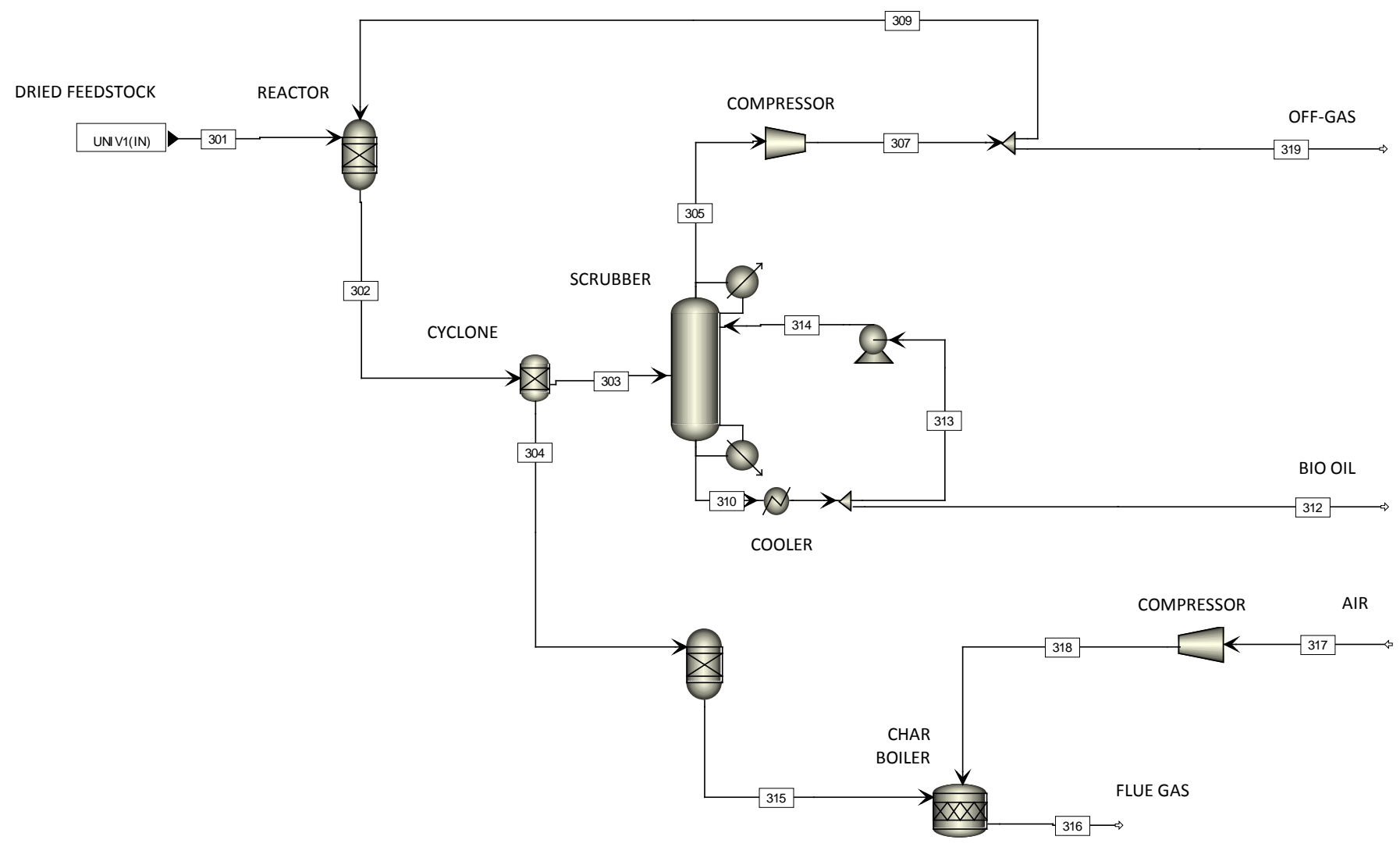




\begin{tabular}{|c|c|c|c|c|c|c|c|c|c|c|c|c|c|c|c|c|}
\hline & 301 & 302 & 303 & 304 & 305 & 307 & 309 & 310 & 312 & 313 & 314 & 315 & 316 & 317 & 318 & 319 \\
\hline Temperature C & 40 & 520 & 520 & & 40 & 65,94556 & 66,5525 & 60,81175 & 35 & 35 & 35,12746 & 480 & 1341,287 & 25 & 37,52781 & 66,5525 \\
\hline Pressure bar & 1,01325 & 1,01325 & 1,01325 & 1,01325 & 1,01325 & 1,2 & 1,2 & 1,01325 & 1,01325 & 1,01325 & 3 & 1,01325 & 1,01325 & 1,01325 & 1,09 & 1,2 \\
\hline Total Flow cum $/ \mathrm{sec}$ & $5,14 \mathrm{E}-04$ & 7,381634 & 7,369977 & 0 & 9,305353 & 8,508202 & 7,968344 & 0,1904098 & $3,32 \mathrm{E}-03$ & 0,1823651 & 0,1823872 & 1,510701 & 72,87562 & 12,99373 & 12,5877 & 0,5415748 \\
\hline Enthalpy $\mathrm{J} / \mathrm{kmol}$ & $-2,85 E+08$ & $-2,50 E+08$ & & & $-1,97 E+08$ & $-1,96 E+08$ & $-1,96 E+08$ & $-3,58 E+08$ & $-3,61 E+08$ & $-3,61 \mathrm{E}+08$ & $-3,61 \mathrm{E}+08$ & $1,37 E+07$ & $-2,63 E+07$ & $-6531,045$ & $3,59 \mathrm{E}+05$ & $-1,96 \mathrm{E}+08$ \\
\hline Total Flow $\mathrm{kg} / \mathrm{hr}$ & 22646,74 & 22646,74 & 17569,7649 & 5076,974 & 40570,77 & 40570,77 & 37988,83 & $8,38 E+05$ & 14988,61 & $8,23 E+05$ & $8,23 E+05$ & 5076,974 & 60494,31 & 55000 & 55000 & 2581,941 \\
\hline $\mathrm{C} 2 \mathrm{H} 4 \mathrm{O}-01$ & 0 & 403,4964 & 403,4964 & 0 & 79,6919 & 79,6919 & 74,62027 & 22287,8 & 398,4162 & 21889,39 & 21889,39 & 0 & 0 & 0 & 0 & 5,071626 \\
\hline $\mathrm{C} 2 \mathrm{H} 6 \mathrm{O}-01$ & 0 & 19,21411 & 19,21411 & 0 & 0,0136091 & 0,0136091 & 0,012743 & 1074,895 & 19,21479 & 1055,68 & 1055,68 & 0 & 0 & 0 & 0 & $8,66 \mathrm{E}-04$ \\
\hline С3H6O-01 & 0 & 432,3176 & 432,3176 & 0 & 14,23302 & 14,23302 & 13,32723 & 24134,57 & 431,429 & 23703,14 & 23703,14 & 0 & 0 & 0 & 0 & 0,9057955 \\
\hline $\mathrm{C} 2 \mathrm{H} 4 \mathrm{O}-02$ & 0 & 1296,953 & 1296,953 & 0 & 18,17706 & 18,17706 & 17,02026 & 72492,53 & 1295,875 & 71196,66 & 71196,66 & 0 & 0 & 0 & 0 & 1,156796 \\
\hline C7H8O-01 & 0 & 1702,37 & 1702,37 & 0 & 1,976963 & 1,976963 & 1,851148 & 95227,71 & 1702,288 & 93525,42 & 93525,42 & 0 & 0 & 0 & 0 & 0,1258148 \\
\hline $\mathrm{C} 5 \mathrm{H} 4 \mathrm{O}-01$ & 0 & 401,575 & 401,575 & 0 & 38,77365 & 38,77365 & 36,30607 & 22327,48 & 399,1256 & 21928,36 & 21928,36 & 0 & 0 & 0 & 0 & 2,467571 \\
\hline LEVOGLUC & 0 & 4114,062 & 4114,062 & 0 & $2,51 \mathrm{E}-07$ & $2,51 \mathrm{E}-07$ & $2,35 \mathrm{E}-07$ & $2,30 E+05$ & 4114,336 & $2,26 \mathrm{E}+05$ & $2,26 \mathrm{E}+05$ & 0 & 0 & 0 & 0 & $1,60 \mathrm{E}-08$ \\
\hline $\mathrm{CO} 2$ & 0 & 1196,893 & 1196,893 & 0 & 18336,39 & 18336,39 & 17169,46 & 1677,977 & 29,99547 & 1647,981 & 1647,981 & 0 & 14456,8 & 0 & 0 & 1166,936 \\
\hline $\mathrm{CH} 4$ & 0 & 162,1525 & 162,1525 & 0 & 2542,921 & 2542,921 & 2381,088 & 17,72398 & 0,3168334 & 17,40714 & 17,40714 & 0 & 0 & 0 & 0 & 161,8325 \\
\hline $\mathrm{H} 2 \mathrm{O}$ & 1811,739 & 4381,867 & 4381,867 & 0 & 1524,35 & 1524,35 & 1427,34 & $2,40 \mathrm{E}+05$ & 4285,122 & $2,35 \mathrm{E}+05$ & $2,35 E+05$ & 0 & 1210,871 & 0 & 0 & 97,01026 \\
\hline N2 & 0 & 0 & 0 & 0 & $1,06 \mathrm{E}-03$ & $1,06 \mathrm{E}-03$ & 9,94E-04 & $1,63 \mathrm{E}-05$ & $2,91 \mathrm{E}-07$ & $1,60 \mathrm{E}-05$ & $1,60 \mathrm{E}-05$ & 12,501 & 43462,5 & 43450 & 43450 & $6,76 \mathrm{E}-05$ \\
\hline $\mathrm{CO}$ & 0 & 1007,404 & 1007,404 & 0 & 15749,84 & 15749,84 & 14747,51 & 283,1287 & 5,061201 & 278,0675 & 278,0675 & 0 & 0 & 0 & 0 & 1002,326 \\
\hline $\mathrm{H} 2$ & 0 & 0 & 0 & 0 & 0 & 0 & 0 & 0 & 0 & 0 & 0 & 123,2526 & 0 & 0 & 0 & 0 \\
\hline 02 & 0 & 0 & 0 & 0 & 0 & 0 & 0 & 0 & 0 & 0 & 0 & 843,1064 & 1049,103 & 11550 & 11550 & 0 \\
\hline NO & 0 & 0 & 0 & 0 & 0 & 0 & 0 & 0 & 0 & 0 & 0 & 0 & $2,50 \mathrm{E}-04$ & 0 & 0 & 0 \\
\hline $\mathrm{s}$ & 0 & 0 & 0 & 0 & 0 & 0 & 0 & 0 & 0 & 0 & 0 & 1,2501 & 0 & 0 & 0 & 0 \\
\hline $\mathrm{C} 2 \mathrm{H} 6-02$ & 0 & 35,3407 & 35,3407 & 0 & 552,2624 & 552,2624 & 517,1162 & 10,8462 & 0,1938864 & 10,65232 & 10,65232 & 0 & 0 & 0 & 0 & 35,14621 \\
\hline $\mathrm{C} 2 \mathrm{H} 4-02$ & 0 & 109,6413 & 109,6413 & 0 & 1711,89 & 1711,89 & 1602,945 & 38,84392 & 0,6943729 & 38,14954 & 38,14954 & 0 & 0 & 0 & 0 & 108,9454 \\
\hline $\mathrm{SO2}$ & 0 & 0 & 0 & 0 & 0 & 0 & 0 & 0 & 0 & 0 & 0 & 0 & 2,504319 & 0 & 0 & 0 \\
\hline С18H3-01 & 0 & 1276,778 & 1276,778 & 0 & 0,0567176 & 0,0567176 & 0,053108 & 71431,17 & 1276,902 & 70154,27 & 70154,27 & 0 & 0 & 0 & 0 & $3,61 \mathrm{E}-03$ \\
\hline $\mathrm{C} 4 \mathrm{H} 10-01$ & 0 & 16,55941 & 16,55941 & 0 & 0,1755143 & 0,1755143 & 0,1643445 & 925,6936 & 16,54768 & 909,1459 & 909,1459 & 0 & 0 & 0 & 0 & 0,0111698 \\
\hline $\mathrm{C} 4 \mathrm{H} 7 \mathrm{~N}-01$ & 0 & 303,8199 & 303,8199 & 0 & 0,0111301 & 0,0111301 & 0,0104218 & 16995,13 & 303,8045 & 16691,32 & 16691,32 & 0 & 0 & 0 & 0 & $7,08 \mathrm{E}-04$ \\
\hline PYROLIGN & 0 & 709,321 & 709,321 & 0 & 6,43E-15 & $6,43 \mathrm{E}-15$ & 6,02E-15 & 39678,21 & 709,2866 & 38968,92 & 38968,92 & 0 & 0 & 0 & 0 & $4,09 \mathrm{E}-16$ \\
\hline Total Flow $\mathrm{kg} / \mathrm{hr}$ & 1811,739 & 17569,76 & 17569,769 & 0 & 40570,77 & 40570,77 & 37988,83 & $8,38 E+05$ & 14988,61 & $8,23 E+05$ & $8,23 E+05$ & 980,1101 & 60181,78 & 55000 & 55000 & 2581,941 \\
\hline Substream: CISOLID & & & & & & & & & & & & & & & & \\
\hline \multicolumn{17}{|l|}{ Mass Flow $\mathrm{kg} / \mathrm{hr}$} \\
\hline C & 0 & 0 & 0 & 0 & 0 & 0 & 0 & 0 & 0 & 0 & 0 & 3784,339 & 0 & 0 & 0 & 0 \\
\hline \multirow{2}{*}{\multicolumn{17}{|c|}{$\begin{array}{l}\text { Substream: } \mathrm{NC} \\
\text { Mass Flow } \mathrm{kg} / \mathrm{hr}\end{array}$}} \\
\hline & & & & & & & & & & & & & & & & \\
\hline CHAR & 0 & 4764,449 & 0 & 4764,449 & 0 & 0 & 0 & 0 & 0 & 0 & 0 & 0 & 0 & 0 & 0 & \\
\hline ASH & 0 & 312,525 & 0 & 312,525 & 0 & 0 & 0 & 0 & 0 & 0 & 0 & 312,525 & 312,525 & 0 & 0 & \\
\hline
\end{tabular}

Note: Stream tables are for one train (out of four) of 500 tDM/day 


\subsection{Fast pyrolysis bio-oil upgrading}

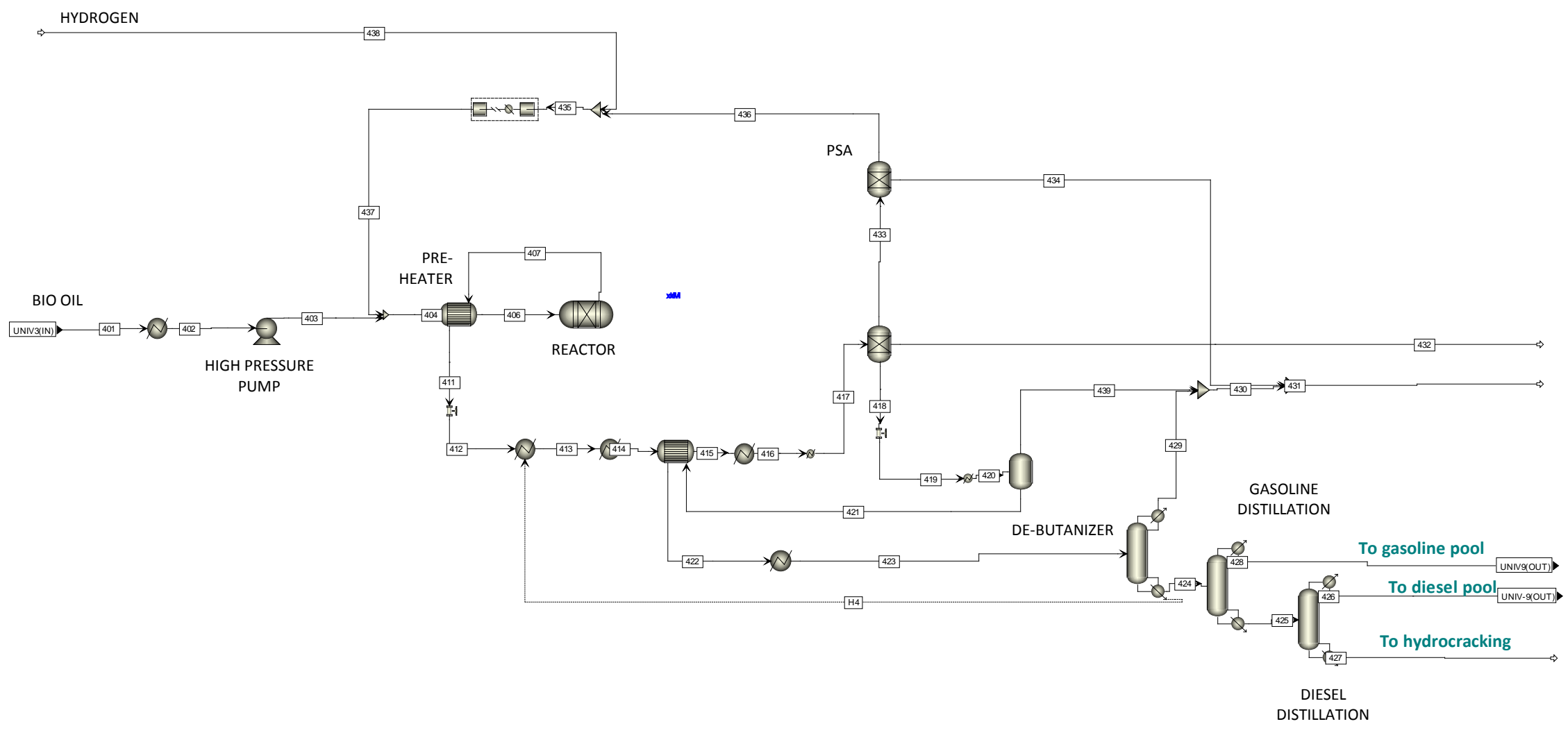




\begin{tabular}{|c|c|c|c|c|c|c|c|c|c|c|c|c|c|c|c|c|c|c|}
\hline & 401 & 402 & 403 & 404 & 406 & 407 & 411 & 412 & 413 & 414 & 415 & 416 & 417 & 418 & 419 & 420 & 421 & 422 \\
\hline Temperature C & 35,00 & 35,00 & 42,83 & 81,39 & 165,56 & 433,36 & 301,10 & 263,83 & 250,07 & 132,22 & 127,12 & 60,00 & 43,33 & 43,33 & 46,03 & 46,03 & 46,03 & 93,33 \\
\hline Pressure bar & 1,01 & 1,01 & 137,41 & 137,27 & 136,93 & 136,24 & 136,21 & 49,99 & 49,92 & 49,88 & 49,88 & 49,74 & 49,39 & 49,39 & 3,79 & 3,79 & 3,79 & 3,72 \\
\hline Vapor Frac & 0,00 & 0,00 & 0,00 & 0,64 & 0,68 & 1,00 & 1,00 & 0,98 & 1,00 & 0,51 & 0,51 & 0,48 & 0,48 & 0,00 & 0,00 & 0,00 & 0,00 & 0,00 \\
\hline Total Flow cum $/ \mathrm{sec}$ & 0,00 & 0,00 & 0,00 & 0,04 & 0,05 & 0,10 & 0,07 & 0,21 & 0,19 & 0,08 & 0,08 & 0.06 & 0.06 & 0,00 & 0,00 & 0.00 & 0,00 & 000 \\
\hline Enthalpy $\mathrm{J} / \mathrm{kmol}$ & -360810000 & -359140000 & -358430000 & -1309900000 & -123580000 & -130100000 & -137900000 & -137900000 & -139100000 & -163530000 & -164110000 & -170060000 & -171280000 & -145980000 & -145980000 & -145980000 & -145980000 & -134110000 \\
\hline Mass Flow $\mathrm{kg} / \mathrm{hr}$ & 14952,35 & 14952,35 & 14952,35 & 16083,07 & 16083,07 & 16083,07 & 16083,07 & 16083,07 & 16083,07 & 16083,07 & 16083,07 & 16083,07 & 16083,07 & 5152,05 & 5152,05 & 5152,05 & 5152,05 & 5152,05 \\
\hline $\mathrm{C} 2 \mathrm{H} 4 \mathrm{O}-01$ & 398,42 & 398,42 & 398,42 & 398,42 & 398,42 & & 0,00 & 0,00 & 0,00 & 0,00 & 0,00 & 0,00 & 0,00 & 0,00 & 0,00 & 0,00 & 0,00 & 0,00 \\
\hline $\mathrm{C} 2 \mathrm{H} 6 \mathrm{O}-01$ & 19,21 & 19,21 & 19,21 & 19,21 & 19,21 & 0,00 & 0,00 & 0,00 & 0,00 & 0,00 & 0,00 & 0,00 & 0,00 & 0,00 & 0,00 & 0,00 & 0,00 & 0,00 \\
\hline $\mathrm{C} 3 \mathrm{H} 6 \mathrm{O}-01$ & 431,43 & 431,43 & 431,43 & 431,43 & 431,43 & 0,00 & 0,00 & 0,00 & 0,00 & 0,00 & 0,00 & 0,00 & 0,00 & 0,00 & 0,00 & 0,00 & 0,00 & 0,00 \\
\hline $\mathrm{C} 2 \mathrm{H} 4 \mathrm{O}-02$ & 1295,88 & 1295,88 & 1295,88 & 1295,88 & 1295,88 & 0,00 & 0,00 & 0,00 & 0,00 & 0,00 & 0,00 & 0,00 & 0,00 & 0,00 & 0,00 & 0,00 & 0,00 & 0,00 \\
\hline C7H $8 \mathrm{O}-01$ & 1702,29 & 1702,29 & 1702,29 & 1702,29 & 1702,29 & 0,00 & 0,00 & 0,00 & 0,00 & 0,00 & 0,00 & 0,00 & 0,00 & 0,00 & 0,00 & 0,00 & 0,00 & 0,00 \\
\hline $\mathrm{C} 5 \mathrm{H} 4 \mathrm{O}-01$ & 399,13 & 399,13 & 399,13 & 399,13 & 399,13 & 0,00 & 0,00 & 0,00 & 0,00 & 0,00 & 0,00 & 0,00 & 0,00 & 0,00 & 0,00 & 0,00 & 0,00 & 0,00 \\
\hline LEVOGLUC & 4114,34 & 4114,34 & 4114,34 & 4114,34 & 4114,34 & 0,00 & 0,00 & 0,00 & 0,00 & 0,00 & 0,00 & 0,00 & 0,00 & 0,00 & 0,00 & 0,00 & 0,00 & 0,00 \\
\hline $\mathrm{CO} 2$ & 0,00 & 0,00 & 0,00 & 0,00 & 0,00 & 1007,65 & 1007,65 & 1007,65 & $\begin{array}{l}1007,65 \\
100\end{array}$ & $\begin{array}{l}1007,65 \\
100\end{array}$ & 1007,65 & $\begin{array}{l}1007,65 \\
100\end{array}$ & 1007,65 & 0,00 & 0,00 & 0,00 & 0,00 & 0,00 \\
\hline $\mathrm{CH} 4$ & 0,00 & 0,00 & $\begin{array}{l}0,00 \\
0,00\end{array}$ & $\begin{array}{l}0,00 \\
0,00\end{array}$ & 0,00 & 480,44 & 480,44 & 480,44 & 480,44 & 480,44 & 480,44 & $\begin{array}{r}00,005 \\
480,44\end{array}$ & 480,44 & 0,00 & 0,00 & 0,00 & 0,00 & 0,00 \\
\hline $\mathrm{H} 2 \mathrm{O}$ & $\begin{array}{r}4285,12 \\
4285\end{array}$ & $\begin{array}{r}4,00 \\
4285,12\end{array}$ & $\begin{array}{r}4285,12 \\
4285\end{array}$ & $\begin{array}{r}4285,12 \\
4285\end{array}$ & $\begin{array}{r}0,000 \\
4285,12\end{array}$ & $\begin{array}{r}480,44 \\
7933,24\end{array}$ & $\begin{array}{r}480,44 \\
7933,24\end{array}$ & $\begin{array}{r}480,44 \\
7933,24\end{array}$ & $\begin{array}{r}488,44 \\
7933,24\end{array}$ & $\begin{array}{r}480,44 \\
7933,24\end{array}$ & $\begin{array}{r}480,44 \\
7933,24\end{array}$ & $\begin{array}{r}488,444 \\
7933,24\end{array}$ & $\begin{array}{r}480,44 \\
7933,24\end{array}$ & 0,00 & 0,000 & 0,000 & 0,000 & 0,00 \\
\hline co & 0,00 & 0,00 & 0,00 & 0,00 & 0,00 & 51,04 & 51,04 & 51,04 & 51,04 & 51,04 & 51,04 & 51,04 & 51,04 & 0,00 & 0,00 & 0,00 & 0,00 & 0,00 \\
\hline $\mathrm{H} 2$ & 0,00 & 0,00 & 0,00 & 1130,73 & 1130,73 & 565,37 & 565,37 & 565,37 & 565,37 & 565,37 & 565,37 & 565,37 & 565,37 & 0,00 & 0,00 & 0,00 & 0,00 & 0,00 \\
\hline NH3 & 0,00 & 0,00 & 0,00 & 0,00 & 0,00 & 60,80 & 60,80 & 60,80 & $\begin{array}{r}60,80 \\
60,8\end{array}$ & 60,80 & 60,80 & 60,80 & $\begin{array}{r}56,5,31 \\
60,80\end{array}$ & 0,000 & 0,000 & 0,000 & 0,000 & 0,00 \\
\hline $\mathrm{C} 2 \mathrm{H} 6-02$ & 0,00 & 0,00 & 0,00 & 0,00 & 0,00 & 402,61 & 402,61 & 402,61 & 402,61 & 402,61 & 402,61 & 402,61 & 402,61 & 0,00 & 0,00 & 0,00 & 0,00 & 0,00 \\
\hline C18H3-01 & 1276,90 & 1276,90 & 1276,90 & 1276,90 & 1276,90 & 0,00 & 0,00 & 0,00 & 0,00 & 0,00 & 0,00 & 0,00 & 0,00 & 0,00 & 0,00 & 0,00 & 0,00 & 0,00 \\
\hline $\mathrm{C} 4 \mathrm{H} 10-01$ & 16,55 & 16,55 & 16,55 & 16,55 & 16,55 & 0,00 & 0,00 & 0,00 & 0,00 & 0,00 & 0,00 & 0,00 & 0,00 & 0,00 & 0,00 & 0,00 & 0,00 & 0,00 \\
\hline $\mathrm{C} 4 \mathrm{H} 7 \mathrm{~N}-01$ & 303,80 & 303,80 & 303,80 & 303,80 & 303,80 & 0,00 & 0,00 & 0,00 & 0,00 & 0,00 & 0,00 & 0,00 & 0,00 & 0,00 & 0,00 & 0,00 & 0,00 & 0,00 \\
\hline PYROLIGN & 709,29 & 709,29 & 709,29 & 709,29 & 709,29 & 0,00 & 0,00 & 0,00 & 0,00 & 0,00 & 0,00 & 0,00 & 0,00 & 0,00 & 0,00 & 0,00 & 0,00 & 0,00 \\
\hline N-HEX-01 & 0,00 & 0,00 & 0,00 & 0,00 & 0,00 & 505,41 & 505,41 & 505,41 & 505,41 & 505,41 & 505,41 & $\begin{array}{l}0,05,41 \\
\end{array}$ & 505,41 & $\begin{array}{r}0,00,41 \\
\end{array}$ & 505,41 & 505,41 & 505,41 & 505,41 \\
\hline N-DOD-01 & 0,00 & 0,00 & 0,00 & 0,00 & 0,00 & 538,89 & 538,89 & 538,89 & 538,89 & 538,89 & 538,89 & 538,89 & 538,89 & 538,89 & 538,89 & 538,89 & 538,89 & 538,89 \\
\hline 4-MET-01 & 0,00 & 0,00 & 0,00 & 0,00 & 0,00 & 546,37 & $\begin{array}{l}546,30,37 \\
\end{array}$ & $\begin{array}{l}546,303 \\
546\end{array}$ & $\begin{array}{l}546,30,37 \\
\end{array}$ & $\begin{array}{l}540,303 \\
546\end{array}$ & 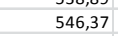 & $\begin{array}{l}540,3037 \\
\end{array}$ & $\begin{array}{l}546,303 \\
546\end{array}$ & $\begin{array}{l}540,3037 \\
46,37\end{array}$ & 546,37 & $\begin{array}{l}546,370 \\
546\end{array}$ & $\begin{array}{l}546,30,37 \\
\end{array}$ & 546,37 \\
\hline ETHYL-01 & 0,00 & 0,00 & 0,00 & 0,00 & 0,00 & 523,29 & 523,29 & 523,29 & 523,29 & 523,29 & 523,29 & 523,29 & 523,29 & 523,29 & 523,29 & 523,29 & 523,29 & 523,29 \\
\hline 1-MET-01 & 0,00 & 0,00 & 0,00 & 0,00 & 0,00 & 4,58 & 314,58 & 314,58 & 314,58 & 314,58 & 314,58 & 314,58 & 314,58 & 314,58 & 314,58 & 314,58 & 314,58 & 314,58 \\
\hline CYCLO-01 & 0,00 & 0,00 & 0,00 & 0,0 & 0,00 & & & & 313,67 & & 313,67 & 313,67 & 313,67 & & 313,67 & 313,67 & 313,67 & 313,67 \\
\hline N-PRO-01 & & & 0, & & & & & & & & & & 33 & & & & & 173,33 \\
\hline 1:3-D-01 & 0,00 & 0,0 & 0,0 & 0,0 & 0,00 & 155, & 155 & 155,41 & 1 & 155 & 155,4 & 155 & 155 & 155 & 155,41 & 41 & 41 & 155,41 \\
\hline 4-МЕT-02 & 0,00 & 0, & 0,00 & 0,0 & 0,00 & 209,44 & $\begin{array}{l}209,44 \\
\end{array}$ & $\begin{array}{l}209,44 \\
\end{array}$ & 209,44 & 209 & 209,44 & 209 & 209 & 209 & 209,44 & 209 & 209 & 209,44 \\
\hline INDAN-01 & 0,0 & & $0, \mathrm{c}$ & 0,00 & 0,00 & & & 175 & 175,58 & 179 & 175,58 & 175 & 175,58 & 175,58 & 175,58 & 175,58 & 175,58 & 175,58 \\
\hline $1-\mathrm{N}-\mathrm{H}-01$ & 0,0 & & 0, & 0, & 0, & & & 285 & 285,92 & 285,92 & 285,92 & 285 & 285,92 & 285,92 & 285,92 & 285,92 & 285,92 & 285,92 \\
\hline PROPA-01 & 0,00 & 0 & 0,00 & 0,00 & 0,00 & & & 248,05 & 248,05 & 248,05 & 248,05 & 248,05 & 248,05 & 0,00 & 0,00 & 0,00 & 0,00 & 0,00 \\
\hline N-BUT-01 & 0,00 & 0,00 & 0,00 & 0,00 & 0,00 & 248,66 & 248,66 & 248,66 & 248,66 & 248,66 & 248,66 & 248,66 & 248,66 & 163,61 & 163,61 & 163,61 & 163,61 & 163,61 \\
\hline N-PEN-01 & 0,00 & 0,00 & 0,00 & 0,00 & 0,00 & 91,46 & 91,46 & 91,46 & 91,46 & 91,46 & 91,46 & 91,46 & 91,46 & 0,00 & 0,00 & 0,00 & 0,00 & 0,00 \\
\hline HYDRO-03 & 0,00 & 0,00 & 0,00 & 0,00 & 0,00 & 5,31 & 5,31 & 5,31 & 5,31 & 5,31 & 5,31 & 5,31 & 5,31 & 0,00 & 0,00 & 0,00 & 0,00 & 0,00 \\
\hline THYMO-01 & 0,00 & 0,00 & 0,00 & 0,00 & 0,00 & 200,00 & 200,00 & 200,00 & 200,00 & 200,00 & 200,00 & 200,00 & 200,00 & 200,00 & 200,00 & 200,00 & 200,00 & 200,00 \\
\hline P-ETH-01 & 0,00 & 0,00 & 0,00 & 0,00 & 0,00 & 354,48 & 354,48 & 354,48 & 354,48 & 354,48 & 354,48 & 354,48 & 354,48 & 354,48 & 354,48 & 354,48 & 354,48 & 354,48 \\
\hline $1: 2-\mathrm{D}-01$ & 0,00 & 0,00 & 0,00 & 0,00 & 0,00 & 367,17 & 367,17 & 367,17 & 367,17 & 367,17 & 367,17 & 367,17 & 367,17 & 367,17 & 367,17 & 367,17 & 367,17 & 367,17 \\
\hline & 0,00 & 0,00 & 0,00 & 0,00 & 0,00 & 87,10 & & & 87,10 & & & & & & & 87,10 & 87,10 & 87,10 \\
\hline O-PHE-UI & 0,00 & 0,00 & 0,00 & 0,00 & 0,00 & 237,80 & 237 & & 237,80 & & 237,80 & & & 237 & 237,80 &, 80 & & 237,80 \\
\hline Total Flow kg & 14952,35 & 9052,35 & 952,35 & 083,07 & 083,07 & 16083,07 & 16083,07 & 16083,07 & 16083,07 & 16083,07 & 16083,07 & 16083,07 & 16083,07 & 5152,05 & 5152,05 & 5152,05 & 5152,05 & 5152,05 \\
\hline
\end{tabular}




\begin{tabular}{|c|c|c|c|c|c|c|c|c|c|c|c|c|c|c|c|c|c|}
\hline & 423 & 424 & 425 & 426 & 427 & 428 & 429 & 430 & 431 & 432 & 433 & 434 & 435 & 436 & 437 & 438 & 439 \\
\hline Temperature $\mathrm{C}$ & 93,33 & 16607 & 24998 & 22633 & 320.04 & 10574 & 48.97 & 48.97 & 2906 & 43.33 & 43.33 & 43.33 & 4162 & 43.33 & 60 & 40 & \\
\hline Pressure bar & 3,72 & 3,45 & 1,36 & 1,08 & 1,08 & 1,36 & 3,31 & 3,31 & 3,31 & 49,39 & 49,39 & 49,39 & 20,00 & 21,70 & 137,27 & 20 & 3,79 \\
\hline Vapor Frac & 0,00 & 0,00 & 0,00 & 0,00 & 0,00 & 0,00 & 1,00 & 1,00 & 1,00 & 0,00 & 1,00 & 1,00 & 1,00 & 1,00 & 1 & 1 & \\
\hline Total Flow cum $/ \mathrm{sec}$ & 0,00 & 0,00 & 0,00 & 0,00 & 0,00 & 0,00 & 0,01 & 0,01 & 0,29 & 0,00 & 0,05 & 0,02 & 0,20 & 0,08 & 0,03 & 0,12 & \\
\hline Enthalpy $\mathrm{J} / \mathrm{kmol}$ & -134110000 & -112260000 & -16803000 & -100800000 & 202913000 & -153340000 & -126260000 & -126260000 & -100930000 & -286700000 & -37454000 & -100430000 & 479119 & 549307 & 1010750 & 432327 & \\
\hline Mass Flow $\mathrm{kg} / \mathrm{hr}$ & 5152,05 & 4990,40 & 2116,02 & 1424,27 & 691,75 & 2874,38 & 161,65 & 161,65 & 2707,14 & 7933,24 & 2997,78 & 2545,49 & 1130,73 & 452,29 & 1130,73 & 678,43 & \\
\hline $\mathrm{C} 2 \mathrm{H} 4 \mathrm{O}-01$ & 0,00 & 0,00 & 0,00 & 0,00 & 0,00 & 0,00 & 0,00 & 0,00 & 0,00 & 0,00 & 0,00 & 0,00 & 0,00 & 0,00 & 0 & 0 & 0 \\
\hline $\mathrm{C} 2 \mathrm{H} 6 \mathrm{O}-01$ & 0,00 & 0,00 & 0,00 & 0,00 & 0,00 & 0,00 & 0,00 & 0,00 & 0,00 & 0,00 & 0,00 & 0,00 & 0,00 & 0,00 & 0 & 0 & 0 \\
\hline С $3 \mathrm{H} 6 \mathrm{O}-01$ & 0,00 & 0,00 & 0,00 & 0,00 & 0,00 & 0,00 & 0,00 & 0,00 & 0,00 & 0,00 & 0,00 & 0,00 & 0,00 & 0,00 & 0 & 0 & 0 \\
\hline $\mathrm{C} 2 \mathrm{H} 4 \mathrm{O}-02$ & 0,00 & 0,00 & 0,00 & 0,00 & 0,00 & 0,00 & 0,00 & 0,00 & 0,00 & 0,00 & 0,00 & 0,00 & 0,00 & 0,00 & 0 & 0 & 0 \\
\hline C7H8O-01 & 0,00 & 0,00 & 0,00 & 0,00 & 0,00 & 0,00 & 0,00 & 0,00 & 0,00 & 0,00 & 0,00 & 0,00 & 0,00 & 0,00 & 0 & 0 & 0 \\
\hline $\mathrm{C} 5 \mathrm{H} 4 \mathrm{O}-01$ & 0,00 & 0,00 & 0,00 & 0,00 & 0,00 & 0,00 & 0,00 & 0,00 & 0,00 & 0,00 & 0,00 & 0,00 & 0,00 & 0,00 & 0 & 0 & 0 \\
\hline LEVOGLUC & 0,00 & 0,00 & 0,00 & 0,00 & 0,00 & 0,00 & 0,00 & 0,00 & 0,00 & 0,00 & 0,00 & 0,00 & 0,00 & 0,00 & 0 & 0 & 0 \\
\hline $\mathrm{CO} 2$ & 0,00 & 0,00 & 0,00 & 0,00 & 0,00 & 0,00 & 0,00 & 0,00 & 1007,65 & 0,00 & 1007,65 & 1007,65 & 0,00 & 0,00 & 0 & 0 & 0 \\
\hline $\mathrm{CH} 4$ & 0,00 & 0,00 & 0,00 & 0,00 & 0,00 & 0,00 & 0,00 & 0,00 & 480,44 & 0,00 & 480,44 & 480,44 & 0,00 & 0,00 & 0 & 0 & 0 \\
\hline $\mathrm{H} 2 \mathrm{O}$ & 0,00 & 0,00 & 0,00 & 0,00 & 0,00 & 0,00 & 0,00 & 0,00 & 0,00 & 7933,24 & 0,00 & 0,00 & 0,00 & 0,00 & 0 & 0 & 0 \\
\hline CO & 0,00 & 0,00 & 0,00 & 0,00 & 0,00 & 0,00 & 0,00 & 0,00 & $\begin{array}{r}0,004 \\
51,04\end{array}$ & $\begin{array}{r}0,00 \\
0,00\end{array}$ & $\begin{array}{r}0,004 \\
51,04\end{array}$ & $\begin{array}{r}0,004 \\
51,04\end{array}$ & 0,00 & 0,00 & 0 & 0 & 0 \\
\hline $\mathrm{H} 2$ & 0,00 & 0,00 & 0,00 & 0,00 & 0,00 & 0,00 & 0,00 & 0,00 & 113,07 & 0,00 & 565,37 & 113,07 & 1130,73 & 452,29 & 1130,73 & 678,43 & \\
\hline $\mathrm{NH3}$ & 0,00 & 0,00 & 0,00 & 0,00 & 0,00 & 0,00 & 0,00 & 0,00 & 60,80 & 0,00 & 60,80 & 60,80 & 0,00 & 0,00 & 0 & 0 & 0 \\
\hline $\mathrm{C} 2 \mathrm{H} 6-02$ & 0,00 & 0,00 & 0,00 & 0,00 & 0,00 & 0,00 & 0,00 & 0,00 & 402,61 & 0,00 & 402,61 & 402,61 & 0,00 & 0,00 & 0 & 0 & 0 \\
\hline $\mathrm{C} 18 \mathrm{H} 3-01$ & 0,00 & 0,00 & 0,00 & 0,00 & 0,00 & 0,00 & 0,00 & 0,00 & 0,00 & 0,00 & 0,00 & 0,00 & 0,00 & 0,00 & 0 & 0 & 0 \\
\hline C4H10-01 & 0,00 & 0,00 & 0,00 & 0,00 & 0,00 & 0,00 & 0,00 & 0,00 & 0,00 & 0,00 & 0,00 & 0,00 & 0,00 & 0,00 & 0 & 0 & 0 \\
\hline C4H7N-01 & 0,00 & 0,00 & 0,00 & 0,00 & 0,00 & 0,00 & 0,00 & 0,00 & 0,00 & 0,00 & 0,00 & 0,00 & 0,00 & 0,00 & 0 & 0 & 0 \\
\hline PYROLIGN & 0,00 & 0,00 & 0,00 & 0,00 & 0,00 & 0,00 & 0,00 & 0,00 & 0,00 & 0,00 & 0,00 & 0,00 & 0,00 & 0,00 & 0 & 0 & 0 \\
\hline N-HEX-01 & 505,41 & 491,97 & 0,00 & 0,00 & 0,00 & 491,97 & $\begin{array}{r}0,00 \\
13,44\end{array}$ & $\begin{array}{l}0,00 \\
13,44\end{array}$ & $\begin{array}{l}0,004 \\
13,44\end{array}$ & 0,00 & 0,00 & 0,00 & 0,00 & 0,00 & 0 & 0 & 0 \\
\hline N-DOD-01 & 538,41 & 538,89 & $\begin{array}{r}0,00 \\
533,25\end{array}$ & $\begin{array}{r}532,82 \\
532\end{array}$ & 0,43 & $\begin{array}{r}5,64 \\
5,64\end{array}$ & $\begin{array}{r}30,44 \\
0,00\end{array}$ & $\begin{array}{r}3,44 \\
0,00\end{array}$ & $\begin{array}{r}0,44 \\
0,00\end{array}$ & 0,00 & 0,00 & 0,00 & 0,00 & 0,00 & 0 & 0 & 0 \\
\hline 4-MET-01 & 546,37 & 546,37 & 0,01 & 0,01 & 0,00 & 546,36 & 0,00 & 0,00 & 0,00 & 0,00 & 0,00 & 0,00 & 0,00 & 0,00 & 0 & 0 & 0 \\
\hline ETHYL-01 & 523,29 & 523,29 & 0,00 & 0,00 & 0,00 & 523,29 & 0,01 & 0,01 & 0,01 & 0,00 & 0,00 & 0,00 & 0,00 & 0,00 & 0 & 0 & 0 \\
\hline 1-MET-01 & 314,58 & 314,58 & 0,00 & 0,00 & 0,00 & 314,58 & 0,00 & 0,00 & 0,00 & 0,00 & 0,00 & 0,00 & 0,00 & 0,00 & 0 & 0 & 0 \\
\hline CYCLO-01 & 313,67 & 312,71 & 0,00 & 0,00 & 0,00 & 312,71 & 0,96 & 0,96 & 0,96 & 0,00 & 0,00 & 0,00 & 0,00 & 0,00 & 0 & 0 & 0 \\
\hline N-PRO-01 & $\begin{array}{l}173,01 \\
173\end{array}$ & $\begin{array}{l}172,1 \\
173,33\end{array}$ & 0,00 & 0,00 & 0,00 & 173,33 & $0,0,00$ & 0,00 & 0,00 & 0,00 & 0,00 & 0,00 & 0,00 & 0,00 & 0 & 0 & 0 \\
\hline 1:3-D-01 & 155,41 & 155,41 & 124,33 & 124,19 & 0,14 & 31,08 & 0,00 & 0,00 & 0,00 & 0,00 & 0,00 & 0,00 & 0,00 & 0,00 & 0 & 0 & 0 \\
\hline 4-MET-02 & 209,44 & 209,44 & 209,44 & 1,17 & 208,27 & 0,00 & 0,00 & 0,00 & 0,00 & 0,00 & 0,00 & 0,00 & 0,00 & 0,00 & 0 & 0 & 0 \\
\hline INDAN-01 & 175,58 & 175,58 & 0,11 & 0,11 & 0,00 & $\begin{array}{r}175,47 \\
\end{array}$ & 0,00 & 0,00 & 0,00 & 0,00 & 0,00 & 0,00 & 0,00 & 0,00 & 0 & 0 & 0 \\
\hline $1-\mathrm{N}-\mathrm{H}-01$ & 285,92 & 285,92 & 285,92 & 97,58 & 188,34 & 0,00 & 0,00 & 0,00 & 0,00 & 0,00 & 0,00 & 0,00 & 0,00 & 0,00 & 0 & 0 & 0 \\
\hline PROPA-01 & 0,00 & 0,00 & 0,00 & 0,00 & 0,00 & 0,00 & 0,00 & 0,00 & 248,05 & 0,00 & 248,05 & 248,05 & 0,00 & 0,00 & 0 & 0 & 0 \\
\hline N-BUT-01 & 163,61 & 16,36 & 0,00 & 0,00 & 0,00 & 16,36 & 147,25 & 147,25 & 232,30 & 0,00 & 85,06 & 85,06 & 0,00 & 0,00 & 0 & 0 & 0 \\
\hline N-PEN-01 & 0,00 & 0,00 & 0,00 & 0,00 & 0,00 & 0,00 & 0,00 & 0,00 & 91,46 & 0,00 & 91,46 & 91,46 & 0,00 & 0,00 & 0 & 0 & 0 \\
\hline $\begin{array}{l}\text { N-PNE-11 } \\
\text { HYDRO-03 }\end{array}$ & 0,00 & $\begin{array}{l}0,00 \\
0,00\end{array}$ & $\begin{array}{l}0,00 \\
0,00\end{array}$ & 0,00 & 0,00 & 0,00 & 0,00 & 0,00 & $\begin{array}{r}r 1,46 \\
5,31\end{array}$ & 0,00 & $\begin{array}{r}r 1,46 \\
5,31\end{array}$ & $\begin{array}{r}r 1,46 \\
5,31\end{array}$ & 0,00 & 0,00 & 0 & 0 & 0 \\
\hline THYMO-01 & 200,00 & 200,00 & 200,00 & 199,58 & 0,42 & 0,00 & 0,00 & 0,00 & 0,00 & 0,00 & $\begin{array}{l}0,51 \\
0,00\end{array}$ & 0,00 & 0,00 & 0,00 & 0 & 0 & 0 \\
\hline P-ETH-01 & 354,48 & 354,48 & 70,90 & 70,87 & 0,03 & 283,58 & 0,00 & 0,00 & 0,00 & 0,00 & 0,00 & 0,00 & 0,00 & 0,00 & 0 & 0 & 0 \\
\hline $1: 2-D-01$ & 367,17 & 367,17 & 367,17 & 306,21 & 60,95 & 0 & 0,00 & 0,00 & 0,00 & 0,00 & 0,00 & 0,00 & 0,00 & 0,00 & 0 & 0 & 0 \\
\hline 1-PHE-01 & $\begin{array}{r}r 6,11 \\
87,10\end{array}$ & $\begin{array}{r}r 6 /, 17 \\
87,10\end{array}$ & $\begin{array}{r}867,11 \\
87,10\end{array}$ & $\begin{array}{r}306,21 \\
3,20\end{array}$ & $\begin{array}{l}63,95 \\
83,91\end{array}$ & 0,00 & 0,00 & 0,00 & 0,00 & 0,00 & 0,00 & 0,00 & 0,00 & 0,00 & 0 & 0 & 0 \\
\hline O-PHE-01 & 237,80 & 237,80 & 237,80 & 88,54 & 149,27 & 0,00 & 0,00 & 0,00 & 0,00 & 0,00 & 0,00 & 0,00 & 0,00 & 0,00 & 0 & 0 & 0 \\
\hline Total Flow $\mathrm{kg} / \mathrm{hr}$ & 5152,05 & $\begin{array}{r}23,00 \\
4990,40\end{array}$ & 2116,02 & $\begin{array}{r}0,54 \\
1424,27\end{array}$ & $\begin{array}{l}149,27 \\
691,75\end{array}$ & 2874,38 & $\begin{array}{r}0,00 \\
161,65\end{array}$ & $\begin{array}{r}0,00 \\
161,65\end{array}$ & 2707,14 & 7933,24 & 2997,78 & 2545,49 & 1130,73 & 452,29 & 1130,73 & 678,43 & \\
\hline
\end{tabular}

Note: Stream tables are for one train of $500 \mathrm{tDM}$ /day 


\subsection{Hydrogen plant}

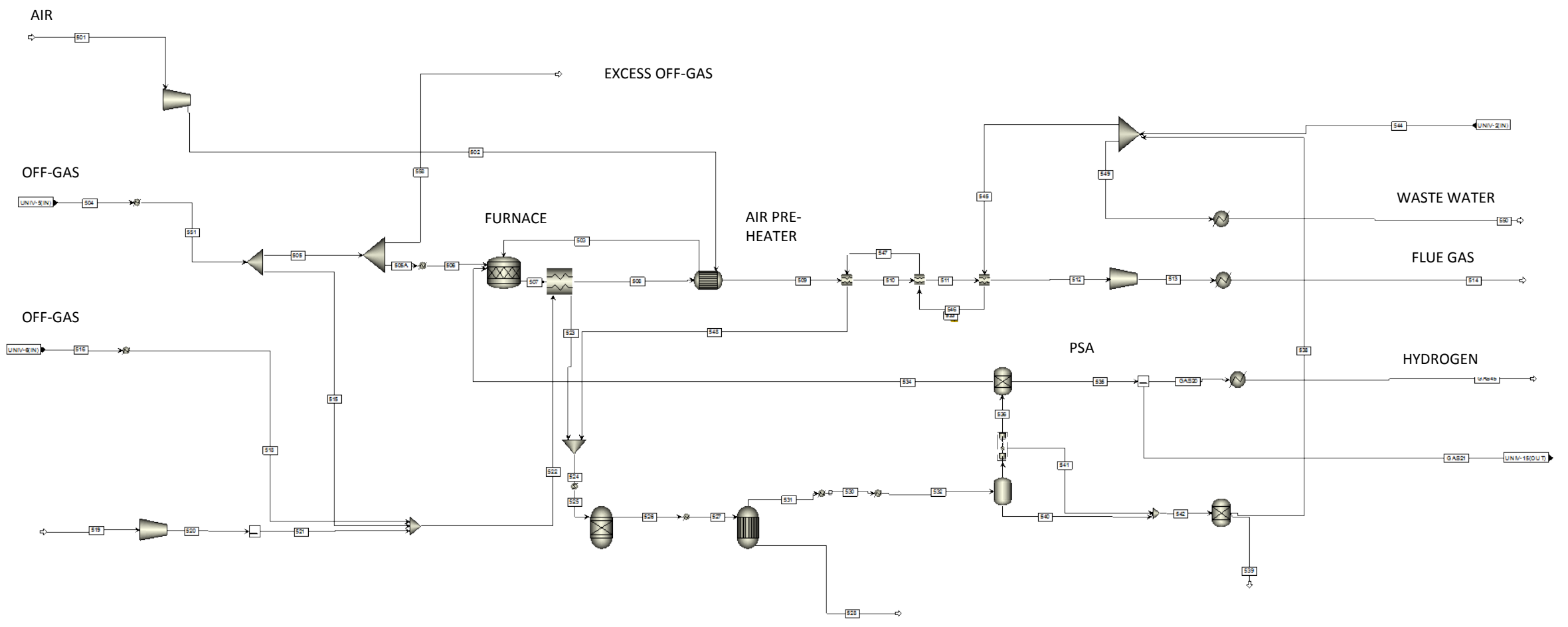




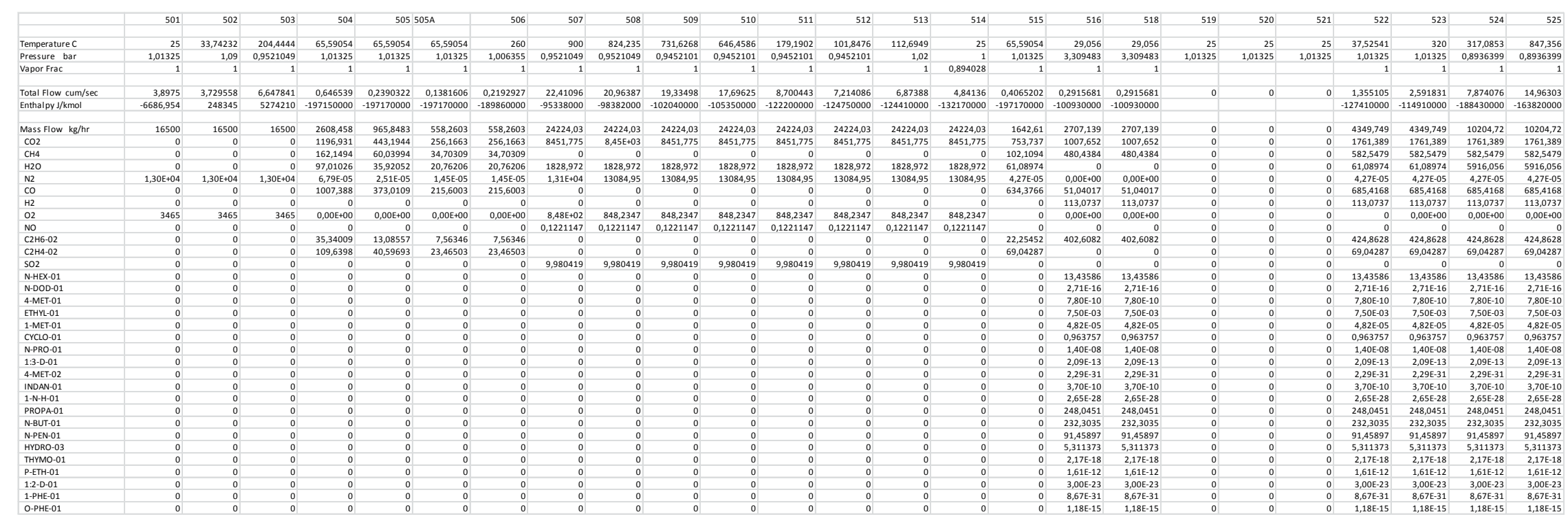

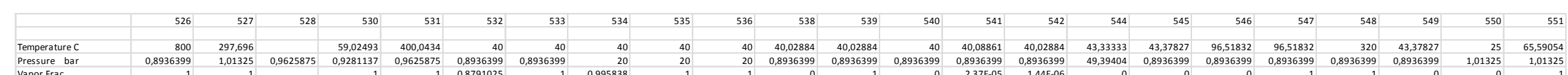

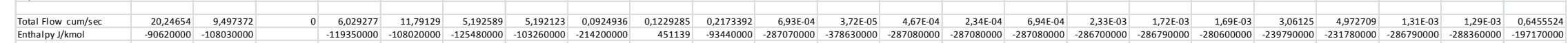

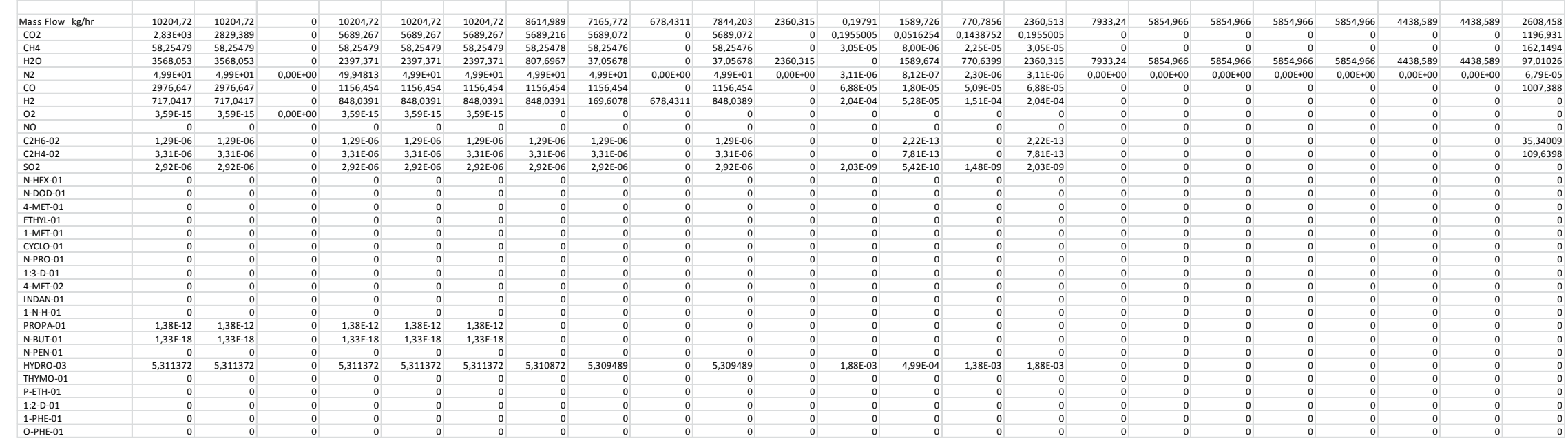

Note: Stream tables are for one train of 500 tDM/day 


\subsection{Area 100 HTL Feed Handling and Prep}

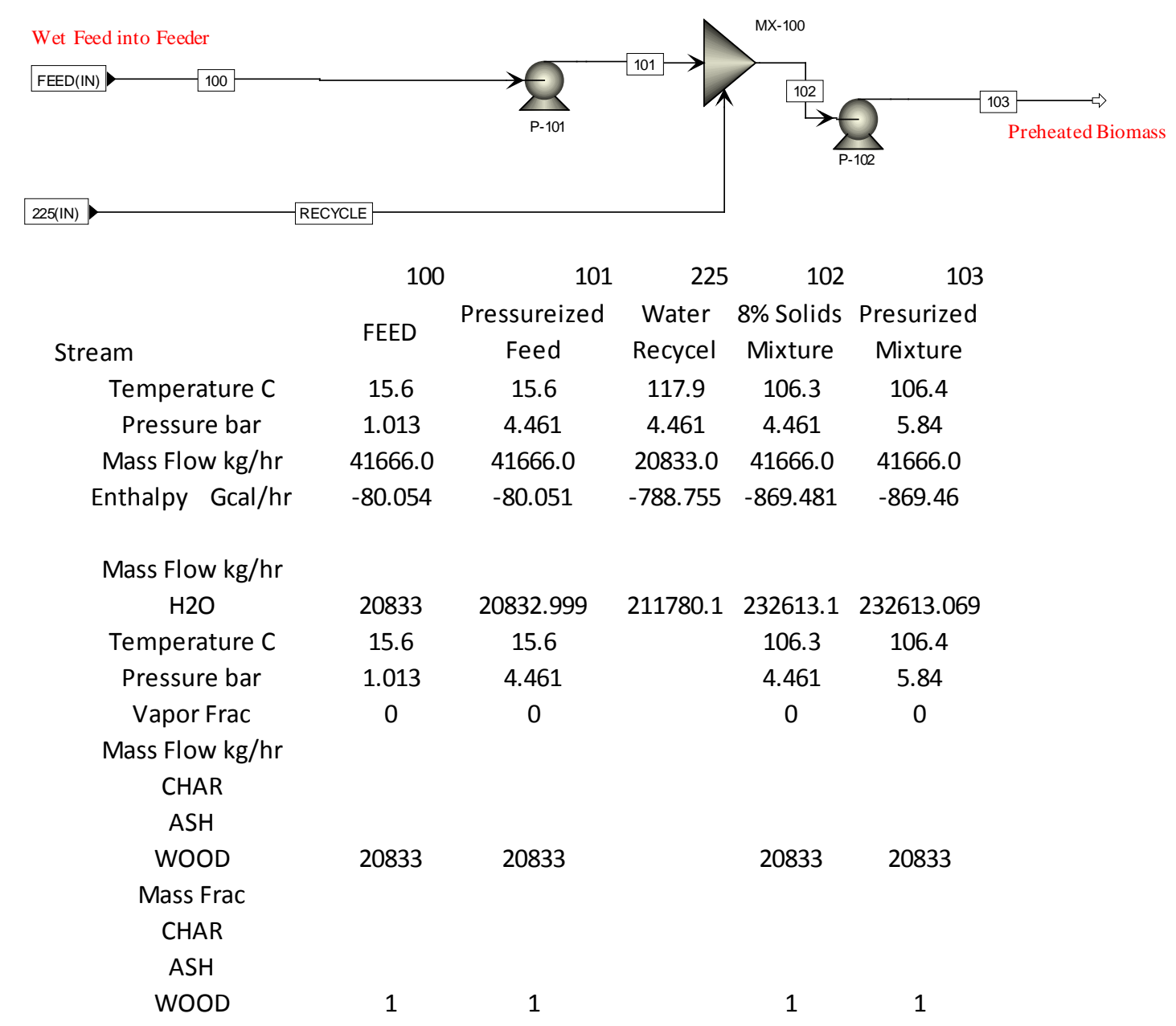




\subsection{Area 200 HTL Conversion}

Solid concentration in feed (S202): 8 wt\% dry biomass

\section{HTL Reactor}

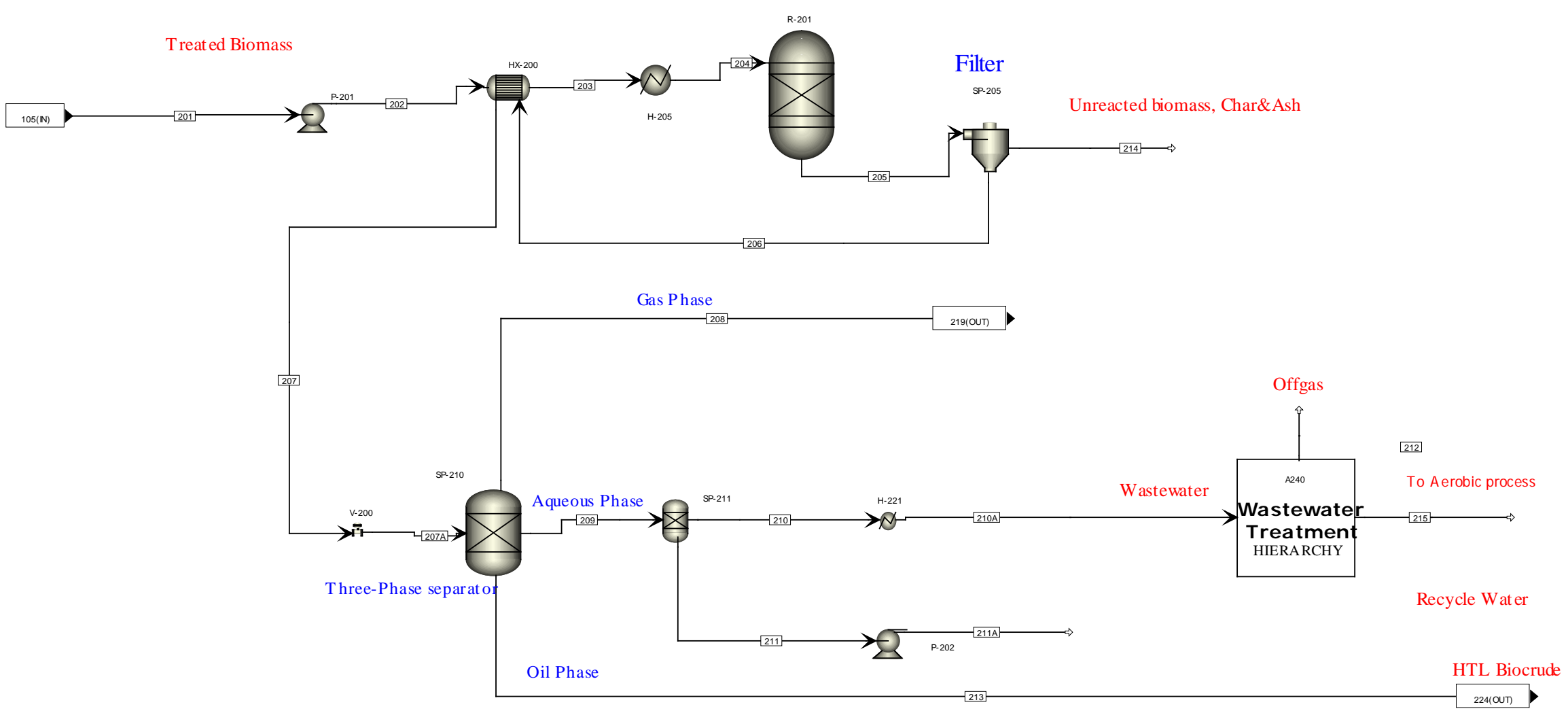




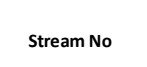

Stream ID

Temperature, $\mathrm{C}$

Pressure, b
Vapor Frac

Enthalpy Gcal/hr

Mass Flow $\mathrm{kg} / \mathrm{hr}$

$\mathrm{H} 2$
$\mathrm{CO} 2$

$\mathrm{H} 2 \mathrm{O}$

$\mathrm{H} 2 \mathrm{~S}$

$\mathrm{NH} 3$
$\mathrm{CH} 4$

C3H8

C3H8

N-C4H10

2-PYRROL

METHANOL

PROACID

BUTACTO

2-BUTANO

12BENOL

13BENAP

23HFDHSM

13BEN45M

PHE-2MAP

CYCLOPEN

CYCPO-2M
2CYC-2M

PHENOL

2CYC23M

PHENO4M

$\mathrm{C} 13 \mathrm{H} 12$

C14H14O

PYROHG

FORMICACID

CHAR

ASH
WOOD

\begin{abstract}
201
\end{abstract}
EED Slurry

$\begin{array}{lll}\text { Pressurized } & \text { Preheated } & \text { Reactor } \\ \text { Feed Slurry } & \text { Feed Slurry } & \text { Inlet }\end{array}$

106
6
0
-869.5

$253446.1 \quad 253446.1 \quad 253446.1253446 .1$

$232613.1 \quad 232613.069 \quad 232613.069 \quad 232613.07$

$\begin{array}{rrr}253446.1 & 251389.7 & 251389.7 \\ 32.791 & 32.791 & 32.791 \\ 3302.447 & 3302.447 & 3302.447 \\ 233145.4 & 233167.255 & 233167.255\end{array}$

$\begin{array}{rrr}109.08 & 109.08 & 109.08 \\ 30.666 & 30.666 & 30.666 \\ 90.265 & 90.265 & 90.265 \\ 76.207 & 76.207 & 76.207 \\ 175.789 & 175.789 & 175.789 \\ 17.666 & 17.666 & 17.666 \\ 544.2 & 544.2 & 544.2 \\ 413.535 & 413.535 & 413.535 \\ 413.535 & 413.535 & 413.555 \\ 205.205 & 205.205 & 205.205 \\ 410.41 & 410.41 & 410.41 \\ 413.535 & 413.535 & 413.535 \\ 1469.768 & 1469.768 & 1469.768 \\ 205.205 & 205.205 & 205.205 \\ 205.205 & 205.205 & 205.205 \\ 1026.025 & 1026.025 & 102.6025 \\ 2055.175 & 2055.175 & 2055.175 \\ 410.41 & 410.41 & 410.41 \\ 410.41 & 410.41 & 410.41 \\ 307.808 & 307.808 & 307.808 \\ 413.535 & 413.535 & 413.535 \\ 205.205 & 205.205 & 205.205 \\ 430.931 & 430.931 & 430.931 \\ 615.615 & 615.615 & 615.615 \\ 820.82 & 820.82 & 820.82 \\ 1109.128 & 1109.128 & 1109.128 \\ 82.082 & 82.082 & 82.082 \\ 2219.756 & 2219.756 & 2219.556 \\ 1765.811 & & \end{array}$

$\begin{array}{llll}20833 & 20833 & 20833 & 20833\end{array}$

1765.811
312.495
208

209
Aqueous
Phase to

210

2104

211

212

$213 \quad 214$

Gas Phase

WWT WW to AD Wastewater Water

Offgass HTL Oil Solids Filter: Effluent

$\begin{array}{rrr}117.8 & 117.8 & 117.8 \\ 2.1 & 2.068 & 2.068 \\ 1 & 0.033 & 0.96 \\ -7.2 & -871.2 & -1932.4\end{array}$

$\begin{array}{rrrrr}60 & 117.8 & 120.4 & 117.8 & 350 \\ 1.931 & 2.068 & 2.068 & 2.068 & 205.81 \\ 0.016 & 0 & 1 & 0.05 & 0 \\ -87.7 & -788.8 & -11.5 & -4.1 & \end{array}$

$\begin{array}{llllllll}3662.3 & 241010.1 & 29209.9 & 29209.9 & 211800.274 & 9081.426 & 7620.971 & 1195.4005\end{array}$ $\begin{array}{rr}32.791 & 25.421 \\ 3302.447 & 2751765\end{array}$ $\begin{array}{lllllrr}3302.447 & & & & & 251.7175 & \\ & 233630.4595 & 21830.1855^{\circ} & 21830.1855 & 211800.274 & 120.394 & 419.701\end{array}$

32.791
3302.447

233167.255

109.08
93.165
69.432
55.374

$\begin{array}{ll}109.08 & 109.08 \\ 30.666 & 93.165 \\ 90.265 & 69.432 \\ 76.207 & 55.374 \\ 175789 & \end{array}$

4.01
2.38

23.68
1413.964$$
\begin{array}{r}
76.207 \\
175.789
\end{array}
$$

17.666
544.2

413.535

413.535

205.205

410.41

413.535
1469.768

1469.768
205.205
252.205

1026.025
2055.175

410.41

410.41
307.808

413.535

205.205

430.931

615.615
820.82

820.82
1109.128

82.082
2219.756

$\begin{array}{rrrrr}166.999 & 166.999 & 166.999 & 0.005 & 8.789 \\ 16.783 & 16.783 & 16.783 & 0.48 & 0.883 \\ 538.758 & 538.758 & 538.758 & 52.857 & 5.442 \\ 409.4 & 409.4 & 409.4 & 55.909 & 4.135 \\ 409.4 & 409.4 & 409.4 & 40.344 & 4.135 \\ 184.685 & 184.685 & 184.685 & 5.144 & 20.521 \\ 287.287 & 287.287 & 281.287 & 54.641 & 123.123 \\ 413.535 & 413.535 & 413.535 & <.001 & \\ 881.861 & 881.861 & 881.861 & 0.17 & 587.907 \\ 203.153 & 203.153 & 203.153 & 4.729 & 2.052 \\ & & & 205.205 \\ 410.41 & 410.41 & 410.41 & \text { trace } & 615.615 \\ 205.518 & 205.518 & 205.518 & 0.958 & 1849.658 \\ & & & 410.41 \\ 164.164 & 164.164 & 164.164 & 115.307 & 246.246 \\ 277.027 & 277.027 & 277.027 & 169.286 & 30.781 \\ 289.475 & 289.475 & 289.475 & 10.356 & 124.061 \\ 10.26 & 10.26 & 10.26 & 2.058 & 194.945 \\ 258.558 & 258.558 & 258.558 & 11.082 & 172.372 \\ 61.562 & 61.562 & 61.562 & 1.186 & 554.054 \\ 82.082 & 82.082 & 82.082 & 0.406 & 738.738 \\ & & & & 1109.128 \\ & & & & 82.082 \\ 2108.768 & 2108.768 & 2108.768 & 1765.124 & 110.988\end{array}$

$\begin{array}{lllll}2108.768 & 2108.768 & 2108.768 & 1765.124 & 82.082 \\ & & & \end{array}$ 


\subsection{Area $\mathbf{3 0 0}$ Hydrothermal Liquefaction Biocrude Hydrotreating}

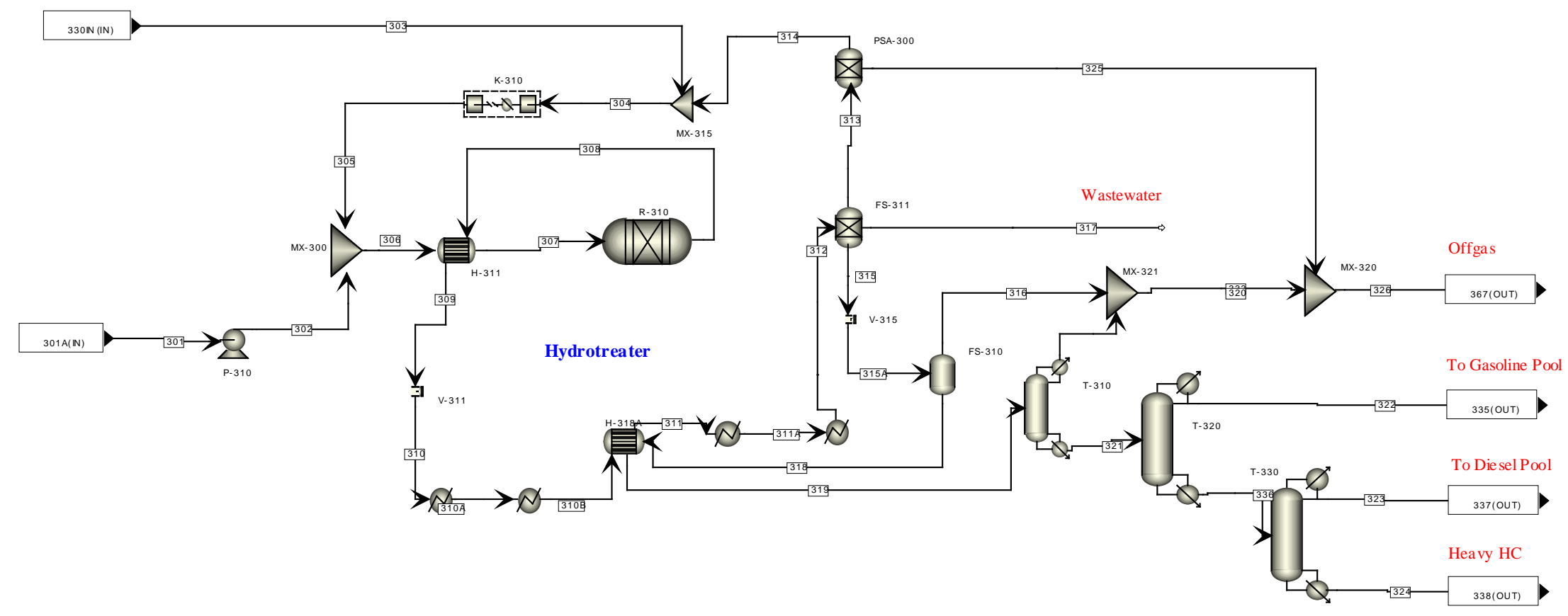




\begin{tabular}{|c|c|c|c|c|c|c|c|c|}
\hline Stream No. & 301 & 302 & 303 & 304 & 305 & 306 & 307 & 308 \\
\hline Stream ID & $\begin{array}{l}\text { HTL Bio- } \\
\text { oil Feed }\end{array}$ & $\begin{array}{l}\text { Cooled/ Con. } \\
\text { B io-oil }\end{array}$ & $\begin{array}{c}\text { Pressurized } \\
\text { Feed }\end{array}$ & $\begin{array}{c}\text { Compressed } \\
\mathrm{H} 2\end{array}$ & $\begin{array}{l}\text { Recycled + } \\
\text { Feed H2 }\end{array}$ & $\begin{array}{l}\text { Pressurized } \\
\text { H2 }\end{array}$ & $\begin{array}{c}\text { Bio-oil + H2 } \\
\text { Reactor Feed }\end{array}$ & $\begin{array}{l}\text { Heated } \\
\text { HTL Oil }\end{array}$ \\
\hline Temperature, $\mathrm{C}$ & 117.8 & 114.5 & 116.5 & 60 & 53.1 & 130.6 & 116.5 & 165.6 \\
\hline Pressure, bar & 2.068 & 2.068 & 137.413 & 29.2 & 21.698 & 137.413 & 137.413 & 137.068 \\
\hline Vapor Frac & 0.05 & 0 & 0.735 & 1 & 1 & 1 & 0.735 & 0.75 \\
\hline Enthalpy MMBtu/hr & -4.06 & -4.098 & -3.903 & 0.029 & 0.04 & 0.156 & -3.903 & -3.607 \\
\hline Mass Flow $\mathrm{kg} / \mathrm{hr}$ & 7621.0 & 7621.0 & 7621.0 & 237.7 & 411.5 & 411.5 & 8032.5 & 8032.5 \\
\hline $\mathrm{H} 2$ & & & & 237.736 & 411.53 & 411.53 & 411.532 & 411.532 \\
\hline $\mathrm{H} 2 \mathrm{O}$ & 419.701 & 419.701 & 419.701 & & & & 419.701 & 419.701 \\
\hline $\mathrm{H} 2 \mathrm{~S}$ & & & & & & & & \\
\hline SO2 & & & & & & & & \\
\hline NH3 & & & & & & & & \\
\hline NO2 & & & & & & & & \\
\hline $\mathrm{CH} 4$ & & & & & & & & \\
\hline $\mathrm{C} 2 \mathrm{H} 6$ & & & & & & & & \\
\hline $\mathrm{C} 3 \mathrm{H} 8$ & & & & & & & & \\
\hline $\mathrm{N}-\mathrm{C} 4 \mathrm{H} 10$ & & & & & & & & \\
\hline N-PENTAN & & & & & & & & \\
\hline HEXANE & & & & & & & & \\
\hline 2-PYRROL & 8.789 & 8.789 & 8.789 & & & & 8.789 & 8.789 \\
\hline ETHYLTHI & 0.883 & 0.883 & 0.883 & & & & 0.883 & 0.883 \\
\hline METHANOL & 5.442 & 5.442 & 5.442 & & & & 5.442 & 5.442 \\
\hline ACEACID & 4.135 & 4.135 & 4.135 & & & & 4.135 & 4.135 \\
\hline PROACID & 4.135 & 4.135 & 4.135 & & & & 4.135 & 4.135 \\
\hline BUTACTO & 20.521 & 20.521 & 20.521 & & & & 20.521 & 20.521 \\
\hline 2-BUTANO & 123.123 & 123.123 & 123.123 & & & & 123.123 & 123.123 \\
\hline 13BEN4P & 587.907 & 587.907 & 587.907 & & & & 587.907 & 587.907 \\
\hline 23HFDH5M & 2.052 & 2.052 & 2.052 & & & & 2.052 & 2.052 \\
\hline 26DMPHE & 205.205 & 205.205 & 205.205 & & & & 205.205 & 205.205 \\
\hline 13BEN45M & 615.615 & 615.615 & 615.615 & & & & 615.615 & 615.615 \\
\hline PHE-2M4P & 1849.658 & 1849.658 & 1849.658 & & & & 1849.658 & 1849.658 \\
\hline CYCLOPEN & 410.41 & 410.41 & 410.41 & & & & 410.41 & 410.41 \\
\hline СYCPO-2M & 246.246 & 246.246 & 246.246 & & & & 246.246 & 246.246 \\
\hline $2 \mathrm{CYC}-2 \mathrm{M}$ & 30.781 & 30.781 & 30.781 & & & & 30.781 & 30.781 \\
\hline PHENOL & 124.061 & 124.061 & 124.061 & & & & 124.061 & 124.061 \\
\hline $2 \mathrm{CYC} 23 \mathrm{M}$ & 194.945 & 194.945 & 194.945 & & & & 194.945 & 194.945 \\
\hline PHENO4M & 172.372 & 172.372 & 172.372 & & & & 172.372 & 172.372 \\
\hline $\mathrm{C} 13 \mathrm{H} 12$ & 554.054 & 554.054 & 554.054 & & & & 554.054 & 554.054 \\
\hline $\mathrm{C} 14 \mathrm{H} 14 \mathrm{O}$ & 738.738 & 738.738 & 738.738 & & & & 738.738 & 738.738 \\
\hline $\mathrm{C} 15 \mathrm{H} 12$ & 1109.128 & 1109.128 & 1109.128 & & & & 1109.128 & 1109.128 \\
\hline PYROLIG & 82.082 & 82.082 & 82.082 & & & & 82.082 & 82.082 \\
\hline FORMI-01 & 110.988 & 110.988 & 110.988 & & & & 110.988 & 110.988 \\
\hline 4-MET-01 & & & & & & & & \\
\hline N-DOD-01 & & & & & & & & \\
\hline ETHYL-01 & & & & & & & & \\
\hline 1-MET-01 & & & & & & & & \\
\hline CYCLO-01 & & & & & & & & \\
\hline N-PRO-01 & & & & & & & & \\
\hline 13-D-01 & & & & & & & & \\
\hline 4-MET-02 & & & & & & & & \\
\hline INDAN-01 & & & & & & & & \\
\hline $1-\mathrm{N}-\mathrm{H}-01$ & & & & & & & & \\
\hline THYMO-01 & & & & & & & & \\
\hline P-ETH-01 & & & & & & & & \\
\hline 12-D-01 & & & & & & & & \\
\hline 1-PHE-01 & & & & & & & & \\
\hline
\end{tabular}




\begin{tabular}{|c|c|c|c|c|c|c|c|c|c|c|c|c|c|c|c|c|c|}
\hline \multirow[b]{2}{*}{ Stream ID } & 309 & 310 & 311 & $\begin{array}{c}312 \\
\text { Further }\end{array}$ & $312 \mathrm{~A}$ & 314 & 315 & 317 & $\begin{array}{c}318 \\
\text { Product }\end{array}$ & 319 & 320 & 321 & 322 & 323 & 325 & 326 & 324 \\
\hline & Reactor Effluent & $\begin{array}{l}\text { Cooled HT } \\
\text { Oil }\end{array}$ & $\begin{array}{c}\text { Depressu } \\
\text { rized } \\
\text { S310 }\end{array}$ & $\begin{array}{l}\text { Cooling/ } \\
\text { Depressur } \\
\text { ization }\end{array}$ & $\begin{array}{l}\text { Feed to } \\
\text { Separators }\end{array}$ & $\begin{array}{l}\text { Recycled } \\
\text { H2 }\end{array}$ & $\begin{array}{c}\text { Low P } \\
\text { Separation } \\
\text { Feed }\end{array}$ & $\begin{array}{c}\text { Ww } \\
\text { Effluent }\end{array}$ & $\begin{array}{l}\text { Oil to } \\
\text { Distillati } \\
\text { on }\end{array}$ & $\begin{array}{l}\text { To First } \\
\text { Distillati } \\
\text { on }\end{array}$ & Offgass & \multicolumn{2}{|c|}{ PSA Offgass Offgass } & $\begin{array}{l}\text { Gasoline } \\
\text { Distillate }\end{array}$ & $\begin{array}{c}\text { Diesel } \\
\text { Distillate }\end{array}$ & $\begin{array}{l}\text { Heavy } \\
\text { Products }\end{array}$ & $\begin{array}{c}\text { To Second } \\
\text { Distillatio } \\
n\end{array}$ \\
\hline Temperature, C & 425.7 & 396.2 & $2 \quad 365.8$ & $3 \quad 118.5$ & 43.3 & 43.3 & 46.4 & 43.3 & $\begin{array}{l}3 \quad 46.4 \\
\end{array}$ & 93.3 & 66.1 & 43.3 & 43.8 & 149.5 & 317.6 & 352.8 & 337.5 \\
\hline Pressure, bar & 136.378 & 136.34 & 49.987 & 49.877 & 49.394 & 21.7 & 3.792 & 49.394 & 3.792 & 3.723 & 3.309 & 3.426 & 3.31 & 1.358 & 1.082 & 1.082 & 1.358 \\
\hline Vapor Frac & 1 & 0.947 & 0.971 & 0.524 & 0.472 & 1 & 0 & 0 & 0 & 0 & 1 & 1 & 1 & 0 & 0 & 0 & 0 \\
\hline Enthalpy $\mathrm{MMB1}$ & -3.633 & -12.879 & -3.93 & -5.908 & -6.384 & 0.011 & -0.27 & -6.1 & -0.27 & -0.167 & -0.01 & -0.317 & -0.327 & -0.542 & 0.56 & 0.258 & 0.836 \\
\hline Mass Flow $k !$ & 8032.5 & 8032.5 & 8032.5 & 8032.5 & 8032.5 & 173.8 & 5715.7 & 1601.3 & 5715.7 & 5715.7 & 21.0 & 541.7 & 562.8 & 2601.99 & 2239.15 & 853.52 & 3092.66 \\
\hline $\mathrm{H} 2$ & 217.245 & 217.245 & 217.245 & 217.245 & 217.245 & 173.796 & & & & & & 43.449 & 43.449 & & & & \\
\hline $\mathrm{H} 2 \mathrm{O}$ & 1601.269 & 1601.269 & 1601.269 & 1601.269 & 1601.269 & & & 1601.269 & & & & & & & & & \\
\hline $\mathrm{H} 2 \mathrm{~S}$ & 0.284 & 0.284 & $\quad 0.284$ & 0.284 & 0.284 & & & & & & & 0.284 & 0.284 & & & & \\
\hline $\begin{array}{l}\mathrm{SO} 2 \\
\mathrm{NH} 3 \\
\mathrm{NO2}\end{array}$ & 1.762 & 1.762 & 1.762 & 1.762 & 1.762 & & & & & & & 1.762 & 1.762 & & & & \\
\hline $\mathrm{CH} 4$ & 101.439 & 101.439 & 101.439 & 101.439 & 101.439 & & & & & & & 101.439 & 101.439 & & & & \\
\hline $\mathrm{C} 2 \mathrm{H} 6$ & 84.241 & 84.241 & 84.241 & 84.241 & 84.241 & & & & & & & 84.241 & 84.241 & & & & \\
\hline СзН8 & 73.76 & 73.76 & 73.76 & 73.76 & 73.76 & & & & & & & 73.76 & 73.76 & & & & \\
\hline $\mathrm{N}-\mathrm{C} 4 \mathrm{H} 10$ & 29.168 & 29.168 & 29.168 & 29.168 & 29.168 & & 19.191 & & 19.191 & 19.191 & 17.272 & 9.977 & 27.249 & 1.919 & & & \\
\hline N-PENTAN & 8.298 & 8.298 & 8.298 & 8.298 & 8.298 & & & & & & & 8.298 & 8.298 & & & & \\
\hline HEXANE & 218.531 & 218.531 & 218.531 & 218.531 & 218.531 & & & & & & & 218.531 & 218.531 & & & & \\
\hline 2-PYRROL & & & & & & & & & & & & & & & & & \\
\hline ETHYLTHI & & & & & & & & & & & & & & & & & \\
\hline METHANOL & & & & & & & & & & & & & & & & & \\
\hline ACEACID & & & & & & & & & & & & & & & & & \\
\hline PROACID & & & & & & & & & & & & & & & & & \\
\hline BUTACTO & & & & & & & & & & & & & & & & & \\
\hline 2-BUTANO & & & & & & & & & & & & & & & & & \\
\hline 13BEN4P & & & & & & & & & & & & & & & & & \\
\hline 23HFDH5M & & & & & & & & & & & & & & & & & \\
\hline 26DMPHE & & & & & & & & & & & & & & & & & \\
\hline 13BEN45M & & & & & & & & & & & & & & & & & \\
\hline PHE-2M4P & & & & & & & & & & & & & & & & & \\
\hline CYCLOPEN & & & & & & & & & & & & & & & & & \\
\hline СYCPO-2M & & & & & & & & & & & & & & & & & \\
\hline $2 \mathrm{CYC}-2 \mathrm{M}$ & & & & & & & & & & & & & & & & & \\
\hline PHENOL & & & & & & & & & & & & & & & & & \\
\hline $2 \mathrm{CYC} 23 \mathrm{M}$ & & & & & & & & & & & & & & & & & \\
\hline PHENO4M & & & & & & & & & & & & & & & & & \\
\hline $\mathrm{C} 13 \mathrm{H} 12$ & & & & & & & & & & & & & & & & & \\
\hline $\mathrm{C} 14 \mathrm{H} 14 \mathrm{O}$ & & & & & & & & & & & & & & & & & \\
\hline $\begin{array}{l}\text { C15H12 } \\
\text { PYROLIG }\end{array}$ & & & & & & & & & & & & & & & & & \\
\hline FORMI-01 & & & & & & & & & & & & & & & & & \\
\hline 4-MET-01 & 243.574 & 243.574 & 243.574 & 243.574 & 243.574 & & 243.574 & & 243.574 & 243.574 & & & & 243.574 trace & & trace & trace \\
\hline N-DOD-01 & 262.555 & 262.555 & 262.555 & 262.555 & 262.555 & & 262.555 & & 262.555 & 262.555 & & & & 262.554 & 0.001 & trace & 0.001 \\
\hline ETHYL-01 & 173.033 & 173.033 & 173.033 & 173.033 & 173.033 & & 173.033 & & 173.033 & 173.033 & 0.03 & & 0.03 & 173.003 & & & trace \\
\hline 1-MET-01 & 221.022 & 221.022 & 221.022 & 221.022 & 221.022 & & 221.022 & & 221.022 & 221.022 & 0.001 & & 0.001 & 221.021 & & & trace \\
\hline CYCLO-01 & 190.336 & 190.336 & 190.336 & 190.336 & 190.336 & & 190.336 & & 190.336 & 190.336 & 3.738 & & 3.738 & 186.598 & & & trace \\
\hline N-PRO-01 & 190.294 & 190.294 & 190.294 & 190.294 & 190.294 & & 190.294 & & 190.294 & 190.294 & & & & 190.294 trace & & trace & trace \\
\hline 13-D-01 & 277.572 & 277.572 & 277.572 & 277.572 & 277.572 & & 277.572 & & 277.572 & 277.572 & & & & 277.377 & 0.195 & trace & 0.195 \\
\hline 4-MET-02 & 1441.738 & 1441.738 & 1441.738 & 1441.738 & 1441.738 & & 1441.738 & & 1441.738 & 1441.738 & & & & trace & 773.081 & 668.656 & 1441.738 \\
\hline INDAN-01 & 493.374 & 493.374 & 493.374 & 493.374 & 493.374 & & 493.374 & & 493.374 & 493.374 & & & & $493.374<0.0$ & 0.001 & trace & $<0.001$ \\
\hline $1-\mathrm{N}-\mathrm{H}-01$ & 200.019 & 200.019 & 200.019 & 200.019 & 200.019 & & 200.019 & & 200.019 & 200.019 & & & & trace & 197.816 & 2.204 & 200.019 \\
\hline THYMO-01 & 173.857 & 173.857 & 173.857 & 173.857 & 173.857 & & 173.857 & & 173.857 & 173.857 & & & & 137.442 & 36.413 & 0.002 & 36.415 \\
\hline P-ETH-01 & 414.838 & 414.838 & 414.838 & 414.838 & 414.838 & & 414.838 & & 414.838 & 414.838 & & & & 414.835 & 0.003 & trace & 0.003 \\
\hline 12-D-01 & 400.947 & 400.947 & 400.947 & 400.947 & 400.947 & & 400.947 & & 400.947 & 400.947 & & & & 0.003 & 399.089 & 1.856 & 400.944 \\
\hline 1-PHE-01 & 1013.349 & 1013.349 & 1013.349 & 1013.349 & 1013.349 & & 1013.349 & & 1013.349 & 1013.349 & & & & trace & 832.547 & 180.802 & 1013.349 \\
\hline
\end{tabular}




\subsection{HTL Hydrogen Plant}

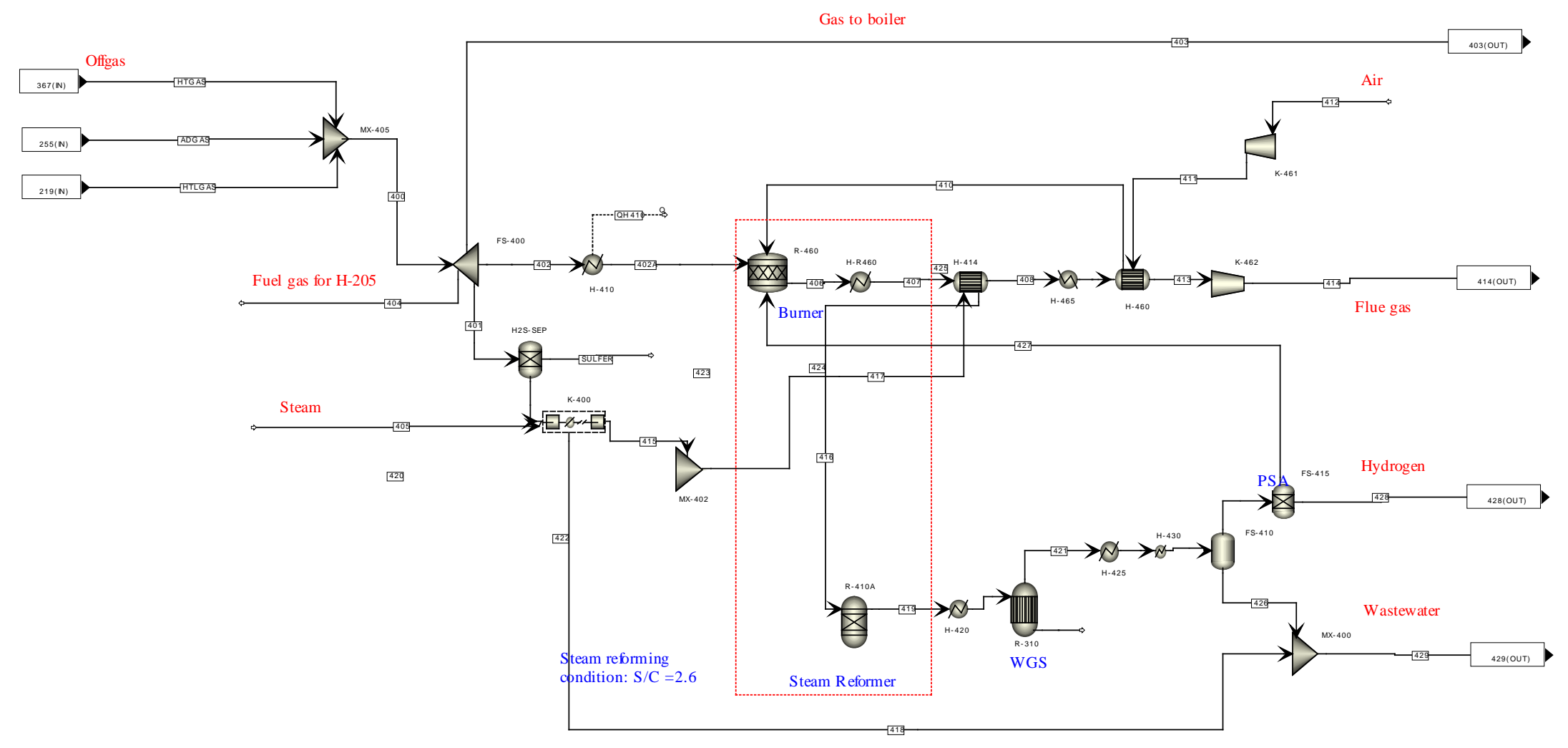




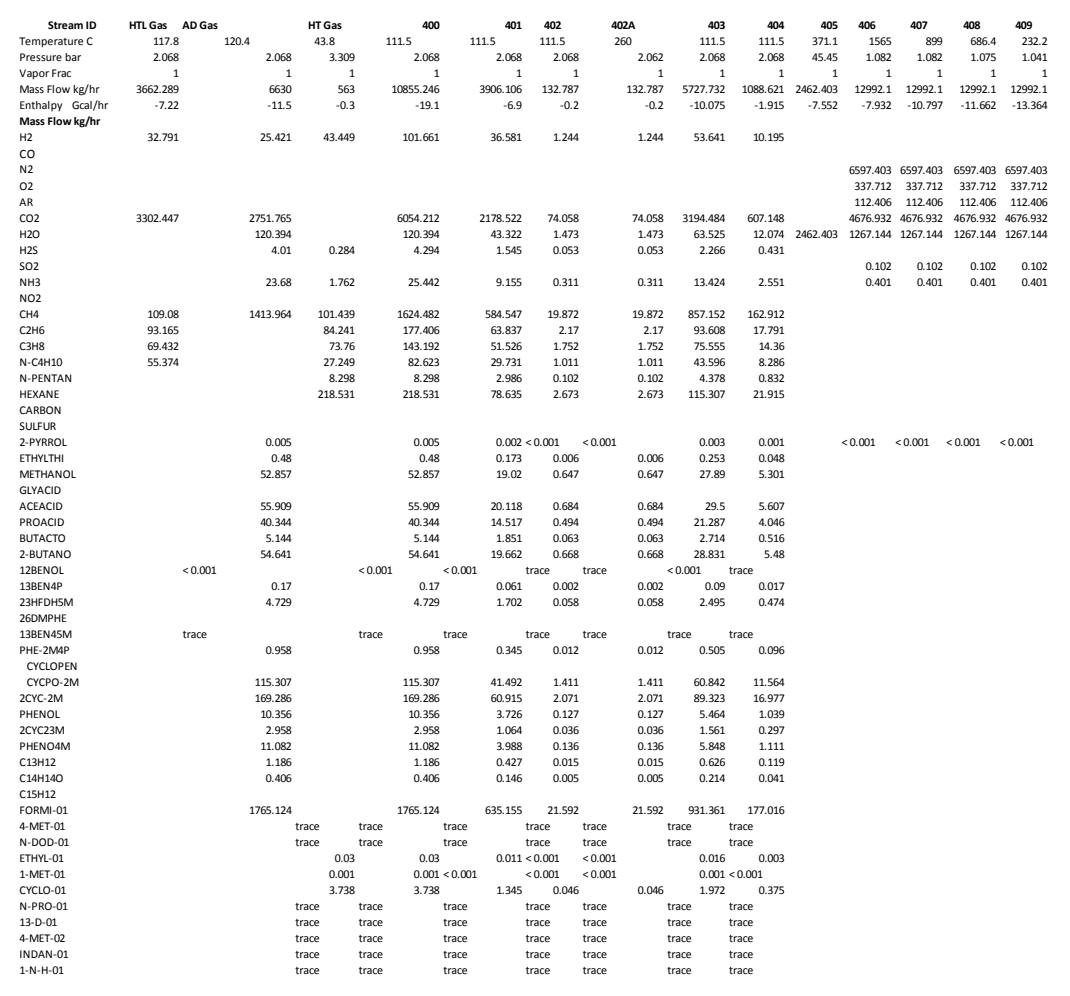

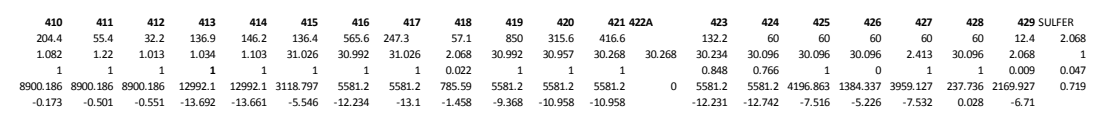

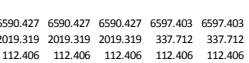

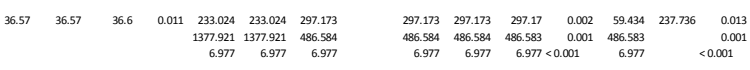

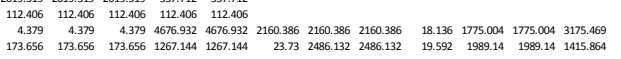
$\begin{array}{lllllllll}0.102 & 0.102 \\ 0.401 & 0.401 & 8.758 & 8.758 & 8.758 & 0.397 & 0.275 & 0.275 & 0.275\end{array}$

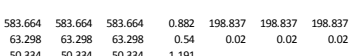

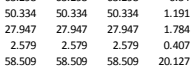

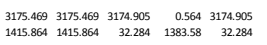
18.699
1403.173 $\quad 1.545$ $\begin{array}{lllllll}0.275 & 0.275 & 0.09 & 0.185 & 0.09 & 0.58\end{array}$

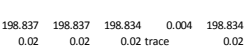
$<0.001<0.001$

trace trace trace trace 0.395

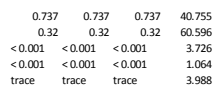
$\begin{array}{llll}<<.001 & <0.001 & <0.001 & 1.064 \\ \text { trace } & \text { trace } & \text { trace } & 3.988 \\ \text { trace } & \text { trace } & \text { trace } & 0.427 \\ & \text { trace } & 0.146\end{array}$ $\begin{array}{cccc}85.083 & 85.083 & 85.083 & 550.072 \\ \text { trace } & \text { trace } \\ \text { trace } & \text { trace }\end{array}$

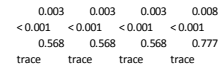




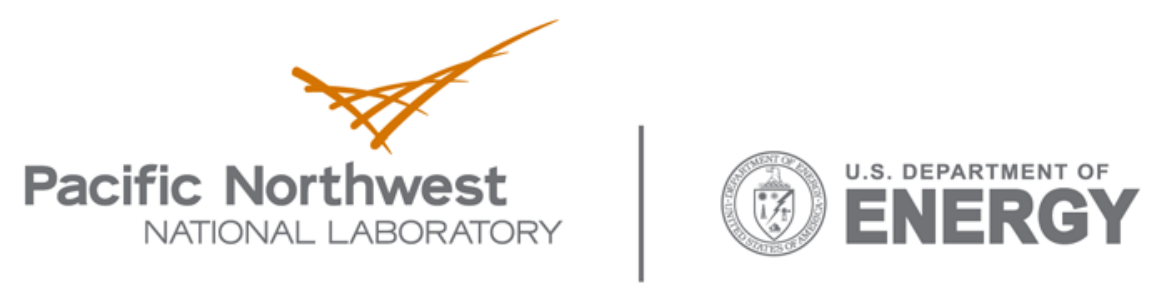

902 Battelle Boulevard

P.O. Box 999

Richland, WA 99352

1-888-375-PNNL (7665)

www.pnl.gov 